Interactive use of simulation models for collaborative knowledge construction The case of flood policy decision-making
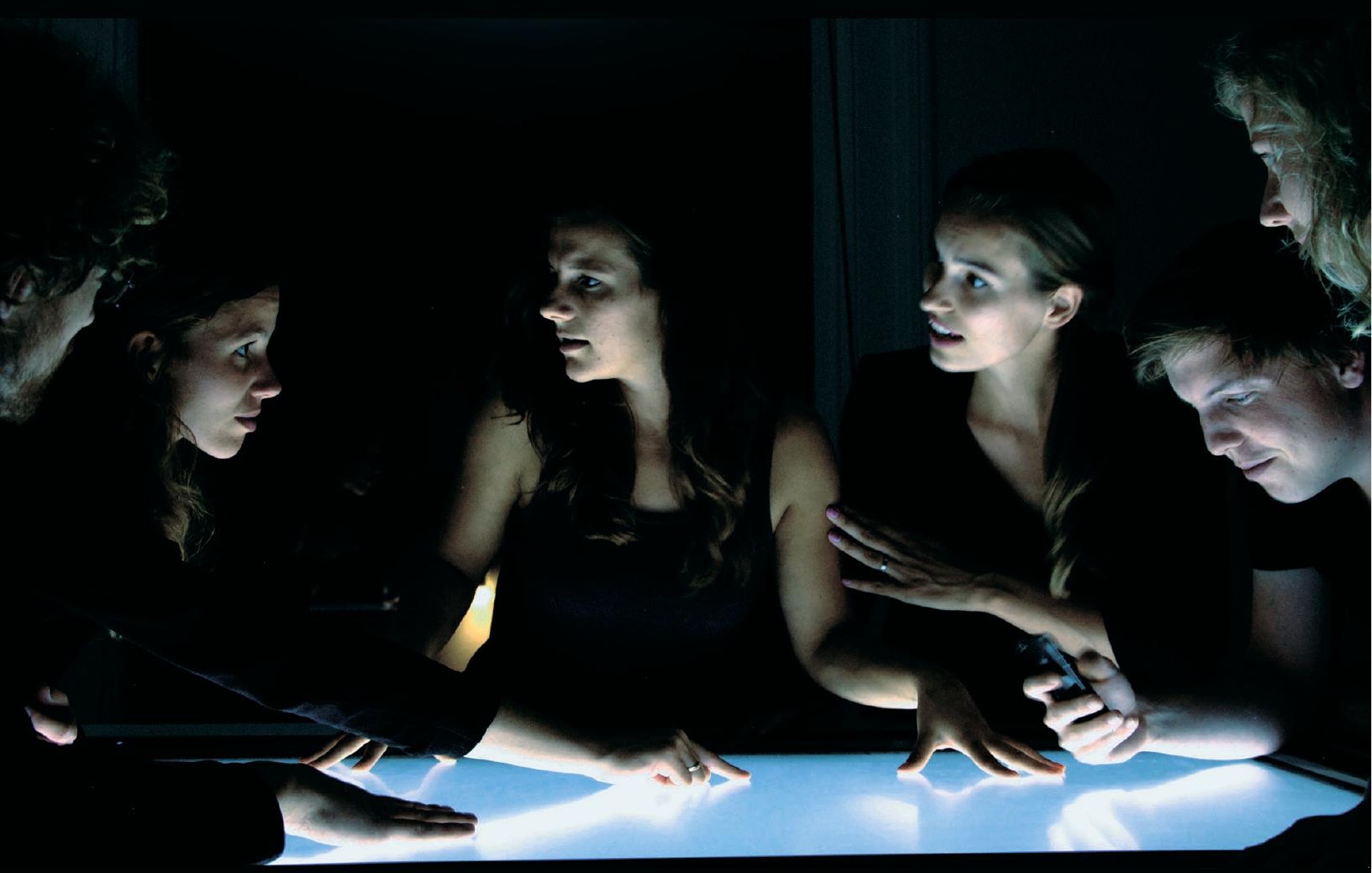
INTERACTIVE USE OF SIMULATION MODELS FOR COLLABORATIVE KNOWLEDGE CONSTRUCTION

THE CASE OF FLOOD POLICY DECISION-MAKING 


\section{Promotion committee:}

prof. dr. G.P.M.R. Dewulf

prof. dr. ir. A.Y. Hoekstra

dr. M. Brugnach

prof. dr. ir. J.P.M. van Tatenhove

prof. dr. E. Eisemann

dr. T. Krueger

prof. dr. J. Th. A. Bressers

prof. dr. J. C. J. Kwadijk
University of Twente, chairman, secretary

University of Twente, promotor

University of Twente, co-promotor

Wageningen University

Delft University of Technology

Humboldt-Universität Berlin

University of Twente

University of Twente

The work described in this thesis was performed at the Department of Water Engineering and Management, faculty of Engineering Technology, University of Twente, Enschede, the Netherlands. The work was carried out as part of the research and development program 3Di Water management, funded by several sources, including Knowledge for Climate, Hoogheemraadschap Hollands Noorderkartier, Hoogheemraadschap van Delfland, Deltares, Delft University of Technology and Nelen \& Schuurmans.

Cover design: Theo Horstink, De Bilt, The Netherlands

Cover photo: Elgard van Leeuwen, De Bilt, The Netherlands

Copyright (C) 2015 by Johannes G. Leskens, Utrecht, The Netherlands

All rights reserved. No part of this publication may be reproduced, stored in a retrieval system, or transmitted, in any form or by any means, without the written permission of the author.

Printed by Gildeprint, Enschede, The Netherlands

ISBN: 978-90-365-3973-9

DOI: $10.3990 / 1.9789036539739$

URL: http://dx.doi.org/10.3990/1.9789036539739 


\title{
INTERACTIVE USE OF SIMULATION MODELS FOR COLLABORATIVE KNOWLEDGE CONSTRUCTION
}

\author{
THE CASE OF FLOOD POLICY DECISION-MAKING
}

PROEFSCHIRFT

ter verkrijging van

de graad van doctor aan de Universiteit Twente,

op gezag van de rector magnificus,

prof. dr. H. Brinksma,

volgens besluit van het College voor Promoties

in het openbaar te verdedigen

op dinsdag 8 december 2015 om 16:45

door

Johannes Gosewinus Leskens

Geboren op 3 januari 1982

te Hattem 
This thesis is approved by:

prof. dr. ir. A.Y. Hoekstra

promotor

dr. M. Brugnach

co-promotor 


\section{Contents}

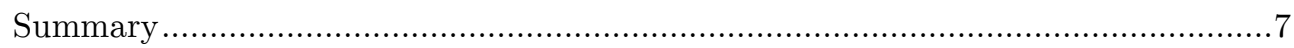

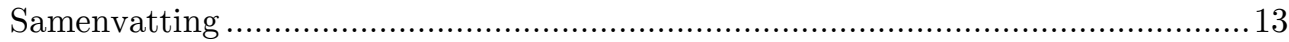

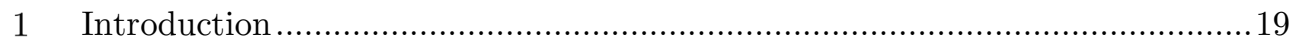

2 The limited use of simulation model outputs in flood disaster management and

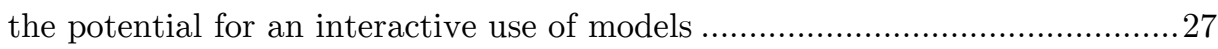

3 Technical feasibility of an interactive use of models by practitioners and

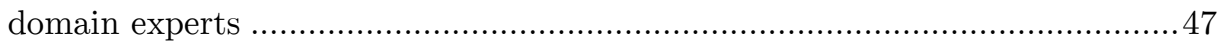

4 Real-world applications of models that can be interactively used....................69

5 Evaluation of the influence of an interactive use of models on the collaborative

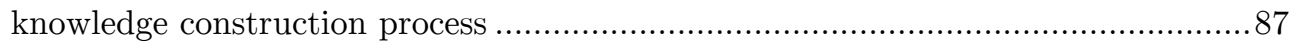

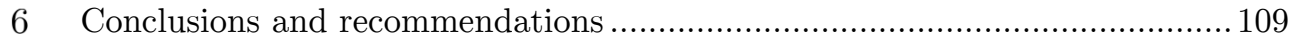

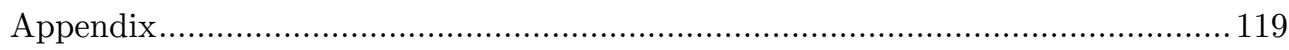

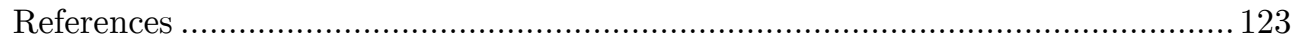

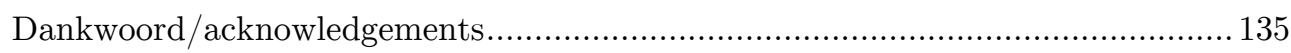

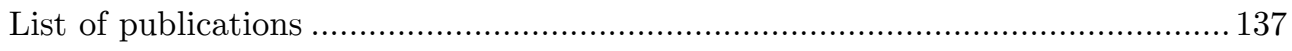

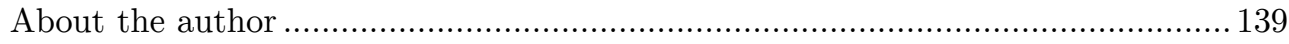





\section{Summary}

The concept of collaborative knowledge construction describes how different participants in work sessions interact, share their knowledge and experience and construct shared knowledge about the issue at hand. Science can support the collaborative knowledge construction process, for example by providing insights into complex physical, social or economic processes and by showing the impact of suggested mitigation or adaptation strategies.

However, it is often indicated in literature that a gap exists between the knowledge that is provided by domain experts (i.e. scientists, domain specialists) and the knowledge demanded by decision-makers, policy analysts and other practitioners outside the domain of experts. There is a growing recognition in the field of policy research that this gap can be reduced when interactive ways of knowledge construction are applied. Instead of a one-way supply of information from the experts' domain to the practitioners' domain, knowledge is shared and developed in multi-actor work sessions by combining perspectives of domain experts, practitioners and other stakeholders involved in the complex problems that are being studied.

In this research we investigate how an interactive use of simulation models can be supportive for collaborative knowledge construction in multi-actor work sessions including domain experts and practitioners. Simulation models are computer programs in which real systems are digitally schematized by using scientific knowledge applied to a certain problem area. These models are used for purposes such as improving understanding about a real system, predicting future behavior of a real system under specified conditions or exploring the effect of interventions. We scope our research to the context of flood policy decision-making since this is a context in which simulation models are commonly used and where knowledge produced by domain experts seems to be underutilized in the process of collaborative knowledge construction. 
We organized our work along four research questions. We will briefly summarize our methods and conclusions per research question.

\section{What are the main reasons for the gap between the knowledge} produced by domain experts and the use of that expert knowledge by practitioners in flood policy decision-making and is there a potential to fill this gap with an interactive use of flood simulation models?

We investigated how knowledge is exchanged between domain experts and practitioners in a practical situation of flood policy decision making management, namely in the situation of flood disasters. We carried out three research activities: (1) reviewing evaluation reports of flood disasters and flood disaster exercises, (2) mapping the exchange of model information between domain experts and practitioners using Social Network Analysis, and (3) evaluating the use of model information in a flood disaster exercise in which a flood simulation model was applied.

We discovered that delays in the provision of model outputs to practitioners often result in model outputs that are outdated and therefore not usable. This is caused by long computation times and the fact that model software can only be applied by a few specialists, so that, as a consequence, information has to pass several intermediaries before it reaches the actual decision-makers. Model experts are also hesitant to provide model information to others in the network, as they are afraid that this information will be used wrongly. Given the division of tasks and responsibilities, they lose the opportunity to explain the applicability of their predictions while, in the same time, they are considered fully accountable for the accuracy of these predictions.

We conclude that these technical and organizational limitations could potentially be solved by models that can be used interactively in work sessions involving both practitioners and experts. Such models should be fast enough to be able to keep pace with the speed of interactions and the frequency of new questions raised in the actual decision-making process.

2. Can flood simulation models, as recently made available, be made accessible for practitioners of flood policy decision-making and used by them to carry out flood analyses together with domain experts in work sessions? 
To answer this question we carried out three research activities. 1) We configured a flood simulation model for a study area in the Netherlands that could be used interactively, based on prototype modelling software named 3Di. This was done in close cooperation with the developers of the prototype software, including researchers and engineers from Delft University of Technology, Deltares, and Nelen \& Schuurmans. 2) We evaluated the usefulness of the model for practitioners of flood management, who are usually not domain experts, in individual tests. In these tests, we asked the participants to perform individual analysis and to comment on different types of visualizations obtained by the model. 3) We evaluated the accessibility of the model for both model experts and practitioners by observing the application of the simulation model during a multi-stakeholder work session and by group evaluations with the participants.

We found that practitioners, who were no model experts, where able to apply the simulation model without the support of a domain expert. The work session showed that the simulation model could also be used collaboratively by both domain experts and practitioners during a multi-stakeholder work session to support the process of assessing flood risks and choosing flood adaptation and mitigation measures.

We conclude that, despite the complexity of flood simulation models and the size of the involved data sets, a process can be introduced in which practitioners of flood management can carry out flood simulations together with domain experts in interactive work sessions.

\section{Is an interactive use of flood simulation models during work sessions accepted by practitioners in real-world decision-making processes and do they perceive this as an improvement, compared to static flood maps that are prepared in advance of a work session?}

Two work sessions that gave input to real decision-making processes were organized in which a flood simulation model was interactively used with practitioners and domain experts. Flood simulation models were configured for both study areas, based on prototype 3Di software. In group evaluations, the participants were asked to express their opinions about if and how the interactive use of the flood simulation model improved the decision-making process during the work sessions in comparison with the use of static flood maps prepared in advance of work sessions. After these sessions, the participants were asked to fill in a questionnaire, scoring different statements relating to their appreciation of the use of an interactive water model during work sessions. 
We found that the interactive use of the simulation model gave the participants of the work sessions better understanding of the problems that heavy rainfall can cause in the study areas and gave them better insight into possible solutions to solve these problems. The interactive use of the simulation model also improved the engagement of the participants in the decision-making process. A majority of the respondents would apply the interactive water model in future work sessions.

Based on the group evaluations and questionnaires we conclude that the interactive use of the models during the work sessions was positively received and was perceived as an improvement compared to static flood maps that are prepared in advance of work sessions.

\section{How does the interactive use of flood simulation models influence the process of collaborative knowledge construction, compared to static flood maps prepared in advance of work sessions?}

We introduced a method to monitor the process of collaborative knowledge construction as it evolves in multi-stakeholder work sessions. Our method was adopted from education sciences and adapted for the use in multi-actor work sessions. In this method, all conversations are recorded by video, fragmented in individual statements and classified on different properties of collaborative knowledge construction. We tested the applicability and usefulness of our method in a flood disaster experiment in which we monitored two cases: the use of conventional static flood maps and the application of an interactive flood simulation model.

We found that the collaborative knowledge construction process concentrated more on the technical properties of the threatening flood, such as critical depths and time to inundate, when the interactive model was used. This resulted in follow-up actions about vertical evacuation instead of evacuation out of the area, prioritizing neighborhoods that could be flooded early after a breach and providing inhabitants with information about the time to inundate. On the other hand, the case that did not make use of an interactive model dedicated its collaborative learning capacity more on developing integral follow-up actions, such as the evacuation of physically disabled people, the warning of cattle farmers and the accessibility of evacuation routes.

We conclude that focusing on collaborative knowledge construction is a helpful perspective to assess the influence of an interactive model use on de the decisionmaking process in work sessions. Our method reveals how model outputs became integrated in the knowledge construction process of practitioners in a flood disaster 
setting and promises to be a useful method for future evaluations of the influence interactive models in a larger number of experimental settings and in real-world situations. 



\section{Samenvatting}

Hoe ontwikkel je samen kennis? Het concept 'collaborative knowledge construction' (gezamenlijke kennisontwikkeling) beschrijft hoe verschillende personen door persoonlijke interactie hun kennis en ervaring met elkaar delen. Zo kunnen ze een gedeeld beeld van hun omgeving creëren. De wetenschap kan dit proces ondersteunen. Dat kan bijvoorbeeld door inzicht te geven in complexe fysische, sociale of economische processen en door de invloed te laten zien van voorgestelde maatregelen of strategieën op deze complexe processen.

Uit onderzoek blijkt dat er een kloof bestaat tussen de wetenschapsdiscipline (onderzoekers en specialisten) en de praktijkwereld (o.a. politici en

beleidsadviseurs). Informatie van specialisten is vaak niet direct bruikbaar voor de praktijk. Recente onderzoeken geven aan dat deze kloof verkleind kan worden als er interactieve vormen van kennisontwikkeling worden toegepast. In plaats van de traditionele informatievoorziening, die gebaseerd is op eenrichtingsverkeer van specialistische kennis naar de praktijk, wordt voorgesteld om specialisten en de praktijkwereld meer samen te laten werken in de kennisontwikkeling van complexe problemen.

In dit onderzoek hebben we onderzocht hoe het interactief gebruik van simulatiemodellen het gezamenlijk kennisontwikkelingsproces beïnvloedt. Deze simulatiemodellen worden gebruikt tijdens workshops, waarin specialisten en mensen uit de praktijk deelnemen. Simulatiemodellen zijn computer programma's waarin delen van de echte wereld digitaal zijn geschematiseerd op basis van wetenschappelijke kennis. Simulatiemodellen worden bijvoorbeeld toegepast om inzicht te krijgen in de werking van een systeem, om het gedrag van een systeem te voorspellen of om te onderzoeken wat het effect is van ingrepen op een systeem. Dit onderzoek focust zich specifiek op het interactief gebruik van overstromingssimulatiemodellen in het proces van politieke besluitvorming in het overstromingsrisicobeheer.

Dit onderzoek is gestructureerd aan de hand van vier onderzoeksvragen. Hieronder zijn de methodes en conclusies behorend bij deze onderzoeksvragen kort samengevat. 
1. Wat zijn de belangrijkste redenen dat specialistische kennis beperkt wordt gebruikt in besluitvormingsprocessen in overstromingsrisicobeheer en is er potentie om dit gebruikt te laten toenemen door het toepassen van interactieve simulatiemodellen?

Eerst hebben we onderzocht hoe kennis wordt uitgewisseld tussen experts en betrokkenen bij het politieke besluitvormingsproces tijdens een dreigende overstromingsramp. We hebben drie onderzoeksmethodes toegepast: (1) literatuuronderzoek van evaluaties van overstromingsrampoefeningen en overstromingsrampen, (2) het in kaart brengen van de informatie-uitwisseling tussen experts en betrokkenen bij het politieke besluitvormingsproces met een Social Network Analysis en (3) het real-time monitoren van de informatievoorziening van resultaten uit simulatiemodellen tijdens een overstromingsrampoefening.

We hebben ontdekt dat vertragingen in de communicatie van expertkennis, afkomstig uit simulatiemodellen, er vaak toe leiden dat deze modelresultaten niet meer actueel zijn en daarom niet bruikbaar zijn. Dit wordt veroorzaakt door lange simulatietijden en ingewikkelde gebruikersinterfaces die alleen door modelexperts gebruikt kunnen worden. Daardoor gaan de modeluitkomsten eerst langs diverse tussenpersonen voordat ze de uiteindelijke besluitvormers bereiken. Daarnaast blijken modelexperts ook terughoudend te zijn in het communiceren van modeluitkomsten naar anderen omdat er een risico bestaat dat deze informatie verkeerd wordt gebruikt. Door de strikte scheiding van taken en verantwoordelijkheden verliezen zij de mogelijkheid om toe te lichten hoe de modeluitkomsten toegepast kunnen worden, terwijl ze wel aansprakelijk zijn voor de betrouwbaarheid van de modeluitkomsten.

We concluderen dat deze technische en organisatorische beperkingen mogelijk opgelost kunnen worden door simulatiemodellen interactief te gebruiken. Deze kunnen worden toegepast tijdens vergaderingen en workshops waarin zowel experts als de betrokken uit het besluitvormingsproces aanwezig zijn. Zulke modellen moeten snel genoeg zijn om de interactiesnelheid tussen besluitvormers bij te houden en snel antwoord kunnen geven op nieuwe informatievragen bij veranderende omstandigheden.

2. Kunnen recent ontwikkelde simulatietechnieken beschikbaar worden gemaakt voor betrokken in het politieke besluitvormingsproces van het overstromingsrisicobeheer zodat zij samen met experts overstromingsanalyses kunnen uitvoeren tijdens vergaderingen en workshops? 
Om deze vraag te kunnen beantwoorden hebben we drie onderzoeksactiviteiten uitgevoerd. 1) We hebben een overstromingssimulatiemodel geconfigureerd voor een studiegebied in Nederland dat interactief gebruikt kan worden, gebaseerd op de prototype modelleersoftware genaamd 3Di. 2) We hebben de bruikbaarheid van dit model getest voor niet-experts in individuele tests. In deze tests hebben we de betrokkenen gevraagd om zelfstandig een overstromingsanalyse uit te voeren en om feedback te geven op verschillende manieren om de resultaten te visualiseren. 3) We hebben het gezamenlijk gebruik van het model door experts en betrokken uit het politieke besluitvormingsproces geëvalueerd door directe observaties van het gebruik tijdens een gezamenlijke workshop en door groepsevaluatie met de betrokkenen.

We hebben ontdekt dat de betrokkenen uit het politieke besluitvormingsproces in staat zijn het simulatiemodel te gebruiken, zonder de hulp van modelexperts. De workshop liet zien dat het simulatiemodel geschikt was voor een gezamenlijk gebruik om de analyse van overstromingsrisico's en het kiezen van maatregelen te ondersteunen.

We concluderen dat, ondanks de complexiteit van overstromingssimulatiemodellen en de grootte van de bijbehorende datasets, er een werkproces opgezet kan worden waarin betrokken uit het politieke besluitvormingsproces samen met experts overstromingsanalyses kunnen uitvoeren tijdens interactieve vergaderingen en workshops.

\section{Wordt een interactief gebruikt van simulatiemodellen tijdens vergaderingen en} workshops geaccepteerd door betrokken in het echte politieke besluitvormingsproces en wordt dit gezien als vooruitgang ten opzichte van statisch kaarten die voorafgaand aan vergaderingen en workshops zijn gemaakt?

We hebben twee workshops georganiseerd die deel uitmaakten van een echt besluitvormingsproces. Hierin hebben we simulatiemodellen toegepast die interactief gebruikt konden worden. Voor beide studiegebieden zijn simulatiemodellen geconfigureerd gebaseerd op de prototypesoftware 3Di. In groepsevaluaties hebben we de betrokkenen gevraagd hun mening te geven over hoe het interactieve gebruik van de simulatiemodellen het besluitvormingsproces had beïnvloed, ten opzichte van het gebruik van statische kaarten. Na de workshops is er een enquête afgenomen onder de deelnemers. Hierin werden ze gevraagd om op verschillende stellingen te reageren die betrekking hadden op de toegevoegde waarde van het interactieve gebruik van simulatiemodellen. 
Het interactieve gebruik van de simulatiemodellen gaf de deelnemers aan de workshops een beter begrip van de problemen die hevige neerslag kon veroorzaken en de mogelijkheden om deze problemen op te lossen. Het interactieve gebruikt van de simulatiemodellen vergrootte ook de betrokkenheid van de deelnemers in het besluitvormingsproces. Een meerderheid van de deelnemers gaf aan dat ze in toekomstige workshops dergelijke modellen weer zouden willen gebruiken.

We kunnen concluderen dat het interactieve gebruik van simulatiemodellen tijdens de workshops positief is ontvangen en dat het wordt gezien als een verbetering ten opzichte van statisch kaarten.

4. Hoe beïnvloedt het interactieve gebruik van simulatiemodellen het proces van gezamenlijke kennisontwikkeling, vergeleken met de situatie waarin statische kaarten worden gebruikt die voorafgaand aan vergaderingen en workshops zijn gemaakt?

Om deze vraag te beantwoorden hebben we een methode ontwikkeld om het proces van gezamenlijke kennisontwikkeling tijdens een vergadering of workshop te kunnen monitoren. Deze methode is afgeleid van methodes die worden gebruikt in de onderwijskunde en aangepast aan de situatie van interactieve workshops. In deze methode worden alle conversaties opgenomen met video. Deze worden opgesplitst in losse opmerkingen en geclassificeerd op verschillende eigenschappen van het proces van gezamenlijke kennisontwikkeling. We hebben de bruikbaarheid en de toepasbaarheid van onze methode getest in een experiment. In dit experiment hebben we twee cases met elkaar vergeleken: (1) het gebruik van statische kaarten en (2) het interactieve gebruik van een simulatiemodel.

Uit het experiment bleek dat het gezamenlijke kennisontwikkelingsproces van de case met het interactieve gebruik van een simulatiemodel zich meer concentreerde op de technische eigenschappen van de dreigende overstroming, zoals de kritische dieptes en de aankomsttijden van het water. Dit resulteerde in besluiten zoals verticale evacuatie in plaats van gebiedsevacuatie, een prioritering van gebieden waar hulp verleend moest worden en informatievoorziening aan de inwoners van het gebied. In de case waarin geen gebruik werd gemaakt van een interactief model had het gezamenlijke kennisontwikkelingsproces een bredere scope. Dit resulteerde in meer integrale oplossingen zoals het evacueren van invaliden, het waarschuwen van veehouders en het vrijhouden van belangrijke evacuatieroutes.

Uit ons experiment concluderen we dat de focus op het gezamenlijke kennisontwikkelingsproces een bruikbaar perspectief is om de invloed te evalueren van een interactief model op het besluitvormingsproces in vergaderingen en 
workshops. Onze methode laat zien hoe modeluitkomsten worden ingebed in het gemeenschappelijke kennisontwikkelingsproces van betrokkenen in het besluitvormingsproces tijdens overstromingsrampen en belooft een bruikbare methode te zijn in toekomstige evaluaties van het interactief gebruik van modellen in meer cases of in echte besluitvormingssituaties. 



\section{Introduction}

\subsection{Collaborative knowledge construction}

A main aspect of a decision-making process consists of collecting and sharing problem relevant information, in order to construct shared knowledge about the issue at hand and the possible interventions that can be undertaken (Weick 1995; Graaf and Hoppe 1996). The concept of collaborative knowledge construction specifically describes the process of how different participants in a decision-making process interact and share their knowledge and experience (Fischer, Bruhn et al. 2002). Constructing this shared knowledge through the process of collaborative knowledge construction can be very challenging, since decision-makers often have to deal with fragmented information, a lack of information, frequently unpredictable physical or social processes and multiple, sometimes contradictory, interpretations of the issues at hand (Pahl-Wostl, Craps et al. 2007; Van den Hoek, Brugnach et al. 2012).

Science can support the collaborative knowledge construction process, for example, by providing insights in complex physical, social or economic processes or by showing the impact of suggested mitigation or adaptation strategies (Hegger, Lamers et al. 2012). However, literature often indicates that a gap exists between the knowledge produced by domain experts (i.e. scientists, domain specialists) and the use of this expert knowledge by decision-makers, policy analysts and other practitioners outside the domain of experts (Seijger, Dewulf et al. 2013; Giebels, van Buuren et al. 2015). Traditionally, the interaction between experts and practitioners has been based on a one-way approach, with knowledge transfer largely originating from the experts (Roux, Rogers et al. 2006), involving the experts as the producers and the practitioners as the users of knowledge (LópezRodríguez, Castro et al. 2015). This expert knowledge may fail to match expectations of practitioners of political decision-making and it may be used differently than was expected or intended. Moreover, the expert domain is fragmented across disciplines (Herrick and Sarewitz 2000) and the interaction between experts and practitioners is difficult due to differences in problem perception, time frames, reward structures, goals, process cycles, criteria for the quality of knowledge and discourse (Bouwen 2001; Hegger, Lamers et al. 2012). 
As a consequence, expert knowledge from the experts' domain is limitedly included in the collaborative knowledge construction process of practitioners.

There is a growing recognition in the field of policy research that the knowledge produced by domain experts (e.g. scientist, modelers, engineers) can be utilized more effectively by practitioners when interactive ways of knowledge construction are applied (Seijger, Dewulf et al. 2013). Instead of a one-way supply of information from the experts' domain to the practitioners' domain, knowledge is shared and developed by obtaining perspectives of domain experts, practitioners and other stakeholders involved in the complex problems that are being studied. To organize this interactive way of collaborative knowledge construction, often multi-actor work sessions are organized, typically lasting a few hours (LópezRodríguez, Castro et al. 2015). In these work sessions, domain experts, practitioners and other stakeholders are invited, for example to collaboratively analyze the issue at hand or discuss suggested solutions for intervention measurers (Linkov, Wood et al. 2009; Walsh, Roberts et al. 2013).

\subsection{Interactive use of simulation models}

Recently, simulation models have been developed that might be supportive for interactive approaches of collaborative knowledge construction between domain expert and practitioners during multi-actor work sessions. Simulation models are computer programs in which real systems are digitally schematized by using scientific knowledge applied to a certain problem area. Examples are geological models, hydrological models or economical models. Simulation models are used for various purposes, for example to build understanding about a real system, to predict future behavior of a real system or to explore the effect of interventions (Brugnach and Pahl-Wostl 2007). These simulation models used to be only accessible for domain experts in advance of work sessions due to specialized software, long computation times and large data sets (Leskens, Kehl et al. 2015).

Nowadays, user interfaces of models have become easy to use and strongly visual and computation times are reduced to such an extent that models can provide outputs in real-time (Zhu and Chen 2005; Kehl and de Haan 2012). In this way, this new technology may allow that model outputs do not anymore have to be produced only by domain experts and be provided to practitioners in a one-way approach to practitioners, but that models can be used during work session, interactively supporting the collaborative knowledge construction process between domain experts and practitioners. It is expected that this interactive use of models can bridge the gap that currently exist between the knowledge production in the experts' domain and the use of that expert knowledge by practitioners. Since the 
required technology has only recently become available, we currently lack examples in which this interactive use of simulation models is tested and evaluated.

\subsection{The case of flood policy decision-making}

Flood policy decision making typically exhibits a gap between knowledge production by domain experts (i.e. hydraulic engineers, hydrologists and modelers) and the use of that expert knowledge by practitioners (i.e. policy analysts or political decision-makers) (Morss, Wilhelmi et al. 2005; Faulkner, Parker et al. 2007; McCarthy, Tunstall et al. 2007; Demeritt, Nobert et al. 2010). Flood policy decision making can be characterized as a complex and uncertain problem environment due to its complex hydrodynamic processes, the interrelation with socio-economic issues and the involvement of many different stakeholders (Downton, Morss et al. 2005; Morss, Wilhelmi et al. 2005; Timmerman, Beinat et al. 2010). Expert knowledge, including the outputs of flood simulation modelling, can therefore be very helpful in the production of knowledge relied upon in the management of flood risks (Porter and Demeritt 2012; Landström and Whatmore 2014).

The required technology for an interactive use of these flood simulation models has recently become available. Nowadays, flood simulation models are very advanced in terms of integration of physical processes, detail of outcomes, computation speed and visualization techniques. For example, flood depth predictions can be provided at a spatial resolution of $0,25 \mathrm{~m} 2$ in several minutes and can be visualized in various formats, including realistic 3D-visualizations (Figure 1-1), comparable to those used in flight simulators (De Haan 2009; Stelling 2012). However, this model technology is not yet applied for interactive model use during multi-actor work sessions. Currently, model outputs are produced in the experts' domain and presented to practitioners in a one-way approach on static maps or described in reports. These maps for example demonstrate the impact of floods in terms of inundation depths or damages under a predefined scenario's consisting of certain storm surges or dam breaches. 


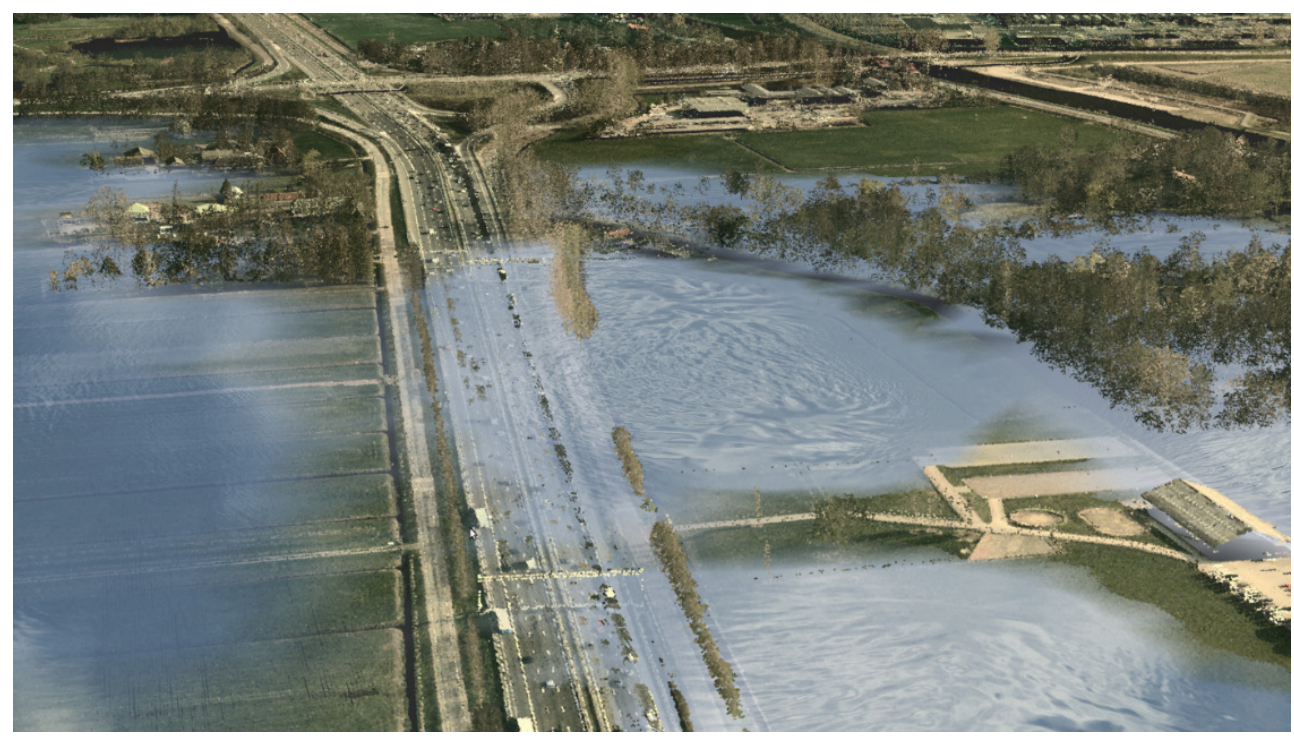

Figure 1-1: 3D visualization of a model output (De Haan 2009)

\subsection{Research objective}

The objective of this research is to investigate how the interactive use of flood simulation models in work sessions with domain experts and practitioners of flood policy decision-making will influence the collaborative knowledge construction process.

\subsection{Research questions}

To reach the research objective, the following research questions are identified:

Question 1: What are the main reasons for the gap between the knowledge produced by domain experts and the use of that expert knowledge by practitioners in flood policy decision-making and is there a potential to fill this gap with an interactive use of flood simulation models?

Question 2: Can flood simulation models, as recently made available, be made accessible for practitioners of flood policy decision-making and used by them to carry out flood analyses together with domain experts in work sessions?

Question 3: Is an interactive use of flood simulation models during work sessions accepted by practitioners in real-world decision-making processes and do they perceive this as an improvement, compared to static flood maps that are prepared in advance of a work session? 
Question 4: How can systematically be assessed if and how an interactive use of simulation models leads to an integration of model outputs in the knowledge construction process of practitioners in flood policy decision-making?

\subsection{Research approach}

To gain a better understanding about why the knowledge that is produced by domain experts is poorly used by practitioners in flood policy decision-making (i.e. research question 1), we investigated how knowledge is exchanged between model specialists and practitioners in a practical situation of flood policy decision-making. We chose a case study in which the separation between the experts' domain and the practitioners' domain is very clear, namely the context of Flood Disasters Management. First, we reviewed ten evaluation reports of flood disasters and flood disaster exercises of the last decade and focused on the general experiences from practitioners about the use of model outputs in the process of decision-making during flood disasters. Second, to understand how model outputs are exchanged during flood disasters, we applied a Social Network Analysis (Liebowitz 2005) to map this exchange in a flood disaster organization, based on fifteen interviews with participants. Third, to investigate how model outputs are perceived by individual practitioners, we organized a flood disaster exercise in which a flood simulation model was applied in a conventional way (i.e. only used by domain experts). The 100 participants of the flood disaster exercise were requested to fill in a questionnaire about their personal experiences with the provided model outputs. Based on our findings from the document review, Social Network Analysis and flood disaster exercise we defined the main reasons for the gap between the knowledge that is produced by domain experts and the use of this expert knowledge by practitioners in flood policy decision-making. We explored how this gap can be filled with an interactive use of flood simulation models.

To answer research question 2, we carried out three research activities. First, we configured a flood simulation model for a study area in the Netherlands that could be interactively used, based on prototype modelling software named 3Di. This was done in close cooperation with the software developers, which were researchers and engineers from Delft University of Technology, Deltares, and Nelen \& Schuurmans. The model that was developed had very short computation times in combination with a high spatial resolution and an accurate physical representation of all relevant processes, was easily adaptable to test suggested measures and had a realistic visualization of model outputs. Second, we evaluated the usefulness of this model for practitioners of flood management, who are usually not domain experts, in individual tests. In these tests, we asked the participants to perform an analysis 
themselves and to comment on different types of visualizations obtained by the model. Third, we evaluated the accessibility of the model for both model experts and practitioners by observing the application of the simulation model during a multi-stakeholder work session and by group evaluations with the participants.

To answer question 3, we had the opportunity to organize two work sessions that gave input to real decision-making processes in the Amsterdam region: (1)

Watergraafsmeer and (2) Purmerend. The workshop in the district

Watergraafsmeer was carried out within a Dutch national research program called Knowledge for Climate. The workshop in Purmerend was carried out within the Urban Water Plan Purmerend 2015. For both work sessions, we configured a flood simulation model in the prototype 3Di software that was used interactively during the work sessions. In group evaluations, the participants were asked to express their opinions about whether the interactive use of the flood simulation model improved the decision-making process during the work sessions in comparison with the use of static flood maps prepared on beforehand. After the work sessions, the participants were asked to respond to a questionnaire in which they were asked to assign scores to different statements pertaining to their appreciation of the interactive water model.

To answer question 4, we introduce a method to monitor the process of collaborative knowledge construction as it evolves in multi-stakeholder work sessions. Our method was adopted from education sciences and adapted for the use in multi-actor work sessions. Collaborative knowledge construction is to a large extent quantifiable through real-time observation (Fischer, Bruhn et al. 2002). These real-time observations were done by video analysis in which the conversations during the process were fragmented into individual statements that were expressed by the participants. Consequently, these individual statements were characterized by different properties of collaborative knowledge construction, such as the participation of different actors and the extent in which participants refer to each other's statements. We applied this assessment method in a flood disaster experiment and made a comparison between two cases: the use of conventional static flood maps and the interactive use of a flood simulation model. Based on these cases, we draw conclusions about the usefulness of our method to reveal how model outputs from interactive models become integrated in the knowledge construction process in a flood disaster setting. We also explain how this method can be used for future evaluations of the influence of interactive models in a larger number of experimental settings and in real-world situations. 


\subsection{Thesis outline}

The thesis consists of six chapters. After this introductory chapter, the thesis continues with four chapters that were written as independent journal publications. Each chapter addresses one of the four specific research questions as mentioned above.

Chapter 2 addresses research question 1, by identifying the main reasons for the gap between the knowledge that is produced by domain experts and the use of this expert knowledge by practitioners in flood policy decision-making. In this chapter we underpin the potential to fill this gap with a flood simulation model that can interactively be used and define its system requirements on headlines.

Chapter 3 addresses research question 2, by demonstrating that a flood simulation model can be configured that is accessible for practitioners of flood management, such that they can carry out flood analyses together with domain experts in interactive work sessions. This chapter gives a technical overview of the technologies available to develop such as flood simulation model and shows its usability along test cases with individuals and a user study with practitioners and domain experts.

Chapter 4 addresses research question 3, by describing two real-world applications of models that were interactively used by practitioners and domain experts in work sessions. We present the outcomes of the individual questionnaires and group evaluations. Based on these outcomes we draw conclusions about the appreciation among practitioners for an interactive use of models during work sessions and give recommendations for the set-up of those work sessions.

Chapter 5 addresses research question 4, by presenting an assessment method to monitor the influence of an interactive use of models on the process of collaborative knowledge construction during a work session. This method consists on of video analysis, in which individual statements are fragmented and scored. It provides insight in six aspects of the collaborative knowledge construction process. Consequentially, we present the application of our assessment method in a comparative experiment, with and without the use of an interactive model, and draw conclusions about the usefulness and usability of the method for future evaluations.

In Chapter 6 consists of a synthesis of the whole research. It contains the main conclusions by summarizing the answers to the four research questions addressed above. Furthermore, an overall reflection on the conclusions is given, our contribution to the scientific and practical community are listed and recommendations for further research are provided. 



\section{The limited use of simulation model outputs in flood disaster management and the potential for an interactive use of models}

This chapter is published as journal paper: Leskens JG, Brugnach M, Hoekstra AY, Schuurmans W (2014b), Why are decisions in flood disaster management so poorly supported by information from flood models? Environmental Modelling \& Software 53: 53-61. This paper won the award for the best PhD paper of 2015 of the Twente Water Centre.

\section{$2.1 \quad$ Abstract}

Flood simulation models can provide practitioners of Flood Disaster Management for sophisticated estimates of floods. Despite the advantages that flood simulation modelling may provide, experiences have proven that these models are of limited use. Until now, this problem has mainly been investigated by evaluations of which information is demanded by decision-makers versus what models can actually offer. However, the goal of this study is to investigate how model information is exchanged among participants in flood disaster organizations and how this exchange affects the use of modelling information. Our findings indicate that the extent to which a model is useful not only depends on the type and quality of its output, but also on how fast and flexible a model can be. In addition, methods of model use are required that support a fast exchange of model information between participants in the flood disaster organization.

\subsection{Introduction}

Flooding is a global phenomenon which causes widespread devastation, economic damages and loss of human lives. The occurrence of floods is the most frequent 
among all natural disasters. In 2010 alone, 178 million people were affected by floods. The total losses in exceptional years such as 1998 and 2010 exceeded $\$ 40$ billion (Wahlström 2012). Floods are not only a problem in developing countries. western Europe, for example, floods occur each year several times. For example, in 2010, France, Germany and Belgium were hit by floods during which more than 30 people died. The estimated damage was more than 1.8 billion US\$ (Source: EMDAT, The OFDA/CRED International Disaster Database - www.emdat.be, Université Catholique de Louvain, Brussels (Belgium)). Flood damages and loss of lives are mitigated through flood risk management. This includes the design of structural protection measures such as dikes and dams; the planning of a flood resilient environment; and flood disaster management (Houghton, Jenkins et al. 1990; Nicholls 2004; EU 2005; Lumbroso, Stone et al. 2011; Stive, Fresco et al. 2011).

In this paper we analyze the use of flood simulation models in flood disaster management, which takes place from about 1-5 days in advance of a potential flood. Specifically in this period, the potential consequences of a flood can be importantly reduced, for example, by reinforcements of dikes or evacuation of people (Kolen and Helsloot 2012). Flood simulation models can support practitioners in these decisions by estimating the consequences of floods, in terms of water depths, flow velocities or damages. They can also be used to test the effectiveness of various measures. These flood simulation models are computer programs based on physical equations, features of an area, such as elevation and roughness resistance, and external forces, such as storm events and dam breaches (Bates and De Roo 2000; Al-Sabhan, Mulligan et al. 2003; De Moel and Aerts 2011; Stelling 2012).

Over the previous decade, the field of flood simulation modelling has rapidly grown, resulting in the development of many new and sophisticated models. The growth in model development has occurred for two main reasons: (1) advances in computer technology and modelling methods have opened new possibilities for modelling and simulating complex systems; and (2) unprecedented socio-economic and technical conditions have put new demands on decision-makers for complex and ready to use flood information (McCarthy, Tunstall et al. 2007). Nowadays, these models are very advanced in terms of the integration of physical processes, detail of outcomes and visualization techniques. For example, flood depth predictions can be provided at a spatial resolution of $0,25 \mathrm{~m}^{2}$ and can be visualized in various formats, including realistic 3D-visualizations comparable with those used in flight simulators (Schuurmans, Leskens et al. 2010) 
Despite the advantages that flood simulation modelling may provide, experiences have proven that the information from these models is of limited use in flood disaster management. Morss et al. (2005) show that practitioners of flood disaster management, operating under regulatory, institutional, political, resource, and other constraints, prioritize other concerns over more sophisticated model information about flood risk, particularly when they cannot readily see the feasibility or value of incorporating new or more detailed information from models. This lack of consideration of sophisticated model information, under circumstances of high time pressure, large consequences, high complexity and uncertainty, can be understood as a 'simplification strategy'. This means that decision-makers, acting under these circumstances, tend to discard information that seems to increase the complexity they already have to deal with (MacCrimmon and Taylor 1976; Janis and Mann 1977; Kahneman and Tversky 1979; Gray 1989). This indicates that the modellers community develops models that provide information that is often not useful for practitioners of flood disaster management.

An underlying reason for this practice, indicated in literature, is the difference in the perception of flood risks between model developers and practitioners (Faulkner, Parker et al. 2007; Janssen, Hoekstra et al. 2009; Timmerman, Beinat et al. 2010; Wood, Kovacs et al. 2012). Modellers generally frame flood risk issues using scientific knowledge and expertise and assume that with more detailed model information analysis will improve and better decisions can be made. Practitioners, on the other hand, often lack the time and resources to perform such complex analyses. Moreover, they frame flood risk issues more on societal goals and values (Morss, Wilhelmi et al. 2005). They therefore need information that supports them in, for example, being decisive about which people have to be evacuated. As a result of these different perceptions of flood risks, a gap exists between what practitioners demand from models and what models provide. To overcome this gap, various solutions are proposed in the literature. They mainly focus on a better communication of model outputs and their accompanying uncertainties and more involvement of decision-makers in de modelling process (Kinzig, Starrett et al. 2003; Holmes 2004; Morss, Wilhelmi et al. 2005; Brugnach, Tagg et al. 2007; Faulkner, Parker et al. 2007; McCarthy, Tunstall et al. 2007; Linkov, Wood et al. 2009; Demeritt, Nobert et al. 2010; Timmerman, Beinat et al. 2010; Voinov and Bousquet 2010; Frick and Hegg 2011)

Even though the proposed solutions can be useful, these solutions are mainly based on evaluations of which information is demanded by decision-makers versus what output models can actually offer. However, these evaluations mostly ignore how decisions are made in the practical situation of flood disaster management. This practical situation can be characterized as a process in which actions are preceded 
Chapter 2: The limited use of simulation model outputs in flood disaster management and the potential for an interactive use of models

by considerations of various participants, all adding insights and information to make sense of the actual situation and to undertake action (Hage 1980; Nonaka 1994; Weick 1995). For example, model specialists are requested by policy analysts to provide information about the potential consequences of a dam breach, in order to advise decision-makers about which actions to undertake. These model specialists depend, among others, on the information about the actual situation, provided by people in the field, to interpret if existing model outputs are applicable or to make new model calculations. In this network of participants and under the dynamics of repeating information requests from policy makers, changing insight in the actual situation and information that is only partially available, model outputs are intended to be used. Therefore, besides the content of the information that models provide and the format in which this is communicated, also process factors, such as how the information is exchanged between modellers, people in the field, policy analysts and decision-makers, are expected to be important in investigating the limited use of models and proposing solutions to overcome this limited use.

The goal of this study is to investigate how model information is exchanged among participants in flood disaster organizations and how this exchange affects the use of modelling information for decision-making. Based on our findings, we propose solutions that increase the acceptability of model information in flood disaster management and overcome the main barriers in its use. We assume that this process of information exchange, including its dynamics of repeating information requests from policy makers and changing insight in the actual situation, is constant across different cases of flood disaster management. We chose the Netherlands practice of flood disaster management for our research. This country has a long history of flood management and has access to the latest model technology. It is therefore suitable to investigate the problems decision-makers are facing in using models. After drawing conclusions for the Netherlands context, we discuss if our findings are applicable for flood disaster management in general. Consequently, we propose new directions for model development and process design.

Although this paper specifically focuses on the use of models in the context of flood disaster management, it is treating the wider topic of how environmental models can be practically applied in decision-making processes. Recently, this topic has received an increased attention in literature and is being investigated by different approaches. For example, Krueger et al. (2012) stress the role of expert opinion in the application of environmental models, Demir and Krajewski (2013) focus on the role of integrated information systems to communicate model outputs to decisionmakers and Balica et al. (2013) and Zagonari and Rossi (2013) investigate how 
model results can be translated in performance indicators, usable in multi-criteria analysis. The findings in this paper contribute to this ongoing field of research and are therefore relevant for the modelling audience in general

\subsection{Methodology}

\subsubsection{General}

To reach our goal, we carried out three research activities. First, to make a description of the state-of-the-art of flood disaster management and the application of model information, we reviewed ten evaluation reports of flood disasters and flood disaster exercises of the last decade. This review focused on the general experiences from practitioners about the use of models in the process of decisionmaking during flood disasters. Second, to understand how model information is exchanged during flood disasters, we applied a Social Network Analysis to map this information exchange, based on fifteen interviews of participants in the flood disaster organization of a Netherlands Water board. Third, to investigate how model information is perceived by individual participants, we organized a flood disaster exercise in which a state-of-the-art model was applied. The 100 people that participated in the flood disaster exercise were requested to fill in a questionnaire about their personal experiences with the model information. The set-up of these research activities are further elaborated below.

\subsubsection{Document review}

Ten evaluation reports of the decision-making process during flood disasters were collected among six different regional Water boards in The Netherlands, including four evaluation reports of real threatening floods and six evaluation reports of flood disaster exercises (see Table 2-1). These evaluation reports referred to situations of flood disaster management encountered in the period of 2003 till 2012. The review focused on finding out how technical information from flood models was used in the decision-making process and which were the constraints encountered during this use. 
Chapter 2: The limited use of simulation model outputs in flood disaster management and the potential for an interactive use of models

Table 2-1: Reviewed evaluation reports

\begin{tabular}{|l|l|l|}
\hline Event & Period & Water board \\
\hline Dike breach Wilnis & August 2003 & Amstel Gooi and Vecht \\
\hline Extensive precipitation period Delfland & July 2008 & Delfland \\
\hline High water river Lek & January 2011 & Stichtse Rijnlanden \\
\hline High water Eems channel & January 2012 & Hunze en Aa's \\
\hline Flood disaster exercise 'Noord-Holland Nat' & 2008 & Hollands Noorderkwartier \\
\hline Flood disaster exercise 'Taskforce flood management' & 2009 & Hollands Noorderkwartier \\
\hline Flood disaster exercise 'FloodEx' & 2009 & Hollands Noorderkwartier \\
\hline Flood disaster exercise 'Laag Holland' & 2011 & Hollands Noorderkwartier \\
\hline Flood disaster exercise 'Hofpoort' & 2011 & Stichtse Rijnlanden \\
\hline Flood disaster exercise 'de Geer' & 2012 & Stichtse Rijnlanden \\
\hline
\end{tabular}

\subsubsection{Social Network Analysis and accompanying interviews}

Fifteen semi-structured interviews were conducted amongst professionals in the context of flood disaster management, selected from the Water board Hollands Noorderkwartier. This Water board covers a vast part of flood prone area in the north-western part of The Netherlands. In order to be able to retrieve insight in how models are embedded in the flood disaster management process, the interviews were used to draw a Social Network (Liebowitz 2005; Ebener, Khan et al. 2006).

Social Network Analysis allows to structure roles, tasks and properties of information exchange in a flood disaster organization. First, participants were asked what their roles and accompanying tasks are in the organization (Meadow and Yuan 1997; Choo 2001; Maguire 2001; Gemert-Pijnen, Karreman et al. 2010). Second, the participants were asked with whom they usually communicate to fulfill their tasks and which information is important in this communication. To help in this process, information was coded into four different types: situational, technical, procedural and political information. Situational information covers the actual situation in the field, such as observed dam breaks and inundation areas. Technical information includes the physical aspects of floods, such as water depths, flow velocities and derived estimations of damages and losses of life (Gummesson 2000). Procedural information covers information about organizational procedures, reports and planning (Leeuwis and Van den Ban 2004; Wesselink, De Vriend et al. 2009). Political information is about the accumulated experience of decision-makers in various governmental organizations, willingness to cooperate, power relations, trust and responsibilities (Collins and Evans 2002). For each information type, an 
indication was given of the lead time in which the information should be generated (Figure 2-1).

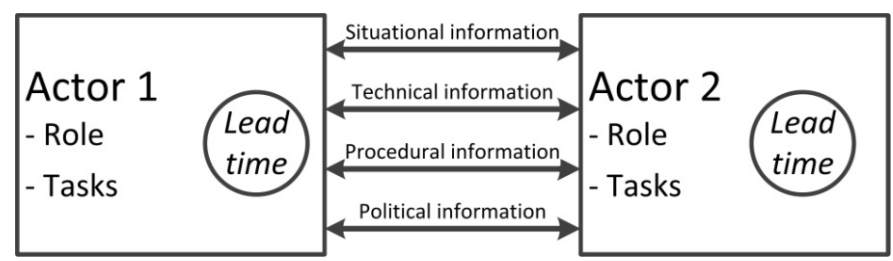

Figure 2-1: Content of interviews: roles and tasks of actors different types of information and the lead time to generate this information

The outcomes of the interviews were verified in a workshop with 10 of the interviewees (Leskens 2011).

\subsubsection{Flood disaster exercise}

A flood disaster exercise was organized in which a state-of-the-art flood model was applied and evaluated. In this flood disaster exercise, a threatening flood was simulated in which the participants had to make decisions about, for example, evacuations and the closure of dam breaks to minimize economic consequences and losses of life. Around 100 professionals involved were selected from the Municipality of Delft, the emergency organization of the area of Haaglanden and the regional Water board Hoogheemraadschap of Delfland. These organizations cover a flood prone area in the south-western part of The Netherlands. The collaboration of these parties is shown in Figure 2-2. 


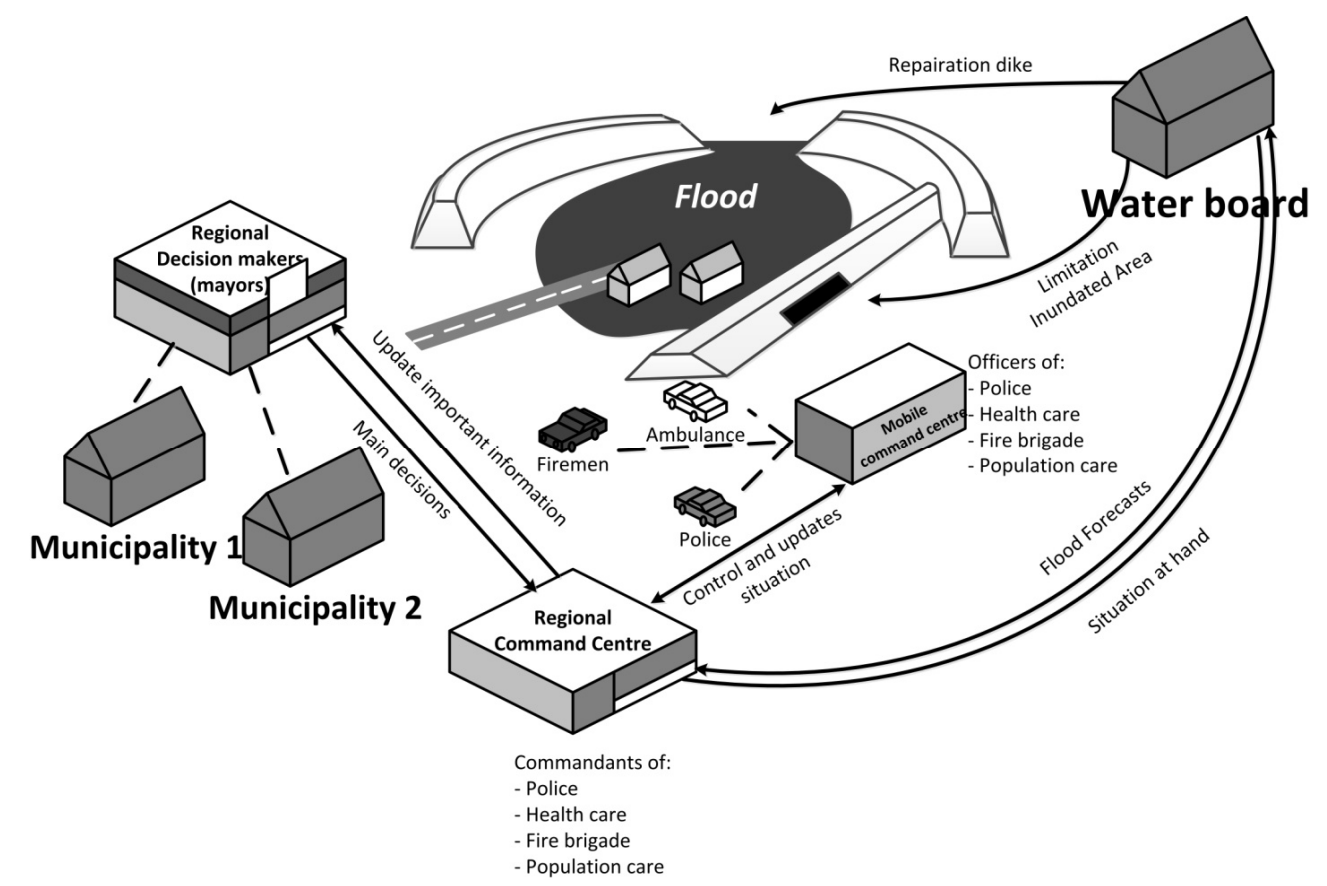

Figure 2-2: General organization structure and information flow during a flood calamity in the Netherlands

In this flood disaster exercise, a crisis was simulated by using a pre-designed script (Table 2-2) with several accidents, which were unknown beforehand by the 100 participants. 
Chapter 2: The limited use of simulation model outputs in flood disaster management and the potential for an interactive use of models

Table 2-2: Time table of event exercise

\begin{tabular}{|c|c|c|}
\hline Time & Events related to water levels & $\begin{array}{l}\text { Events related } \\
\text { to water quality }\end{array}$ \\
\hline 5:00 AM - 9:00 AM & $\begin{array}{l}\text { Heavy rains and high water levels in main discharge } \\
\text { canal 'the Schie' }\end{array}$ & \\
\hline 9:00 AM & $\begin{array}{l}\text { Inner city of Delft is threatened by high water levels } \\
\text { (canals of inner city are directly connected to the } \\
\text { Schie). }\end{array}$ & \\
\hline 9:30 AM & $\begin{array}{l}\text { Sluices that close off the inner city of Delft from the } \\
\text { Schie fail to work automatically }\end{array}$ & \\
\hline 9:30 AM -10:30 AM & Sluices have to be closed by hand & \\
\hline 11:00 AM & $\begin{array}{l}\text { Accident with a truck containing a tank with } \\
\text { poisonous matter that bumps against one of the } \\
\text { main pumps in Delft. This pump has the function of } \\
\text { pumping the excess of rainwater from the canals of } \\
\text { Delft into the Schie in case of a closure of the sluices. }\end{array}$ & $\begin{array}{l}\text { Accident with } \\
\text { truck: poisonous } \\
\text { liquid flows into } \\
\text { the inner city } \\
\text { canals of Delft }\end{array}$ \\
\hline 11:00 AM - 3:00 PM & \multicolumn{2}{|c|}{$\begin{array}{l}\text { Dilemma: open the sluices to dilute the poisonous matter and accept } \\
\text { inundation, or: remain the sluices closed and accept the poisonous matter } \\
\text { in the inner city. }\end{array}$} \\
\hline
\end{tabular}

A sophisticated inundation model (Deltares 2015) was made available to the team of model specialists. This model was able to simulate the overland flow and distribution of polluted water at a high spatial resolution of $1 \mathrm{~m}$. The model results were communicated through digital maps in an internet interface and 3D visualizations on a projector screen to the policy makers (Table 2-3, Figure 2-3 and Figure 2-4).

Table 2-3: Decision supporting model tools

\begin{tabular}{|l|l|}
\hline Property & Description \\
\hline Processes modelled & $\begin{array}{l}\text { Hydrodynamic overland flow, distribution of liquid pollutions in } \\
\text { water }\end{array}$ \\
\hline Available results & $\begin{array}{l}\text { Flood maps, flood simulations (movies), distribution maps of } \\
\text { pollution }\end{array}$ \\
\hline Detail (resolution) & $\begin{array}{l}\text { Spatial: } 1 \mathrm{~m} 2 \\
\text { Levels: } 0.01 \mathrm{~m}\end{array}$ \\
\hline Communication of results & $\begin{array}{l}\text { Digital maps and movies in web portal, 3D-visualisation (see } \\
\text { Figure 2-3 and Figure 2-4) }\end{array}$ \\
\hline Initial conditions & $\begin{array}{l}\text { Water level gradient in canal } \\
\text { An initial concentration of the marker at a certain position }\end{array}$ \\
\hline
\end{tabular}


Chapter 2: The limited use of simulation model outputs in flood disaster management and the potential for an interactive use of models

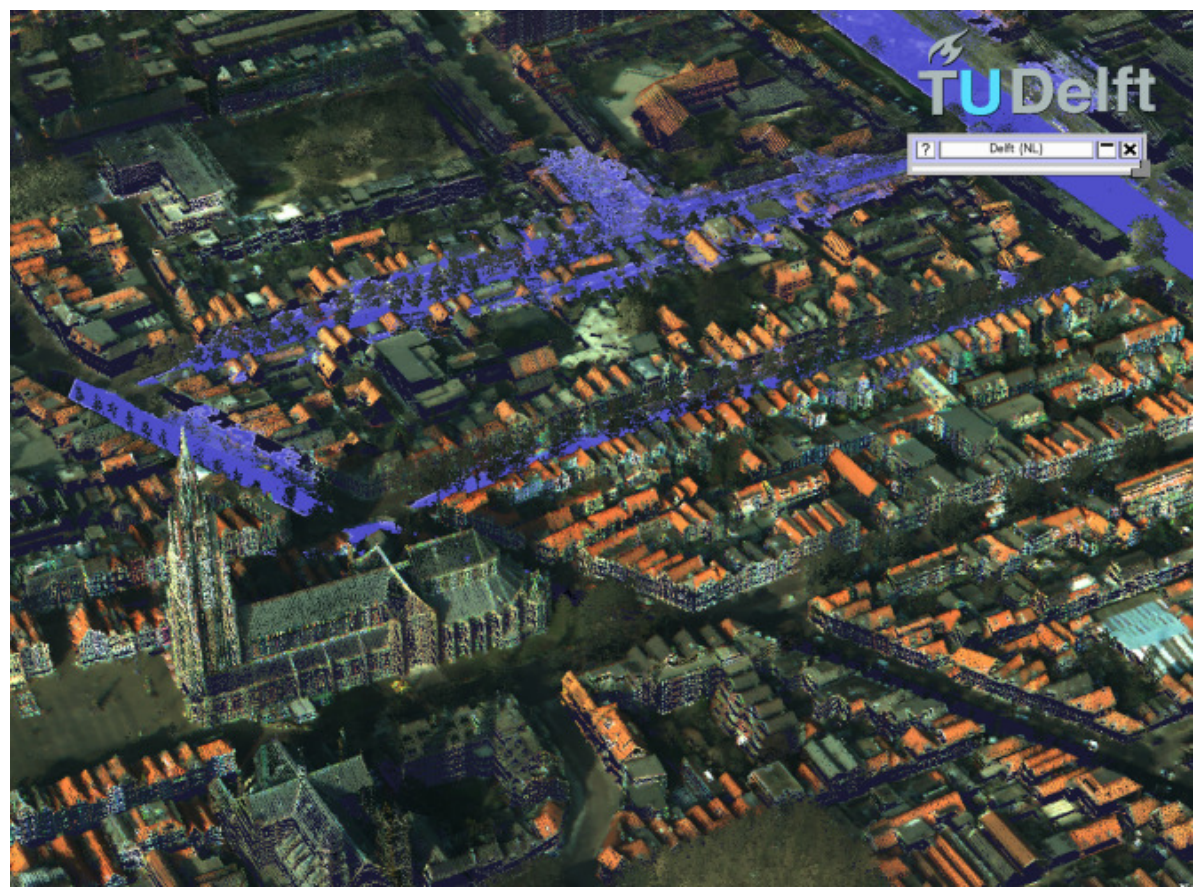

Figure 2-3: 3D-visualisation: prediction of the inundation in the city of Delft

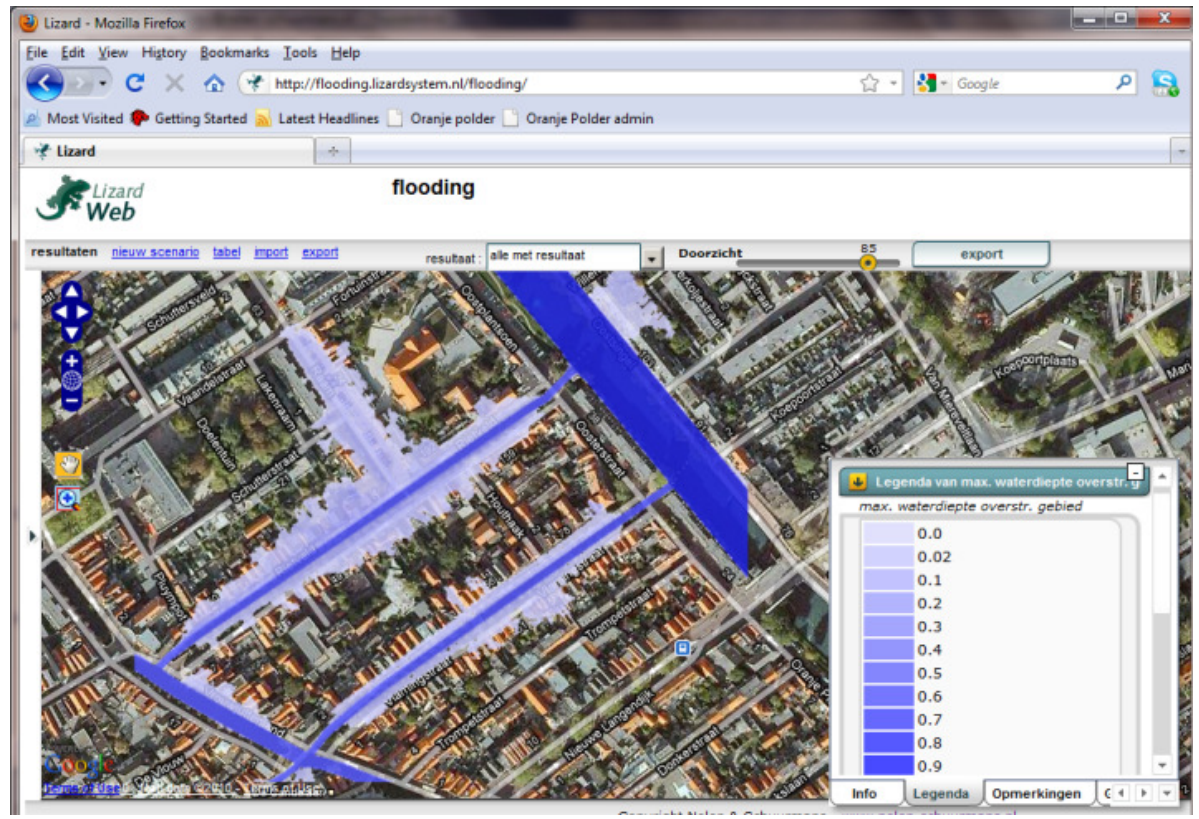

Figure 2-4: Web portal with model results: prediction of the inundation in the city of Delft 
At the end of the disaster exercise, the use of the model was evaluated by a questionnaire to all participants at the end of the exercise. In this questionnaire it was asked whether or not the participants used model information and, in the case they did, how this was valued. The results of the questionnaire were validated in a focus group with 8 representatives of the participants (Leskens and Pleumeekers 2011).

\section{$2.4 \quad$ Results}

\subsubsection{Results of the document review}

The evaluation reports gave a general impression of the constraints in the use of technical information encountered during practical situations of flood disaster management. The information provided by flood simulation models is largely neglected and is still substituted by other preferred sources of information, such as elevation maps or rules of thumb, even when these sources do not capture the technical complexity of how floods evolve over time and depth under various conditions like model outputs do. Shortcomings of these preferred information sources are dealt with by assuming worst-case scenarios. For example, evacuation plans are based on the maximum area of inundation, which is the result of a comparison between maximum water levels and the elevation map. Flow patterns of water are not considered in this, whereas they highly influence the area that can be inundated and give valuable information about the course over time of the inundation. In short, decision-makers rather used basic information in combination with assumptions for worst-case scenarios than using advanced flood simulation models. In literature, this simplification strategy is well recognized under comparable situations of decision-making, characterized by time pressure, multiactor collaboration and high complexity and uncertainty (MacCrimmon and Taylor 1976; Janis and Mann 1977). Unfortunately, this has sometimes led to wrong or unnecessary measures, for example the evacuation of areas that are not at risk of being inundated (Hoekstra 2008) 
We identified different reasons for this limited use of model results. Obviously, decision-makers required predictions that specifically connect to the actual situations and to the available means to undertake action. First, this overview of the actual situation was often not known by the modellers, whereas this insight was required to make model predictions that fit to the actual circumstances. Second, even when these actual circumstances were known, the used models were not fast enough to make model calculations during a flood disaster event. The decisions that were made were therefore usually based on the information that was directly available, such as an elevation map and basic rules of thumb as mentioned above. In cases that pre-calculated flood scenarios were available, an interpretation of this information had to be made in order to make it applicable in the actual circumstances. A recurring theme was that decision-makers were unsure if this information from flood models was reliable and whether they should make decisions based on that information.

\subsubsection{Results of interviews and Social Network Analysis}

The Social Network Analysis provided in-depth insight in the flow of model information in the network of participants in a flood disaster organization. As for each individual participant the communication lines were mapped, a densely branched network was drawn. We summarized this network in Figure 2-5, by aggregating individuals with the same connections and information exchange into groups. The connections between those people in one group are not shown to have a better overview. The interviews showed that the interaction between participants within a group consisted mostly of face-to-face contact. The interaction between the different groups was arranged in formal meetings, in which representatives of the groups gathered and exchanged information. Also telephone and e-mail was used in the exchange of information between different groups. Given the discrimination between different types of information, the indication for the importance of this information and the lead time in which this information was generated, insight could be gained in the flow of information during a flood disaster. In Figure 2-5 the type and lead time of the exchanged information is shown. 


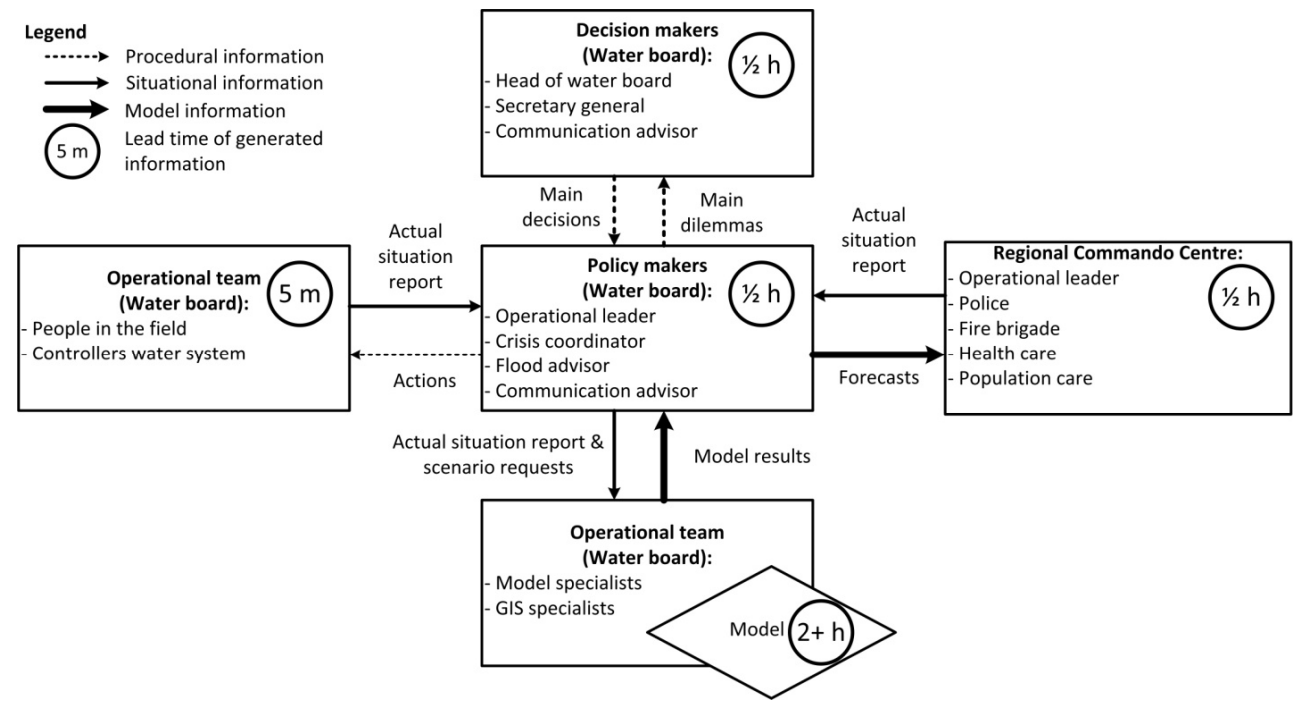

Figure 2-5: Information flow during a flood calamity; in circles the typical lead time is shown per category of actors

The following points can be concluded from the Social Network, specifically concerning the role of model information:

- $\quad$ The main consumers of model information are the policy makers, who need information to advise the decision-makers about the effectiveness of various measures and give the regional command centre forecasts about the arrival of a flood. Demanded information includes variables such as predicted future water levels and flow velocities in order to judge the seriousness of the situation and predicted arrival times of the flood in order to plan responses.

- Model information is generated by the operational team of model specialists. To provide model predictions that fit the actual situation in the field, these model specialists are dependent on situational reports of the policy makers, who in turn receive this from the operational team and the regional command centre.

- Both the situational reports and the demands for required scenarios are received by the model specialists with a delay. This delay is caused by the lead time in which situation information is passed to the model specialists in the meetings of the policy analysts, which generally takes place every half hour. For example, when information about the width of dam breach is observed in the field, which is a vital input for the models, this has to be passed from the regional command centre to the policy analysts and then from the policy analysts to the model specialists. As each team meets half hourly, this information will only reach the model specialists after approximately an hour. 
Given the calculation time of actual models, predictions fed with this new information, can be provided at the soonest after 2 hours. Including the meetings that are required to hand over this information to the regional command centre, the total time between observation of the new dam breach width and the accompanying predictions is around 4 hours.

- Sequences of events in the flood prone area can evolve rapidly, but information about events is received only gradually by the regional command centre. Moreover, information can be contradictory as it is reported by different people. As a result, model information can fall far behind on the actual situation in the field and therefore become useless in a fast changing environment. In these cases, the model specialists tend to just use their common sense and give general advice instead of continuing to use the output of the detailed models.

\subsubsection{Results of flood disaster exercise}

In this questionnaire the decision-makers and policy analysts were asked if they used the model output as an input for their decisions and how they valued this. 24 of the 100 participants filled in the questionnaire. The main reason that the 74 other participants did not fill in the questionnaire was that they had no direct interaction with model information. This fact already confirms the limited use of model information during the flood disaster exercise. Also the outcomes of the questionnaire show the limited use of models in the decision-making process for both decision-makers and policy analysts at the Water board and the Municipality. They mainly disagree with the statements concerning the usefulness of model information as input for decisions (see Table 2-4). The main source of technical information for these decision-makers and policy analysts are the general estimates of the water experts. Only minor differences in the results of the questionnaire exist between decision-makers and policy analysts and members of the Water board and members of the Municipality of Delft. 
Table 2-4: Results of questionnaire flood disaster exercise

\begin{tabular}{|c|c|c|c|c|c|c|c|c|c|c|}
\hline & $\begin{array}{l}\overrightarrow{1} \\
0 \\
\stackrel{+}{D}\end{array}$ & $N$ & 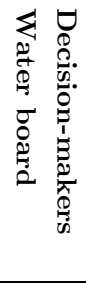 & $N$ & 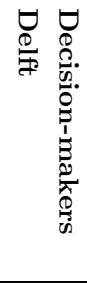 & $N$ & 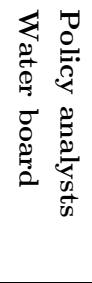 & $N$ & 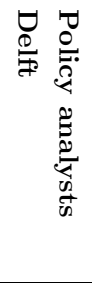 & $N$ \\
\hline $\begin{array}{l}\text { Calculated water } \\
\text { velocities useful as } \\
\text { input for decisions }\end{array}$ & 1.7 & 23 & 1.0 & 1 & 1.3 & 4 & 1.9 & 14 & 1.5 & 4 \\
\hline $\begin{array}{l}\text { Calculated water } \\
\text { depths useful as input } \\
\text { for decisions }\end{array}$ & 1.4 & 23 & 1.0 & 1 & 1.3 & 4 & 1.4 & 14 & 1.5 & 4 \\
\hline $\begin{array}{l}\text { Calculated flood } \\
\text { animations useful as } \\
\text { input for decisions }\end{array}$ & 2.0 & 24 & 1.0 & 1 & 1.3 & 4 & 2.3 & 14 & 1.8 & 5 \\
\hline $\begin{array}{l}\text { Calculated water } \\
\text { quality useful as input } \\
\text { for decisions }\end{array}$ & 2.2 & 24 & 1.0 & 1 & 1.3 & 4 & 2.7 & 14 & 1.8 & 5 \\
\hline $\begin{array}{l}\text { Water specialists are a } \\
\text { useful source for model } \\
\text { information }\end{array}$ & 2.8 & 24 & 4.0 & 1 & 2.0 & 4 & 3.0 & 14 & 2.8 & 5 \\
\hline $\begin{array}{l}\text { Digital water portal } \\
\text { useful as source for } \\
\text { model information }\end{array}$ & 1.9 & 22 & 1.0 & 1 & 1.3 & 4 & 2.1 & 12 & 2.2 & 5 \\
\hline $\begin{array}{l}3 \mathrm{D} \text { visualization useful } \\
\text { as source for model } \\
\text { information }\end{array}$ & 2.0 & 24 & 1.0 & 1 & 1.5 & 4 & 2.2 & 14 & 2.0 & 5 \\
\hline
\end{tabular}

The focus group, in which the results of the questionnaire were evaluated, yielded the following insights:

- While the specialists are the main source for model information for policy analysts and decision-makers, these experts are very restrained in providing this information. They lost trust in the model when it proved to be not flexible enough to predict the exact scenarios they were interested in. Given their responsibility in providing technical information to the policy makers and the big impact of the measures under consideration, they would not risk giving wrong interpretations to scenarios that are already calculated and therefore would rather switch to providing general information without using the model.

- Uncertainty of the technical information was mainly a consideration for specialists. They demanded ranges, numbers or percentages from the model 
results that quantified this uncertainty. As this information could mostly not be given in the desired extent, they were very cautious to hand over model results to the policy makers. Since other actors in the network considered information provided by the specialists as reliable, the specialist were cautious to supply information.

- The following answers were given to the question asked to model experts about what would constitute a useful decision-support flood model during a flood disaster:

a. The flood model should support the expert by making new simulations, in the light of the current circumstances. The current model was considered to be too static as a consequence of fixed options in the model that did not allow re-calculation of the scenarios that were under consideration.

b. Scenarios should be calculated quickly to be able to provide information to keep pace with events during a flood calamity. The current model had a calculation time of 2 hours, but this should be in the order of minutes.

c. The users wish to practice regularly with the flood model.

d. The communication of model results in the current internet portal should be customized for various types of users. Two main groups were identified. First, water experts, to understand the actual situation and explore the effects of different measures and explain their advice to the decision-makers. Second, the decision-makers and stakeholders: to get an impression of the actual situation and effective measures.

Results from the document review, Social Network Analysis and the flood disaster exercise confirm that flood models are currently rarely used, although they are very sophisticated in terms of detail, physical processes and visualization means. This limited use was primarily caused by the delay in which this information is provided to decision-makers. According to our analysis, delays are caused by two main reasons. First, by technical reasons such as inflexibility to adapt a model to current situations and the computation times that are too long to match the frequency of the decisions that have to be made. Second, by delays that emerge in the exchange of information among participants in the flood disaster organization, which cause that decision-makers receive outdated information that is not useful. This delay in communication is related to the standardization of the flood disaster organization in terms of tasks, roles and communication lines. This standardization is very common in flood disaster management, as such a clear command structure, 
comparable with those in armies or fire departments, functioning well under circumstances of disasters and time pressure. However, this command structure causes that model information is often outdated and therefore not used Moreover, once model information is sent into the network of actors, experts lose the possibility to give explanation to the applicability of this information, which can therefore be used wrong. This makes the model experts reserved to send model information to others in the network.

These technical and organizational limitations are inter-related. Namely, technical limitations of models make it necessary that model outputs are first interpreted by model specialists and, consequently, are translated by policy makers to useful information for decision-makers. In the same time, this exchange of information between specialists, policy analysts and decision-makers cause the delays that are an important reason for the limited use of the model outputs. These interdependencies between technical limitations, organization structure and use of models by decision-makers are shown in Figure 2-6.

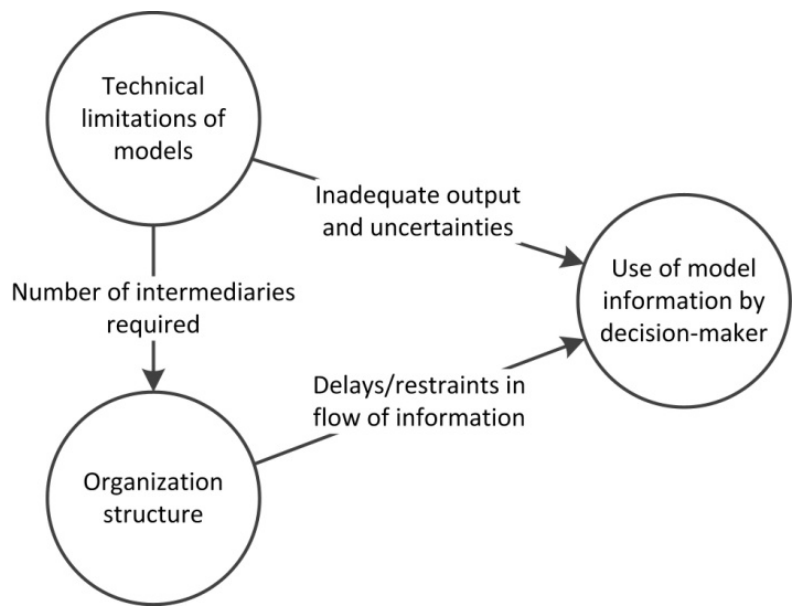

Figure 2-6: interdependencies between technical limitations, organization structure and use of models by decision-makers

\subsection{Discussion}

The results of this research show that the discrepancy between what decisionmakers demand from models and what models can actually provide is not only an issue of inadequate model output and levels of uncertainty but also an issue of slow and inflexible models and too many intermediaries between model output and decision-makers. These results were found in various case studies in the Netherlands practice of flood disaster management. We argue that the conditions, under which our findings are valid, can also be found in many cases outside the Netherlands. These conditions are that slow and inflexible models are applied in a 
Chapter 2: The limited use of simulation model outputs in flood disaster management and the potential for an interactive use of models

complex network of participants, mutually depending on each other's information and having a strict division of tasks and responsibilities. This causes delays in providing model information as input for actions and hesitations with model experts to provide model information to others in the network, as they are considered fully accountable for its accuracy. Case studies of flood disaster management with comparable conditions can be found all over the world, for example in Sweden (Nobert, Demeritt et al. 2010), the US (Wood, Kovacs et al. 2012), Vietnam (Tran, Shaw et al. 2009) and the UK (McCarthy, Tunstall et al. 2007).

Regarding the methods we used, Social Network Analysis has proven to be helpful to better understand the technical and organizational limitations of current flood disaster management. It provided valuable insights in which information the participants in the decision-making processes need in order to fulfill their tasks and it showed how information is passed on between different participants. One should be careful to draw generalized conclusions based on Social Network Analysis beyond flood disaster management. As the decision-making process during flood disasters is to a significant extent standardized in terms of tasks, roles and communication lines, generalized conclusions could be drawn for this specific field. Applying Social Network Analysis in other, less standardized decision-making contexts, such as decision-making about a flood resilient spatial planning, will yield mainly conclusions that count for that specific group of participants.

Although nowadays models are limited by long computation times and are too inflexible for the use during flood calamities, this does not mean that they are useless. For example, in the decision-making context in which structural protection measures are designed, such as dikes or dams, the variety of design options will be smaller and the available time to do model analysis much longer. Also the preparation to floods using flood hazard maps can still be done with present models, although this research shows that these maps often do not grasp the specific question of decision-makers facing flood disasters. These maps often reflect the technical view of the water expert who prepared them, whereas information demands that emerge during a flood calamity can hardly be taken into account.

The results of this research shed a new light on the methods proposed by scholars to overcome the discrepancy between what models provide and what decisionmakers demand. The application of one of the method proposed, direct involvement of decision-makers in de computation of flood predictions, (Voinov and Bousquet 2010), will only work if technical limitations of models are overcome in terms of computation time and flexibility to adapt models to actual circumstances. Besides this, organizational delays in the exchange of situational information should be 
solved to use these actual circumstances as input for the model. The other method proposed, improved output of models, such as ensemble calculations (Walker, Rahman et al. 2001; Demeritt, Nobert et al. 2010; Kwakkel, Walker et al. 2010; Frick and Hegg 2011), also sets high demands on technical requirements of the model. This method requires short computation times to provide ensemble results on time and flexibility to vary input parameters. This variation of input should also be communicated properly and situational information should be exchanged fast. This will result in a range of outcomes which at least defines the scope of what may happen and what may not. This information can be valuable for decision-makers because actions can be undertaken in areas that, for example, will definitely be inundated, and further investigation can be undertaken for areas where inundation is uncertain.

\subsection{Conclusions}

In this paper we identify why important decisions in flood disaster management are so little supported by information from flood simulation models. The document review, Social Network Analysis and flood disaster exercise showed the importance that flood predictions have for policy analysts and decision-makers to plan measures and inform other parties, such as the emergency services. At present, data sources such as elevation maps and rules of thumb are used to provide these predictions. However, our results indicate that this information could be improved by models that provide rapid predictions of floods, based on actual information.

It was shown that these rapid predictions are hard to provide for model specialists due to both technical limitations of the current models and organizational limitations. Technical limitations imply that current models are too inflexible to adapt to the current situation or to predict the effect of responses and have too long calculation time to keep up the frequency in which decisions are made. Organizational limitations imply that the exchange of situational information and model information gets delayed by the several intermediaries it has to pass. Division of tasks and responsibilities in the flood disaster organization also cause hesitations with model experts to provide model information to others in the network, as they are considered fully accountable for its accuracy. Moreover, experts lose the possibility to give explanation to the applicability of their predictions, which makes them extra reserved to do so.

In conclusion, our research clearly provided new insights in the reasons for limited use of models for decisions in flood disaster management. Besides the discrepancy between what information is demanded by decision-makers and what models can actually offer in terms of output and accompanying uncertainties, also delays and 
constraints that emerge in the exchange of model information through the network of participants influence the use of models by decision-makers.

For model development this means that the first bottlenecks to solve are the technical limitation of models in terms of inflexibility and long computation times. For example, new numerical schemes for the computations of overland flow are available that that allow for computation times that are more than 100 times shorter than conventional models (Stelling 2012; Casulli and Stelling 2013). This will not only provide more adequate model outputs, but will also decrease model uncertainties, as ensemble calculation become a serious option.

Our research shows that, even when in the future flexible and fast models become available, current communication lines in the flood disaster organization can still delay the communication of model results and can cause that they are easily outdated and not used. Currently, this is a consequence of the strict communication protocol during flood disasters, characterized by the exchange of model information during fixed periodic meetings with a frequency of a half to one hour. To benefit from future flexible and fast models, this frequency should be higher to provide policy makers and decision-makers for model information that fits in the actual circumstances. An option is to use those models directly during meetings in which decision-makers gather to diagnose flood risks and test the effectiveness of suggested measures. We suggest further research to explore how such an interactive use of models can be effectively applied in the decision-making process during flood disasters, in which, according to our results, decision-makers follow simplification strategies to deal with the large complexities and uncertainties (Kahneman and Tversky 1979). Under such circumstances, vivid imagery from flood models can lead to an overestimation of the probability that a flood will actually materialize (Sunstein 2002) and fast outcomes of models can easily be interpreted wrongly or differently by different decision-makers, which can lead to opposed measures (Weick and Sutcliffe 2005). This demands a systematic and understandable framework to organize the various sources of technical information and requires expert judgment (Thacher 2009). Also Multi-Criteria Decision Analysis (MCDA) can provide a systematic methodology to combine these inputs with cost/benefit information to rank decision alternatives (Huang, Keisler et al. 2011). Different web-based communication systems are already available but need further implementation and improvement to be actually used for this information management. 


\section{Technical feasibility of an interactive use of models by practitioners and domain experts}

This chapter was published as journal paper: Leskens JG, Kehl C, Tutenel T, Kol T, Haan Gd, Stelling G, Eisemann E (2015) An interactive simulation and visualization tool for flood analysis usable for practitioners, Mitigation and Adaptation Strategies for Global Change 1573-1596.

\subsection{Abstract}

Developing strategies to mitigate or to adapt to the threats of floods is an important topic in the context of climate changes. Many of the world's cities are endangered due to rising ocean levels and heavy rainfall. It is therefore crucial to develop analytical tools that allow us to evaluate the threats of floods and to investigate the influence of mitigation and adaptation measures, such as stronger dikes, adaptive spatial planning and flood disaster plans. Up until the present, analytical tools have only been accessible to domain experts, as the involved simulation processes are complex and rely on computational and data-intensive models. Outputs of these analytical tools are presented to practitioners (i.e. policy analysts and political decision-makers) on maps or in graphical user interfaces. In practice, this output is only used in limited measure because practitioners often have different information requirements or do not trust the direct outcome. Nonetheless, literature indicates that a closer collaboration between domain experts and practitioners can ensure that the information requirements of practitioners are better aligned with the opportunities and limitations of analytical tools. The objective of our work is to present a step forward in the effort to make analytical tools in flood management accessible for practitioners to support this collaboration between domain experts and practitioners. Our system allows the user to 
interactively control the simulation process (addition of water sources or influence of rainfall), while a realistic visualization allows the user to mentally map the results onto the real world. We have developed several novel algorithms to present and interact with flood data. We explain the technologies, discuss their necessity alongside test cases and introduce a user study to analyze the reactions of practitioners to our system. We conclude that, despite the complexity of flood simulation models and the size of the involved data sets, our system is accessible for practitioners of flood management so that they can carry out flood simulations together with domain experts in interactive work sessions. Therefore, this work has the potential to significantly change the decision-making process and may become an important asset in choosing sustainable flood mitigations and adaptation strategies.

\subsection{Introduction}

Climate changes already have drastic implications for ocean levels and precipitation patterns, and the situation is likely to worsen (Houghton, Jenkins et al. 1990). Over $50 \%$ of the world population lives in cities (WHO 2013) and more than two thirds of the largest cities are vulnerable to rising sea levels as a result of climate change (McGranahan, Balk et al. 2007). Hence, millions of people are therefore exposed to the risk of extreme floods and storms.

Developing strategies to mitigate or to adapt to the threats of floods is an important topic in the context of climate changes. Several countries and unions, including the European Union (EU), have put a multi-layer safety approach into place as a framework for the development of these mitigation and adaptation strategies (EU 2005). The multi-level safety approach consists of three layers. Layer 1 focuses on protection measures in the form of levees and dikes, and has traditionally received most attention and funding (Kabat, Fresco et al. 2009). For example, in the Netherlands, a 5-year maintenance cycle as well as a standardization for reinforcements has been established (STOWA 2008). Layer 2 consists of waterproof spatial planning, while Layer 3 considers disaster management. Examples of mitigation measures through spatial planning (Layer 2) are local protection of hospitals, schools and utility companies or spatial planning measures that improve the chances of evacuation from a flooded area. Flood disaster management (Layer 3) can be improved by setting up disaster protocols and practicing decision-making under worst-case scenarios.

One of the main challenges for following a multi-level safety approach is the integrated decision-making process it requires. This means that different practitioners, related to the three layers mentioned above, have to collaborate and find integrated solutions for flood management. These practitioners include policy 
analysts or political decision-makers from municipalities, water boards and provinces or representatives from fire and police departments, hospitals and energy companies.

In this process, it is important to build the capacity among these practitioners for involvement in flood management. Analytical tools, e.g., Sobek (Deltares 2015) or Mike11 (DHI 2015), can be used to gain insight into the consequences of floods under different climate scenarios or alternative measures in terms of water depths, flow velocities or damages. They offer predictions by simulating the physical processes involving various area features such as elevation and roughness resistance, and external forces such as storm events and dam breaches (Bates and De Roo 2000; Al-Sabhan, Mulligan et al. 2003; Stelling 2012). To address model uncertainties, analytical tools are normally validated with historical events or, when such measurements are not available, a sensitivity analysis or ensemble calculations can be carried out (Demeritt, Nobert et al. 2010)

Up to the present, analytical tools have only been accessible to domain experts, such as hydraulic engineers and modelers, as the involved simulation processes are complex and rely on computational and data-intensive models. Practitioners (i.e. policy analysts and political decision-makers) are usually only presented with resulting maps. Typically, these indicate the impacts of individual flood hazards or the results of risk analyses, in which multiple hazard scenario's, each having a certain likelihood, are combined into risk maps (Apel, Thieken et al. 2004).

Despite the advantages that these maps may provide for practitioners of flood management, poor use is often made of this information for supporting decisions (Leskens, Brugnach et al. 2014). Mors et al. (2005) show that practitioners of flood management, operating under regulatory, institutional, political, resource and other constraints, prioritize other concerns over more sophisticated maps with model information about flood risks. An underlying reason might be the difference in perception of the threats of floods between domain experts, such as modelers or hydraulic engineers, and practitioners (Faulkner, Parker et al. 2007; Janssen, Hoekstra et al. 2009; Timmerman, Beinat et al. 2010; Wood, Kovacs et al. 2012). Domain experts generally frame flood issues using scientific knowledge and expertise. They assume that with more detailed model information analyses will improve and better decisions can be made. Practitioners, on the other hand, often lack the capacity and time to incorporate the results of these complex analyses in their decisions.

A way to better support practitioners with the output of analytical tools is to improve their involvement in the application of these tools (Voinov and Bousquet 2010; Leskens, Brugnach et al. 2014). This involvement can improve the alignment 
of the information requirements of practitioners with the opportunities and limitations of analytical tools (Leskens, Brugnach et al. 2014). However, as mentioned, the existing analytical tools are only accessible to domain experts, as the involved simulation processes are complex and rely on computational and dataintensive models. These analytical tools have specialized interfaces and their application -for example, to picture a future flood scenario- takes multiple hours (Leskens, Brugnach et al. 2014)

In this paper, we present a system that is focused on making the use of flood analysis tools accessible for practitioners of flood management, such that they can carry out flood analysis together with domain experts in interactive work sessions. The system gives the user the possibility to test several disaster scenarios and to receive direct visual feedback. It provides realistic images to help practitioners in interpreting these outputs of the system. We conducted a user study to test the effectiveness of this interface and its outputs. In order to investigate the applicability in practice, we illustrated the use of our system for real-world data in a case study for the area of West-Friesland, The Netherlands. This work makes a two-fold contribution: We present a working system and show the usefulness of our approach and furthermore explain the technical contributions needed to achieve a working solution.

\subsection{Our system}

\subsubsection{Development of the system}

The system presented here builds upon a prototype developed between 2011 and 2014, involving researchers and engineers from Delft University of Technology, Deltares, and Nelen $\backslash \&$ Schuurmans. The key features of the system are based on user requirements that were derived from thirteen semi-structured interviews among policy analysts of the regional water board Hoogheemraadschap van Delfland (The Netherlands), conducted in 2011 and reported in Leskens et al (2014). The interviews focused specifically on three questions. (1) What is your task or role in decision-making processes? (2) What information do you require to carry out this task? (3) What functions do you need from an analysis tool that can be operated during a work session? From these thirteen interviews it emerged that the following capabilities were considered important for using an analysis tool during a work session with domain experts: (1) technical reliability; (2) the possibility to assess the effectiveness of multiple scenarios within the time horizon of a work session and (3) understandable output for non-water specialists.

Based on these user requirements, the key features of our system focus on a realistic visualization of floods and interactivity to enable practitioners to explore various options for flood mitigation and adaptation measures rapidly, together with 
domain experts. To ensure technical reliability (i.e. the first user requirement) our system combines a high spatial resolution (i.e. 0,5 meter by 0,5 meter) and the inclusion of all relevant processes (i.e. overland flow, groundwater flow, canal flow and sewer flow) (Casulli and Stelling 2013).

There are other flood analysis tools available that provide comparable features and user interfaces (Bates and De Roo 2000; Nóbrega, Sabino et al. 2008). However, our system is unique in providing the distinct features in the required scale $(>1000$ square kilometers) and resolution (>10 height values per square meter). Making an interactive system with a realistic visualization for such large areas is a very challenging goal.

\subsubsection{D Visualization}

Our $3 \mathrm{D}$ visualization is aimed at supporting practitioners in interpreting and understanding the impact of simulated flood hazards. It shows the properties of simulation results in three spatial dimensions and a realistic rendering, mapped to real-world phenomena. In respect to $2 \mathrm{D}$ visualizations, in which the impacts of flood hazards can only be viewed directly from above, the $3 \mathrm{D}$ visualization show the impacts also from the side. Flood depths can therefore be examined without the use of a legend in which typically different shadings of blue are used to indicate the depth of a flood. The basis for this realistic $3 \mathrm{D}$ visualization is data from Light Detection And Range (LiDAR) scans coupled to output of water simulations. LiDAR data is collected by a technology that measures distance by illuminating a target with a laser and analyzing the reflected light. The result of these LiDAR scans, usually carried out by helicopters, are points specified in three spatial dimensions $(\mathrm{x}, \mathrm{y}, \mathrm{z})$, with a resolution of around 15-50 points per square meter. These points, colored via aerial images, ensure recognition of the area and its features (e.g. houses, cars and trees) in high detail. Water properties, based on the simulations, are projected realistically into this $3 \mathrm{D}$ visualization. For example, flow directions are visualized by moving waves and water depth is displayed by adjusting the light extinction. Furthermore, the system supports stereo rendering to create the illusion of depth, if the corresponding equipment is available. Extensive interactive device support gives users the possibility to navigate the 3D world with ease. This also allows us to adapt the system's navigation to the cognitive and motoric capacities of different audiences (e.g. general public, museum visitors, decision-makers, managers, hydrologists etc.).

Our system builds upon an efficient out-of-core rendering system that displays large-scale LiDAR data (De Haan 2009; De Haan 2010; Kehl and de Haan 2012). Even though large-scale point-based rendering is a classic rendering topic (Rusinkiewicz and Levoy 2000; Dachsbacher, Vogelgsang et al. 2003) a solution 
that combines large-scale water and terrain visualizations was previously unavailable.

\subsubsection{Interaction}

For interaction with the simulation process, our system relies on a simulation display that shows the map of the study area (Figure 3-1). Different from the 3D visualization system, as presented in the former section, the study area in the simulation display can only be viewed directly from above. Once a simulation is carried out, the outcome can be presented in the $3 \mathrm{D}$ visualization system and be viewed by a helicopter perspective.

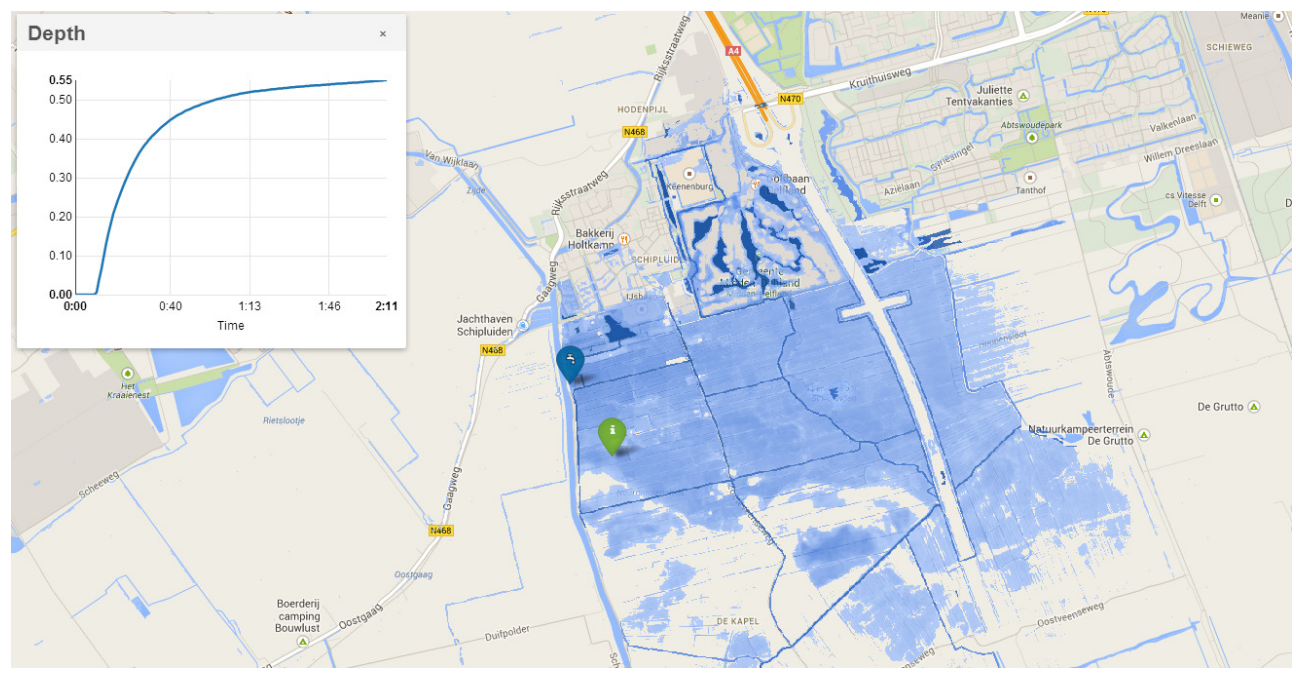

Figure 3-1: A screenshot of the 2D interface used for interaction

A user can choose two different methods to add water flows to the study area. First, a point source can be added, consisting of a flow discharge or a water level. This point source can, for example, be used to simulate a dam breach or a leaking sewer pipe. Second, a spatially distributed source can be added, consisting of a flow discharge to a selected area, which can be used to simulate rainfall events. Several properties can be selected for both types of water sources, for example whether the flow discharge of a point source is constant or time-dependent, or whether the distributed discharge has a circular or an irregular shape. The impact of these sources on the area can be assessed simultaneously with the simulation process. The water depths are indicated by a dynamic blue overlay and can also be assessed by a graph on random points, or over a random cross-section. Flow velocity is indicated by bubbles in the water.

Aside from the various options to add water sources, the properties of the study area's terrain can be adjusted as well. This can be done in three ways. First, the 
elevation of the area can be locally increased or decreased - for example, to simulate the effectiveness of digging passages in local elevations that obstruct water flowing to storage areas, or to test the effectiveness of elevating levees with sand bags. Second, the land use type can be changed - for example, to increase the rainwater infiltration capacity of the ground by changing paved areas into unpaved areas. Third, the water system in the study area, consisting of canals, pumps, weirs and culverts, can be adjusted - for example, to test the effectiveness of stronger pumps, broader canals or higher weirs.

Adding water sources to the study area and adjusting the study area itself can be done at any time by the user during the simulation process. The simulation can also be stopped to make adjustments to the water sources or the study area, after which the process is resumed. The display is made accessible via an internet browser. Therefore, users do not need to install special software on their computers. In case multiple users access the system at the same time, one of the users has the authority to make adjustments to the simulation. This depends on the pre-specified user rights.

The interactive character of the simulation display, as described above, is made possible by a strong computation core. This computation core consists of numerical methods to solve the $2 \mathrm{D}$ hydraulic equations for water flow, under the conditions of short computation times while still conserving the details of the study area. The technical details of this flood simulation model can be found in Stelling (2013) and in Casulli and Stelling (2013).

\subsubsection{Technical Contributions}

Several hurdles were overcome to obtain a system that is accessible to practitioners who are no domain experts. We added four extensions to the existing 3D visualization techniques (De Haan 2009; De Haan 2010; Kehl and de Haan 2012). First, we introduce a solution to directly manipulate the LiDAR point sets to improve collaborative aspects. Second, we present a new visualization technique to add rainfall information. Third, we developed a scalable solution for water rendering to make it possible to investigate large-scale flooding scenarios. Finally, our system can be easily executed on network-connected display devices, hereby abstracting the used hardware, whether it be a single screen, a multi-screen setup, or a stereo device. In the following, we will give a short overview of these technical contributions.

\subsubsection{Direct Interaction with Data Points}

To facilitate discussions and support multi-user interaction, we designed a webbased solution for collaborative interaction that allows concurrent users to areas or even modify data. The aforementioned changes in the simulation display 
(terrain lifting, soil changes etc.) and annotations can be transferred directly to the virtual 3D LiDAR model. The on-the-spot visualization of concurrent changes on 3D topographic models of comparably-sized datasets has not been demonstrated before within the scientific geospatial community. Our solution also allows highlighting of areas via common user interfaces, such as Lizard, Google Maps, or Open Street Maps to ensure a good acceptance of the system amongst the various users. Such possibilities can be helpful for discussions by directly visualizing the impact of the suggested solutions (Isenberg, Isenberg et al. 2013). The input applications can be executed on widely-used smart devices (e.g. tablets and smartphones), making our algorithms accessible to a wide audience.

The modifications can manipulate any point property, such as color, but also height. The algorithm reads as an input Keyhole Markup Language (KML) files, which are readily produced with the above-mentioned software packages. These 2D polygonal definitions are shared among various users, who can then concurrently define modifications.

Technically, the approach modifies the LiDAR points on the fly by restricting the changes to the points that are currently visible to the observer in the $3 \mathrm{D}$ visualization software. Hereby, we avoid treating the entire data set, which would be too large to allow for interactive rates. Each LiDAR point is localized on the fly via a hierarchical structure build from the user-defined polygonal areas in the KML file (Kehl and de Haan 2012). The latter stores in each area the wanted attribute modification. This modification can then be applied to the localized LiDAR point, prior to being drawn on the screen.

\subsubsection{Rainfall visualization}

Previous 3D visualization systems produced realistic imagery from simulation data, which improves understanding for practitioners. In this work, we further introduce a rainfall data visualization, which is particularly interesting for urban floods; dense construction (e.g. buildings, pavements, roads) and their disadvantageous infiltration properties leads to water accumulating on the pavement.

In order to naturally embed precipitation information in a realistic 3D visualization, we developed a method to render, dynamically update and animate clouds according to measurements provided by the Koninklijk Nederlands Meteorologisch Instituut (KNMI). Figure 3-2 shows an example of the reflection of these clouds for an urban flood scenario in the city of Rotterdam, but the cloud layer is also directly visible, e.g., in a top-down view. We render satellite imagery (Holleman 2008) as a realistic cloud layer, positioned 10 kilometers above the ground, that is streamed in real-time into our $3 \mathrm{D}$ visualization software. 


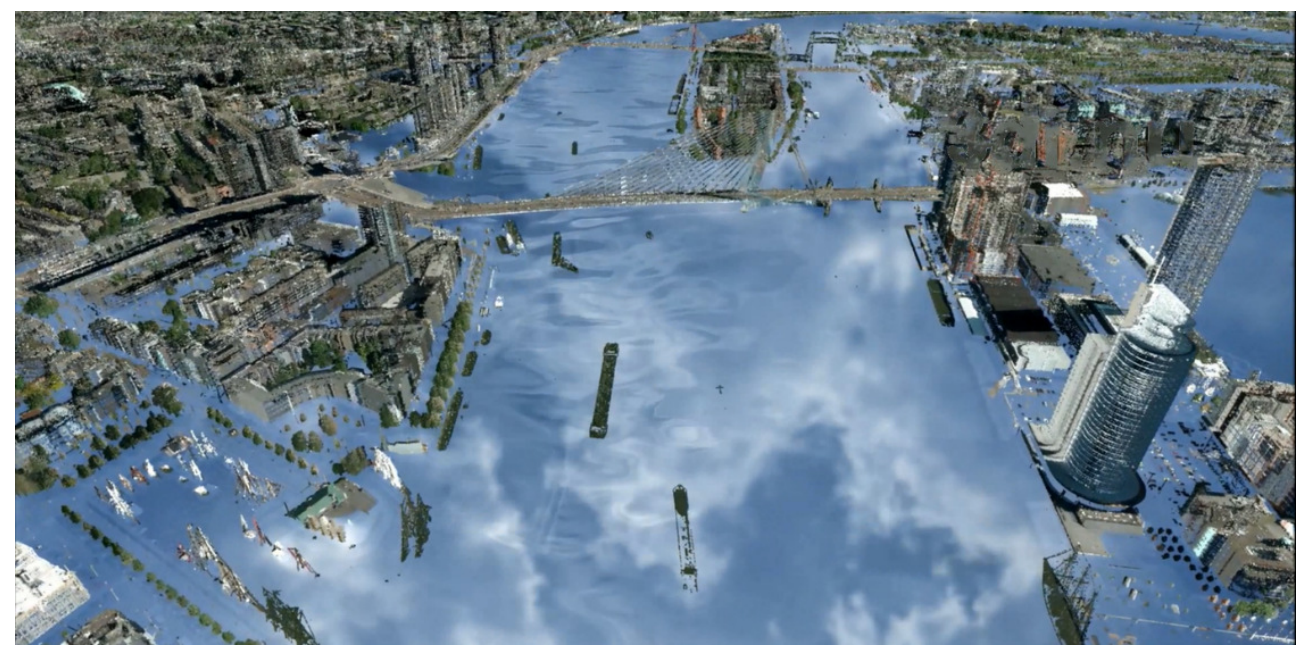

Figure 3-2: Cloud reflection for a flood in the city of Rotterdam due to a hypothetical scenario of heavy rainfall (100 mm/hour)

\subsubsection{Water Rendering}

The rendering of large-scale water bodies is particularly challenging. No previous solution existed to directly render the results of hierarchical simulation processes (Stelling 2012) despite the fact that such scenarios are very common in the investigation of large-area impacts.

The challenge is that the simulation relies on an approximation in the form of an adaptive quadtree, which respects water properties. These data sets, even in a hierarchical representation, are too large to be displayed entirely at real-time rates. Hence, an efficient display method is needed to simplify the representation. This adaptive scheme should be based on the viewing distance to add details only in the proximity to the observer, where they are needed.

The problem relates to terrain-rendering solutions, but, previous work used a uniformly sampled height field (Losasso and Hoppe 2004), while we need support for the hierarchical simulation results. Additionally, we want to support wave patterns to illustrate the underlying water properties, but previous work synthesized waves independently of any underlying simulation data (Ren and Zhou 2012) or did not allow for view-dependent simplifications (Kryachko 2005). These aspects are crucial for our large-scale data sets.

In our approach, we load and display only the simulation results that are currently in view. We use a hierarchical grid attached to the camera location that is very close to the observer and coarser in distance. As such, the grid resolution respects the distance to the observer. To transform this grid into a water representation, its 
vertices recover information from the underlying hierarchical flood simulation by querying the hierarchical structure based on their position. Depending on the stored water properties (presence, height, flow and velocity), the vertices are displaced to represent the water levels and the recovered values are interpolated across each grid cell, which enables us to apply a texture-based wave-synthesis algorithm.

\subsubsection{Display Setups}

We designed a display algorithm that distributes the workload amongst networkinterconnected rendering machines. Such a solution makes it easy to run our solution on various 2D displays, multi-display setups, as well as $2 \mathrm{D}$ and $3 \mathrm{D}$ stereo projector systems. This is an interesting aspect as different visualization setups are common (Marton, Agus et al. 2012; Reda, Febretti et al. 2013; Kuchera-Morin, Wright et al. 2014).

Since particularly high resolution results involve extensive computations in order to maintain interactivity at a high quality, our approach allows the involvement of multiple computers, which all contribute to the final images by sharing their results over the network. To illustrate the generality of this solution, we tested several different screen setups (screen walls of various screen arrangements, stereo devices and cylindrical projection, as shown in Figure 3-3. We also refer the interested readers to the accompanying video.

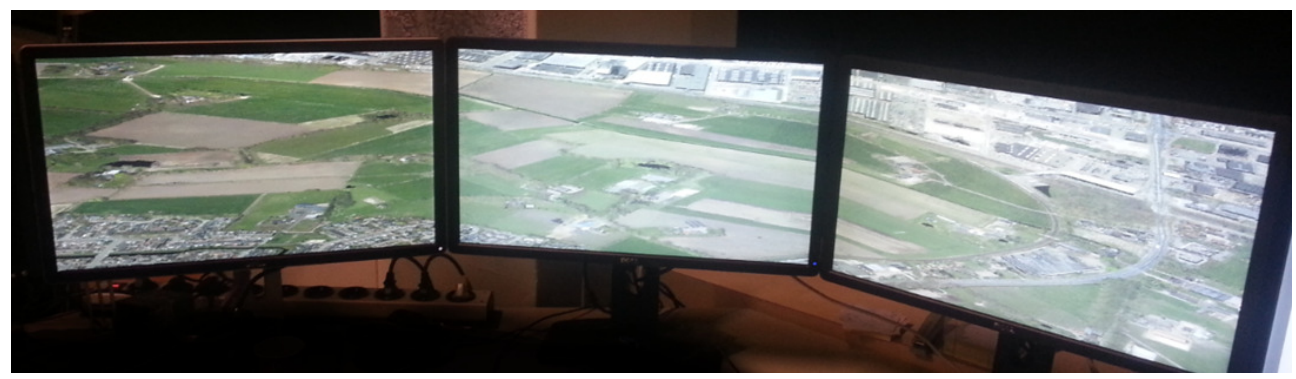

Figure 3-3: Multi-Screen setup, visualizing the city of Delft on a 3-screen panorama

\subsection{Flooding Analysis}

To test whether the two key features of our system (i.e. realistic visualization and interactivity) can contribute to a better accessibility of flood analysis tools for practitioners and support collaborative flood analyses with domain experts, we carried out two tests. The first was aimed at the usability of our system for individual practitioners who are no domain experts. The second was a use case to test whether our system could support collaborative flood analysis with practitioners and domain experts in a real-world application. 
We gathered the data input for our system from the aerial LiDAR scan AHN2 (Actueel Hoogtebestand Nederland (AHN 2015)) together with satellite imagery. The data was further augmented by object databases and soil maps provided by the Dutch Water Boards and conversion tables to transform land use into infiltration rates, as well as roughness, interception, permeability and porosity values (Grotentraast 1988). In common modelling practices, preferably a calibration and validation with real measured data is applied to assure the validity of the model outcomes. However, our case study was focused on testing the interface and user interaction and therefore a validation and calibration with real measured data was not necessary, although in this test the outcomes had to be within a reasonable range of likelihood to be of use to the users.

\subsubsection{User Study}

In this part, we evaluate the usefulness of our system for practitioners of flood management, who are usually no domain experts. To this end, we asked the participants to perform an analysis themselves and to comment on different types of visualizations obtained by our system.

\section{$\underline{\text { Participants }}$}

7 subjects participated in our study (5 male and 2 female, aged between 24-46 - the mean age was 30). All had normal or corrected-to-normal vision. While they were not familiar with the system and goals, they all had experience in working with computers.

\section{Methodology}

The experiment took around 15 minutes per participant, including instructions, and subjective feedback. It consisted of two parts: 1) a comparison between a simulated flood hazard represented with an illustration directly from above (2D) and a helicopter view (3D) and 2) an assignment in which the interactive simulation display was used (Figure 3-4). 

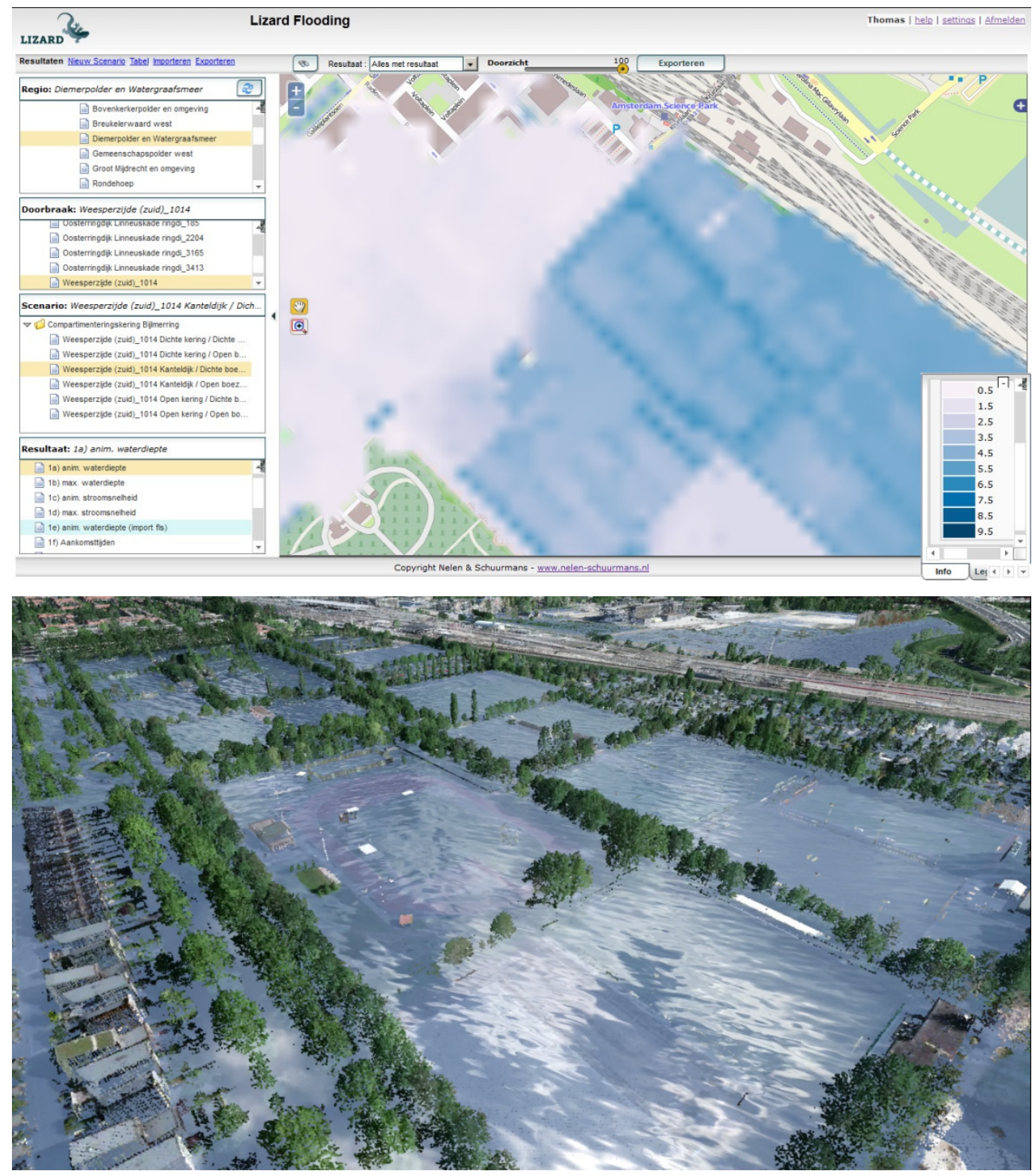

Figure 3-4: A simulated flood hazard in the Watergraafsmeer area represented with an illustration directly from above (2D) and a helicopter view (3D).

For part 1 of the experiment a flood was simulated in a study area in Amsterdam called Watergraafsmeer. The calculated maximum water depths of this simulation where projected in two ways. First, our 3D visualization system was applied, in which the user could make a realistic helicopter flight over the flooded area. Second, a conventional 2D visualization was applied, consisting of a digital map (Google), in which the maximum water depths where projected that could only be viewed directly from above. We showed both visualizations to each participant 
individually and asked them to respond to three closed questions and one open question:

1. Which visualization is best suitable to estimate damages to houses? [options: $2 \mathrm{D}, 3 \mathrm{D}$, neutral]

2. Which visualization is best suitable to estimate loss of lives? [options: 2D, 3D, neutral]

3. Which visualization is best suitable to estimate whether evacuation is necessary? [options: 2D, 3D, neutral]

4. Does the $3 \mathrm{D}$ visualization have added value in respect to the $2 \mathrm{D}$ visualization and, and if so, what is this added value? [open question]

In part 2 of the experiment the participants were asked to use the interaction possibilities to study the area Watergraafsmeer in Amsterdam. First, an introduction to our system was given to explain how the simulation display works. Second, the participants were given the opportunity to familiarize themselves with the simulation display. No explicit time limit was given for this. When they indicated that they understood how the simulation display had to be operated, they were asked to give an answer to the following question: Which streets in the study area will be inaccessible for cars after a rain shower of $100 \mathrm{~mm}$ in one hour? The time it took to answer this question was then measured.

\section{$\underline{\text { Apparatus }}$}

We used an Intel Core i7 @ 2.67 gigahertz processor, 6 gigabytes of main memory and a video processing card from NVIDIA, type Quadro FX380, with a 20-inch Samsung 2233RZ (120 hertz, 1680x1050 pixels) screen. The participants used a classic 3-button mouse device for interaction. For the 3D visualization, the main device used an Intel Xeon 6 core hyperthreaded processor @ 3.2 gigahertz, 12 gigabytes of main memory and a video processing card from NVIDIA, type GeForce GTX 680, with a common screen (60 hertz, 1920x1080 pixels) attached.

\section{$\underline{\text { Results user study }}$}

The responses to the closed question in part 1 of the test (i.e. the comparison between a $2 \mathrm{D}$ and $3 \mathrm{D}$ visualization of the same flooded area) are listed in Table 3-1. 
Table 3-1: The table presents the questions that were asked to each individual participant and, per question, the number of participants preferring a $2 \mathrm{D} / 3 \mathrm{D}$ visualization

\begin{tabular}{|l|c|c|c|}
\hline Question & 2DVisualization & 3DVisualization & Neutral \\
\hline $\begin{array}{l}\text { Which visualization is best suitable for } \\
\text { the estimation of damages to houses? }\end{array}$ & 2 & 5 & 0 \\
\hline $\begin{array}{l}\text { Which visualization is best suitable for } \\
\text { the estimation of loss of lives? }\end{array}$ & 3 & 3 & 1 \\
\hline $\begin{array}{l}\text { Which visualization is best suitable for } \\
\text { the estimation whether evacuation is } \\
\text { necessary? }\end{array}$ & 3 & 3 & 1 \\
\hline
\end{tabular}

The open question about what the added value of the $3 \mathrm{D}$ visualization was with respect to the $2 \mathrm{D}$ visualization, was answered with the following statements:

- It makes it better possible to imagine the consequences of the flood.

- It enhances prediction of what a flood means for an area and helps to better empathize with the situation.

- It is more realistic and detailed. It is easier to interpret what a flood means for the area.

- $\quad$ It is more vivid and therefore better understandable.

- Less interpretation is required to estimate the consequences of the flood.

- It helps the user to better imagine how serious the flood is.

- It shows the consequences for the environment better.

The average time the participants needed to answer which roads would not be accessible for cars after a rain event of 100 mm was 6 minutes, with a minimum of 4 and a maximum of 7 .

\subsubsection{Case study}

To test whether our system is accessible for both model experts and practitioners such that they can carry out flood analysis together in an interactive way, we organized a case study. This case study was organized together with the Province of North-Holland and the Waterboard Hollands Noorderkwartier in the Netherlands. Various stakeholders of the pilot area West-Friesland were invited to a workshop to discuss flood mitigation and adaptation measures within the multilevel safety approach. The West-Friesland area is a large, flood prone area (781 $\mathrm{km}^{2}$ ), located north of Amsterdam and lies approximately 3 meters under sea level. It is protected by dikes from water in the IJsselmeer/Markermeer-lake. The area is inhabited by approximately 400000 people. 


\section{Set-up case study}

A broad workshop was organized to create a decision-making environment in which various stakeholders in the area were informed about the threats of floods and were involved in investigating mitigation and adaptation measures in spatial planning and flood disaster management. During the workshop, the stakeholders were separated into groups to answer the central questions: "Which measures can be taken?" and "How can these measures be implemented?" Ideas of the stakeholders, resulting from their own backgrounds and perspectives on the threats of floods, could immediately be tested and discussed using our system.

The system was also used to produce maps ahead of time. The results are the following four maps, each post-processed per flood scenario:

1. Flooded roads: highways, secondary and urban roads

2. Flooded utility companies: divided into electricity, gas and water

3. Flooded vulnerable objects; hospitals, day care centers, generated schools and old age homes

4. Arrival times in order to provide information for planning evacuations

Figure 3-5 shows an example of the arrival times of a simulated flood and Figure 3-6 indicates the accessibility of roads. 


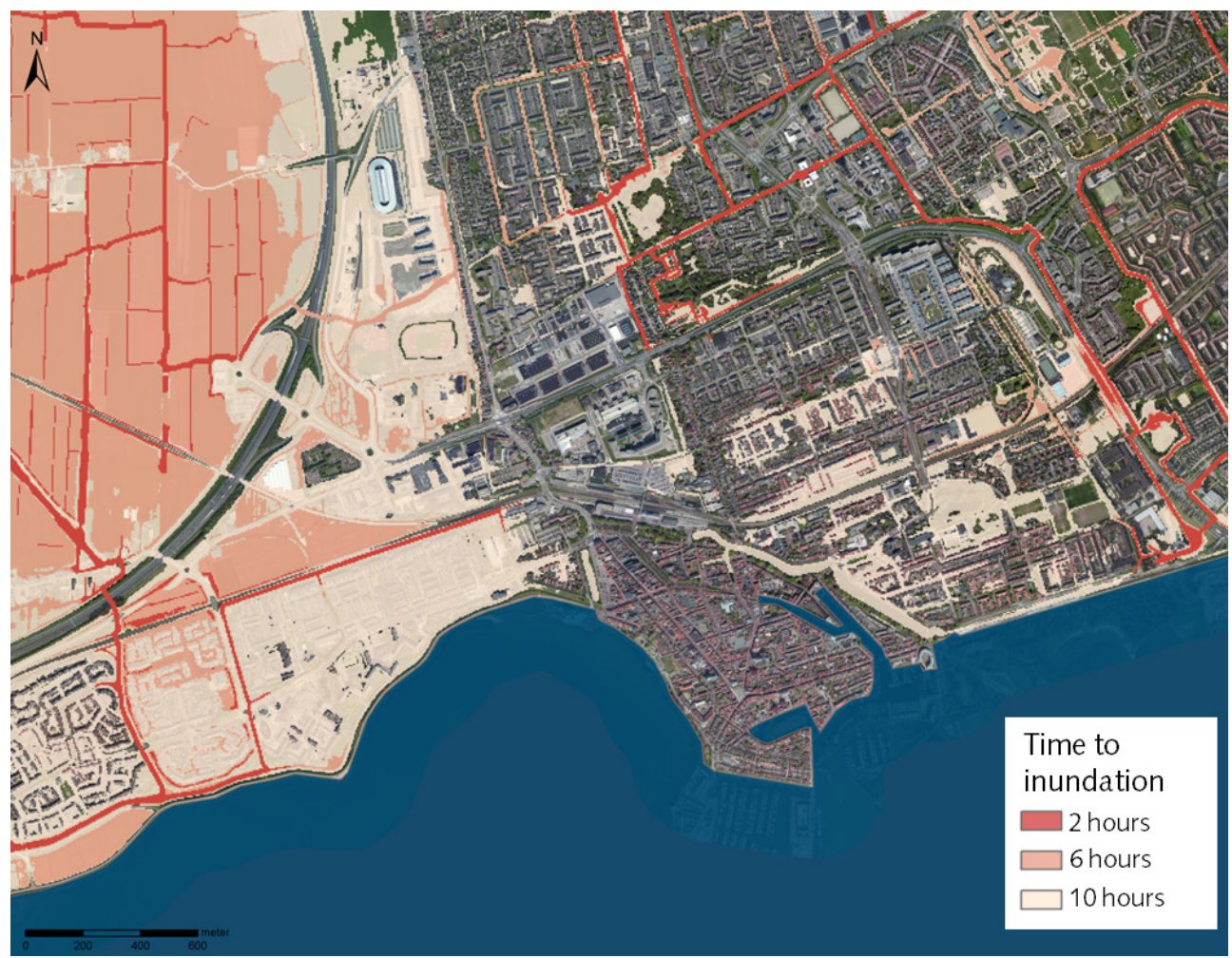

Figure 3-5: Arrival times - An exemplary map showing flood arrival times in different zones, which can be used for city evacuation planning
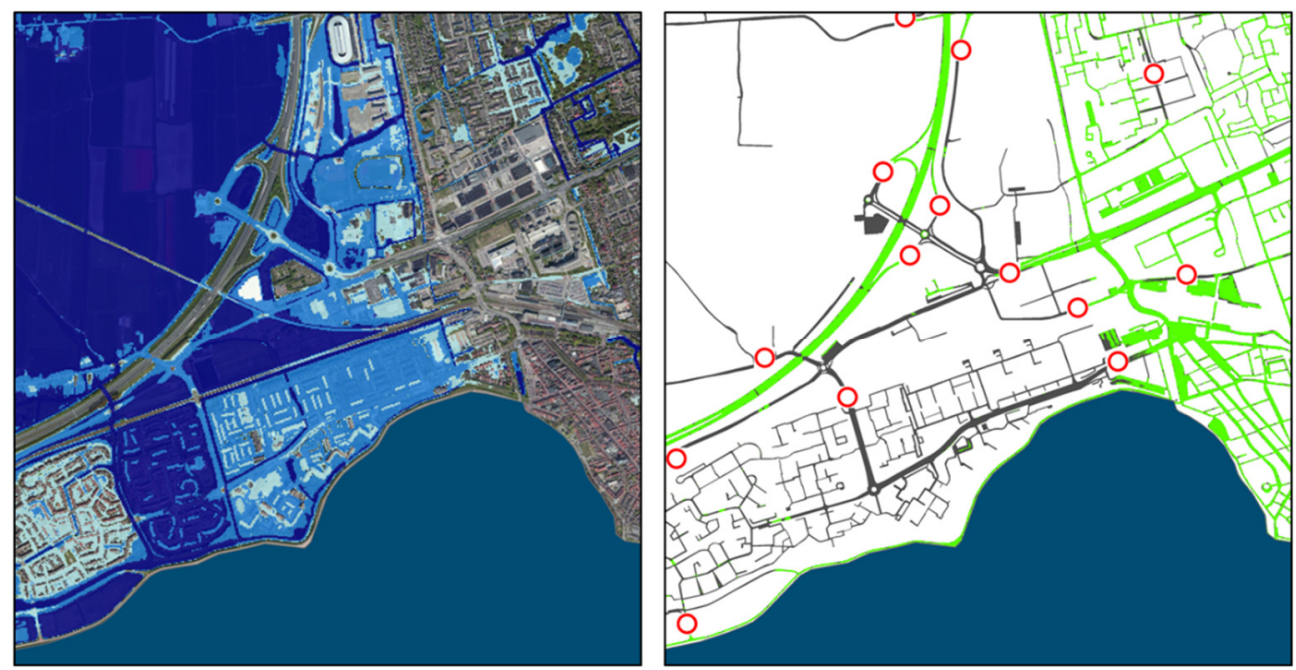

Figure 3-6: Accessibility of roads - Another map resulting from the system that shows the mitigation of the flood (left) and the road access in the study area (right) accordingly. In the access map (right), green paths show usable road paths while red-circled icons symbolize access bottlenecks 


\section{$\underline{\text { Participants }}$}

35 stakeholders attended the workshop. This group existed of representatives of the province of North-Holland (official organizer of the workshop), the Waterboard, municipalities, agriculture, business, project developers, energy providers, health service, fire department and an insurance company. These stakeholders covered most of the parties involved in choosing mitigation measures. Apart from 5 domain experts from a consultancy company and the water board who were used to applying analysis tools, most of the other participants were not used to involvement in the application of analysis tools.

\section{$\underline{\text { Results case study }}$}

The work session yielded a number of measures that were proposed by the participants and could be directly tested with our system. The measures were assigned to responsible stakeholders for further elaboration. An overview of these measures is listed in Table 3-2. One of the measures that emerged during the workshop, which is considered to be of high potential, was dividing the area in different components by "'dry dikes" (Figure 3-6) 
Table 3-2: Flood mitigation and adaptation measures that where proposed by the participants of the work session and could be directly tested with our system. The measures were assigned to responsible stakeholders for further elaboration

\begin{tabular}{|c|c|c|}
\hline Stakeholder & Measure & Elaboration \\
\hline Province & $\begin{array}{l}\text { Include water safety in water } \\
\text { regional planning }\end{array}$ & $\begin{array}{l}\text { Use official strategic plan for } \\
\text { spatial planning and raise and } \\
\text { maintain regional roads in } \\
\text { order to provide evacuation } \\
\text { routes }\end{array}$ \\
\hline Municipality & $\begin{array}{l}\text { Incorporate water safety in } \\
\text { building standards and } \\
\text { regulations }\end{array}$ & $\begin{array}{l}\text { Adapt official building } \\
\text { standards }\end{array}$ \\
\hline Water board & $\begin{array}{l}\text { Create awareness and inform } \\
\text { stakeholders on water safety }\end{array}$ & $\begin{array}{l}\text { Apply the water system to } \\
\text { reduce the consequences of } \\
\text { floods, for example, by using } \\
\text { compartments in discharge } \\
\text { canals. } \\
\text { Supply flooding data and } \\
\text { information on a non-expert } \\
\text { level } \\
\text { Apply the water system for } \\
\text { flood reduction and practice }\end{array}$ \\
\hline $\begin{array}{l}\text { Utility companies (energy and } \\
\text { water) }\end{array}$ & $\begin{array}{l}\text { Ensure drinking water and } \\
\text { electricity (Electricity supply } \\
\text { and communication systems } \\
\text { tend to break down easily) }\end{array}$ & $\begin{array}{l}\text { Keep pumping stations dry and } \\
\text { assure emergency power supply } \\
\text { Redirect mobile communication } \\
\text { supply towards flooded area }\end{array}$ \\
\hline Companies and entrepreneurs & $\begin{array}{l}\text { Take private measures in case } \\
\text { the level of protection ensured } \\
\text { by the water board is not } \\
\text { enough }\end{array}$ & $\begin{array}{l}\text { Take local measures such as } \\
\text { dikes around the property }\end{array}$ \\
\hline Inhabitants & $\begin{array}{l}\text { Take private measures to } \\
\text { survive for a longer period in } \\
\text { case of flooding }\end{array}$ & Prepare a survival-kit \\
\hline $\begin{array}{l}\text { Emergency services (fire } \\
\text { departments, police) }\end{array}$ & $\begin{array}{l}\text { Switch from procedural scripts } \\
\text { to scenario-related evacuations }\end{array}$ & $\begin{array}{l}\text { Enhance evacuation scripts and } \\
\text { the supply of information } \\
\text { during calamities }\end{array}$ \\
\hline
\end{tabular}



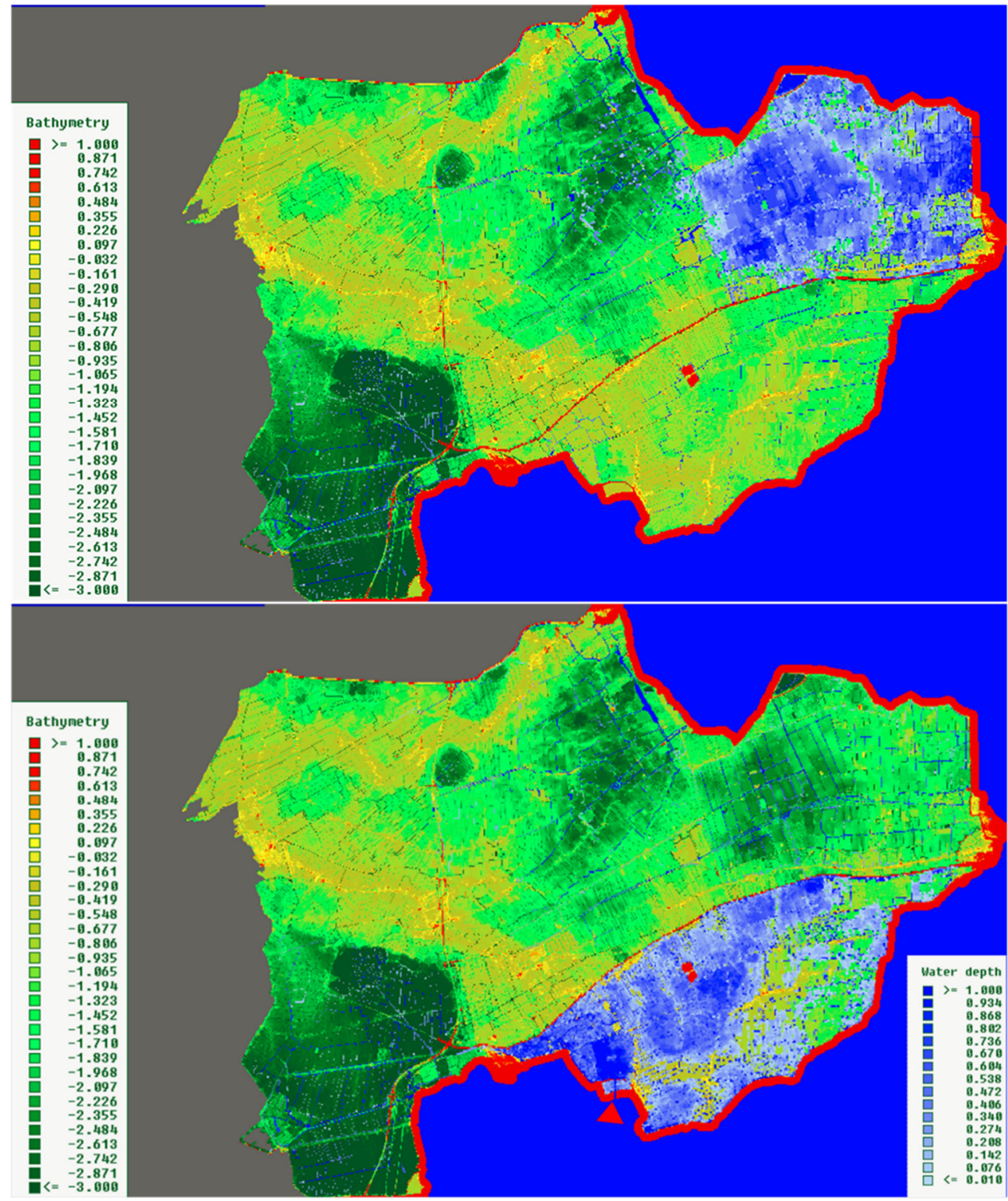

Figure 3-7: One investigated measure for flood protection is shown in this figure. The illustration shows the effect of dividing the area of West-Friesland in a southern part and a northern part by a dry dike (red line) at both dam breach locations

The evaluation of the use of our system in the workshop indicated that a combination of interaction with the system and the realistic visualization allows the users to quickly judge the effectiveness of the solutions suggested in the various flood scenarios. The $3 \mathrm{D}$ visualization was considered a benefit over conventional $2 \mathrm{D}$ 
visualizations on maps. Users indicated that it was easier to estimate the impact of the calculated flood with the $3 \mathrm{D}$ visualization as they could relate the flood depths directly to familiar objects, such as trees, cars and houses. With 2D visualizations, users first have to translate the different shades of blue into flood depths and then estimate the impact of the calculated flood.

The positive impact on decision making was attributed to the possibilities of testing the effectiveness of measures in a direct way. In the past, the effectiveness could only be evaluated by the intervention of model experts and was presented in a following work session. The post-processed map layers that illustrate additional information, such as damage, hindrance and costs allocation were deemed extremely useful for gaining additional insights beyond the physical values, such as water depths or flow velocity. Furthermore, this representation addressed the legal responsibilities of the different stakeholders.

\subsection{Discussion}

The results of our user study show that our system is accessible and usable for users who are not domain experts like hydraulic engineers or model specialists. First, the 3D visualization helped most of the participants to better understand the consequences of a flood scenario in terms of damages, loss of life and the urgency to evacuate in respect to the $2 \mathrm{D}$ visualization. In the open question about the added value of the $3 \mathrm{D}$ visualization over the $2 \mathrm{D}$ visualization, all participants agreed that the $3 \mathrm{D}$ visualization helped them to better imagine what a flood means for an area. Second, it was shown that these non-expert participants all were able to use our interactive simulation display. Moreover, they were able to carry out an expert analysis about the availability of roads after a heavy rain event within minutes. With conventional models, which have specialist user interfaces and require hours of computation time, this would not have been possible.

The case study showed that our system was usable for collaborative application by practitioners and domain experts. The simulation display was effectively used on the level of at least three aspects. First, it enabled practitioners from different backgrounds to understand what floods meant for their specific field of profession. Second, it helped these practitioners to contribute in suggesting suitable solutions, following the multi-level safety approach. Third, the simulation display helped the practitioners to retrieve direct feedback on the effectiveness of their suggested solutions.

Our results show that our system is accessible for practitioners of flood management such that they can carry out flood analysis together with domain experts in interactive work sessions. However, one should be careful to draw 
conclusions about the appreciations of our system. In our case the simulation display and 3D visualization were mainly used for a general exploration of solutions which on the short term have no direct financial or political consequences. The impact of the decisions and the time pressure for making these decisions were therefore low. It is expected that our system will be used differently when time pressure and consequences are high. Experiences show that decision-makers in these circumstances highly value the accuracy of the outcomes of a model (Brugnach, Tagg et al. 2007).

We expect that interactive modelling can contribute to a better understanding of uncertainties in model outputs among decision-makers as they can directly examine if current data were used in the model set-up. They can also see how suggested solutions are translated into the model and therefore better understand the scope of the outcomes. Still, a calibration and validation with real measured data, as applied in common model practices, is always advisable. However, in environmental problems related to climate changes, the future is unpredictable and the nature of the relationship between processes is sometimes unknown (Leedal, Neal et al. 2010). In these cases, different model concepts or variation in input data in ensemble calculations can be considered (Walker, Harremoës et al. 2003; Renner, Werner et al. 2009). Methods to cope with model uncertainty, such as the use of real measured data or ensemble calculations, are all applicable with our system.

Regarding the technical aspects of our studies, we report that our system is efficient enough to be executed on a standard desktop PC. For all scenarios, we could ensure a framerate of roughly 20 frames per second, which leads to a good tradeoff between speed and accuracy. Figure 3-8 shows a few images from a flythrough with an evolving flood. The interaction component was executed on a tablet, but would run on most web-capable devices, which is a big advantage as it makes a large part of our system accessible anywhere and to anyone.
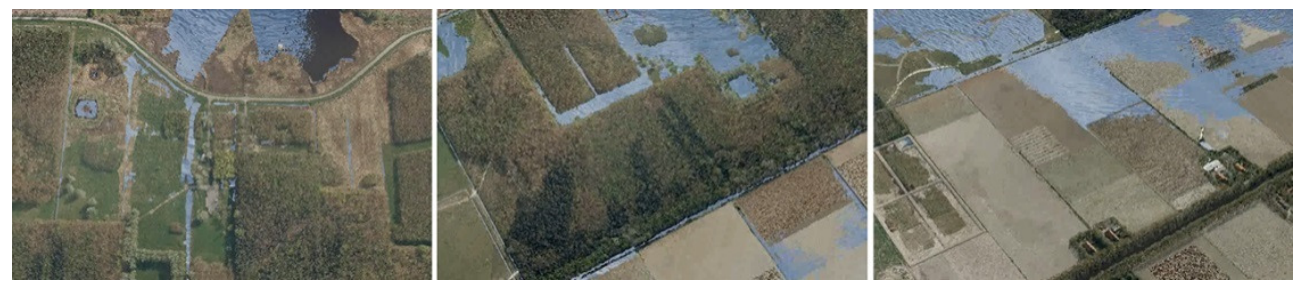

Figure 3-8: Our system is interactive and maintains a stable framerate. Here we show an evolving flood during a real-time flythrough on a standard desktop computer

\subsection{Conclusions}

In this paper, we presented our system for analyzing flooding scenarios. We showed that, despite the complexity of the involved models and the size of the involved 
data sets, our system is accessible for practitioners of flood management such that they can carry out flood analysis together with domain experts in interactive work sessions.

In particular, the realistic 3D visualization helps practitioners, who are no domain experts, to better estimate the scale as well as the impact of a flood. The simulation display allows them to interact with the system and to explore complex flooding scenarios. Both results have been demonstrated in a user study and a case study, showing that our system represents an important step ahead towards the closer involvement of practitioners in the analysis driving the decision-making process for developing mitigation and adaption strategies for the threats of floods.

The accessibility of our system can also be underlined by the fact that a modified version was recently installed in two museums in The Netherlands, namely the Delft Science Center, as well as the Watersnoodmuseum in Zeeland. The two installations rely on our 3D visualization system to illustrate the impact of the 1953 flooding, which led to an enormous destruction of large parts of the Netherlands. Our solution gives people a direct access to flood-related information and offers insights into decision making for flood mitigation and adaption strategies. 


\section{Real-world applications of models that can be interactively used}

This paper was published as journal paper: Leskens JG, Brugnach M, Hoekstra AY (2014a) Application of an interactive Water Simulation Model in urban water management, a case study in Amsterdam, Water Science $\&$ Technology 70 (11): 1729-1739.

\subsection{Abstract}

Water simulation models are available to support decision-makers in urban water management. To use current water simulation models, special expertise is required. Therefore, model information is prepared prior to work sessions, in which decisionmakers weigh different solutions. However, this model information quickly becomes outdated when new suggestions for solutions arise and are therefore limitedly used. We suggest that new model techniques, i.e. fast and flexible computation algorithms and realistic visualizations, allow this problem to be solved by using simulation models during work sessions.

A new Interactive Water Simulation Model was applied for two case study areas in Amsterdam and was used in two workshops. In these workshops, the Interactive Water Simulation Model was positively received. It included non-specialist participants in the process of suggesting and selecting possible solutions and made them part of the accompanying discussions and negotiations. It also provided the opportunity to evaluate and enhance possible solutions more often within the time horizon of a decision-making process. Several preconditions proved to be important to successfully apply the Interactive Water Simulation Model, such as the willingness of the stakeholders to participate and the preparation of different general main solutions that can be used for further iterations during a work session.

\subsection{Introduction}

Water simulation models are computer programs that can simulate the physical processes that are involved in water management, such as rainfall-runoff, surface 
flow, drainage and sewer flow. These models allow decision-makers to diagnose extreme storm events and to identify and dimension alternative solutions. Model simulations are based on physical equations, features of an area, such as elevation and roughness resistance, and external forces, such as storm events (Bates and De Roo 2000; Al-Sabhan, Mulligan et al. 2003; De Moel and Aerts 2011; Stelling 2012).

To use water simulation models, special expertise is required. This includes expertise about how input model parameters have to be set, how model runs have to be executed and how model outputs have to be post-processed to tangible results. Organizations such as water boards or municipalities often have separate departments to operate models, staffed by model specialists. To actually use models for the decisions that need to be made, model outcomes are communicated from this separated modelers' domain to the decision-makers' domain (Morss, Wilhelmi et al. 2005). Traditionally, this is done by documents or maps in which the model outputs are translated to standardized performance indicators, such as the duration of inundation under a standardized storm event (e.g. 100 millimeters of rain in one hour). When these indicators exceed their norm, measures are prescribed from which decision-makers can choose, such as enlarged sewer pipes or a higher pump capacity (Rioned 2010).

Nowadays this standardized generation of model results and solutions does not fully meet the needs of the decision-makers' domain anymore. Instead of standardized solutions for improving sewer or drainage systems, a broader scope of possible solutions is being investigated, such as vegetation roofs that slow down the discharge of rain water, squares that can function as water storage basins or elevated roads to maintain important transportation routes (Dawson 2007; MacKenzie 2010). These alternative solutions often benefit from specific opportunities that emerge in time, for instance when a road is restructured or when new houses are built (Lindley, Handley et al. 2007). It is therefore harder to prescribe this in standardized solutions, as is indeed possible in the case of solutions for sewer and drainage systems. Therefore, participants from departments and organizations that are active in spatial planning are involved in the decisionmaking process to explore opportunities to solve water problems as well (Walsh, Dawson et al. 2011). To involve these parties, often multi-stakeholder work sessions are organized, for example to define problems, choose measures and divide responsibilities to take actions, or else less defined work sessions such as brainstorming sessions (Linkov, Wood et al. 2009).

As models can only be operated by model specialists in the 'modelers' domain', model information is prepared prior to these multi-stakeholder work sessions (Walsh, Roberts et al. 2013). However, this model information quickly becomes 
outdated when problem definitions change or when new suggestions for solutions arise (Leskens, Brugnach et al. 2014). This leads to work sessions in which decisionmakers have to deliberate about solutions whose technical effectiveness they do not know. It can even lead to decisions in which the technical effectiveness is ignored, since it is not directly available (Morss, Wilhelmi et al. 2005).

We suggest that available model technology, i.e. fast and flexible computation algorithms and realistic visualizations, allow this problem to be solved by using simulation models during work sessions so that decision-makers are directly involved in diagnosing water problems and in assessing suggested solutions. This is further clarified in Figure 4-1. It shows the decision-making process as a sequence of work sessions, typically lasting a few hours, to solve a certain issue (Lindblom 1959; Mintzberg, Raisinghani et al. 1976). Each work session is prepared by models and preceded by actions, such as a redefinition of the issue, further research, the involvement of other actors, an elaboration of selected solutions or, finally, a satisfying solution (Hage 1980). Models used to be applied exclusively in the preparation phase. We propose the use of models in both the preparation phase the work session itself.

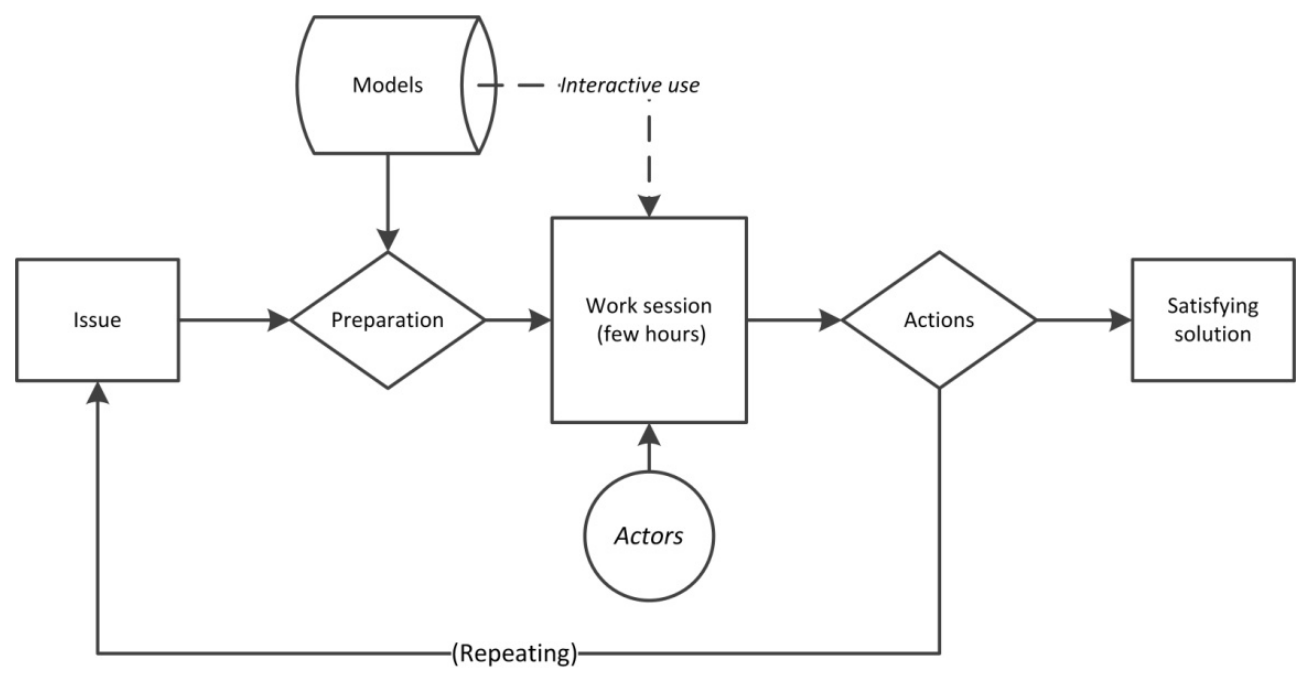

Figure 4-1: Use of models for preparation or interactive use in the sequence of work sessions

Naturally, this requires simulation models that can be easily adapted to assess suggested solutions during work sessions and are fast enough to provide multiple outcomes within the duration of a work session. It also requires a methodology to effectively apply such models in decision-making processes.

It cannot automatically be expected that technical outputs from interactive models will always be appreciated and used by decision-makers. Decision-makers may also 
have other motivations to value one solution above the other (March 1978; Simon 1987), such as former personal or political experiences with other participants in a work session (Langley, Mintzberg et al. 1995). Moreover, the demands for sophisticated information from models depend on the degree of routine with which decisions have to be made, how regularly a decision is required, what the level of impact is that a decision will have and how quickly a decision needs to be made (Butler, Astley. et al. 1979). For example, in situations in which decision-makers are acting under circumstances of high time pressure, large decision impact and high complexity, they tend to discard sophisticated model results that seems to increase the complexity they already have to deal with (MacCrimmon and Taylor 1976; Janis and Mann 1977; Kahneman and Tversky 1979; Gray 1989; Morss, Wilhelmi et al. 2005).

The goal of this paper is to explore whether an interactive model can improve the decision-making process in urban water management and how it is accepted by decision-makers. To this end we applied an interactive model in two workshops and evaluated its use by group evaluations and questionnaires. This interactive model is named 'Interactive Water Simulation Model' and was recently developed in the project 3Di Water Management in the period 2010-2013. It was technically developed by a team of model developers from the Delft University of Technology and Deltares, in close cooperation with two regional water boards (Hoogheemraadschap Holland Noorderkwartier and Hoogheemraadschap van Delfland) and Nelen\&Schuurmans consultants.

In this paper we focus on how the gap between the modelers' domain and the decision-makers' domain in environmental decision-making can be bridged by using a fast and easy adaptable model during work sessions. We hope our findings can contribute to the ongoing field of research concerning the practical application of environmental models in decision-making processes. This topic has recently become the subject of increasing attention in literature and is being investigated by different approaches. For example, Krueger et al. (2012) stress the role of expert opinion in the application of environmental models, Demir and Krajewski (2013) focus on the role of integrated information systems to communicate model outputs to decision-makers and Balica et al. (2013) and Zagonari and Rossi (2013) investigate how model results can be translated in performance indicators usable in multi-criteria analysis.

Aside from the introduction, this paper consists of five more sections. In the second section, the Interactive Water Simulation Model is presented. This is deliberately done in a separate section, since the development of this new model itself is not part of our research. However, the reader should have sufficient insight into the 
interactive characteristics of the model to be able to understand the findings of this research. Third, the methodology is presented, consisting of a case study in Amsterdam in which the Interactive Water Simulation Model was applied for a specific area, used in two workshops and evaluated by group evaluations and questionnaires. In the fourth section the results of these evaluations and questionnaires are presented. Finally, we discuss our findings and draw conclusions in the last two sections.

\subsection{The interactive water simulation model}

\subsubsection{Development of the model}

Before the technical development of the Interactive Water Simulation Model was carried out, the user needs were investigated by means of interviews. These user needs are related to the functions that participants in a work session desire from an interactive model to support the decisions they make. For example, participants in a work session can desire that the model computes instantaneously the effectiveness of different proposed solutions in terms of reduced inundation depths and damages.

The interactive water model presented in this paper is based on user needs that were derived from interviews among policy analysts involved in the field of Urban Water Management, who often participate in stakeholder work sessions. The interviews were conducted in 2011 among thirteen employees of the regional water board Hoogheemraadschap van Delfland and the municipality of Rijswijk, located in the southwest of the Netherlands. Each interview lasted one hour and was semistructured. The interviews focused specifically on three questions. (1) What is your task or role in decision-making processes in urban water management? (2) What information do you require to carry out this task? (3) What functions do you need from a model that can be operated during a work session?

The thirteen semi-structured interviews yielded that the following functions were considered important in using an interactive model: (1) technical reliability; (2) the possibility to assess the effectiveness of multiple scenarios within the time horizon of a work session and (3) understandable output for non-water specialists. A full report of the interviews can be requested from the author (Leskens and Pleumeekers 2012). Technical experts of the development program 3Di Water Management translated these functions to technical model properties by finding appropriate modelling techniques and implement these in the model software (see Table 4-1). This is further elaborated in the following sections. 
Table 4-1: Technical model properties derived from user needs mentioned in the interviews

\begin{tabular}{|c|c|c|}
\hline User needs & Technical model properties & Details \\
\hline \multirow[t]{2}{*}{ Technical reliability } & Current input data & $\begin{array}{l}\text { Current data of elevation, land } \\
\text { use, sewer system and water } \\
\text { system (ditches, canals, weirs, } \\
\text { siphons, pumps, culverts) }\end{array}$ \\
\hline & $\begin{array}{l}\text { Accurate physical } \\
\text { representation of processes }\end{array}$ & $\begin{array}{l}\text { Rainfall-runoff, overland flow } \\
\text { and sewer flow processes } \\
\text { included }\end{array}$ \\
\hline \multirow{2}{*}{$\begin{array}{l}\text { Ability to assess the } \\
\text { effectiveness of multiple } \\
\text { scenarios within the time } \\
\text { horizon of a work session }\end{array}$} & Short computation times & $\begin{array}{l}\text { 2-5 minutes for a rainfall or } \\
\text { dam break event of } 48 \text { hours } \\
\text { (standard area of } 6 \mathrm{~km}^{2} \text { ) }\end{array}$ \\
\hline & $\begin{array}{l}\text { Ease in adapting input of the } \\
\text { model to test suggested } \\
\text { measures during work sessions }\end{array}$ & $\begin{array}{l}\text { Adaptable elevation map, } \\
\text { infiltration layer, interception } \\
\text { layer and water system }\end{array}$ \\
\hline \multirow[t]{2}{*}{$\begin{array}{l}\text { Understandable output for non- } \\
\text { water specialists }\end{array}$} & $\begin{array}{l}\text { Resolution of output that } \\
\text { connects to the spatial } \\
\text { variability of inundations }\end{array}$ & $\begin{array}{l}\text { Spatial resolution of } 1 \text { by } 1 \\
\text { meter. Depths in centimeters }\end{array}$ \\
\hline & Realistic visualization & $\begin{array}{l}\text { Spatial visualization of } \\
\text { inundation on topographic } \\
\text { maps or images ( } 2 \text { or } 3 \\
\text { dimensional) }\end{array}$ \\
\hline
\end{tabular}

\subsubsection{Technical properties of the model}

The interactive water model we applied consisted of three core innovative aspects: (1) short computation times in combination with a high spatial resolution and an accurate physical representation of all relevant processes, (2) ease of model adaptability to test suggested measures and (3) a realistic visualization of model outputs. These properties are further elaborated below. The description of other technical properties can be requested from the development team of 3Di Water Management (Deltares, Nelen\&Schuurmans et al. 2015)

\section{Short computation times}

The model combines a high spatial resolution (i.e. 0,5 meter by 0,5 meter) and the inclusion of all relevant processes (i.e. overland flow, groundwater flow, canal flow 
and sewer flow) with computation times in the order of minutes. This make the Interactive Water Simulation Model much faster than conventional models. These conventional models, such as Sobek (Deltares 2015) or Mike11 (DHI 2015) have computation times in the order of hours, under the same level of detail. A further explanation about which process are included in the model and which computation algorithms are used to ensure the short computation times is given in the appendix.

\section{Ease in the adaptability of the model to test suggested measures}

A user interface was developed that allows the users to easily adapt the schematized study area on three aspects. First, the elevation map can be incrementally increased and decreased on specific locations. Changes to the elevation map can, for instance, be applied to simulate water storage basins, gutters or elevated roads. Second, the land use can be changed in the user interface. This land use is related to the surface roughness, interception volume, infiltration rate, crop type and the porosity and permeability of the soil. By changing the land use from paved area into grass land, for instance, all the aforementioned physical parameters are changed in the model. This allows the user to simulate solutions such as permeable parking lots or green roofs. Third, the dimensions of the water system and sewer system can be changed in the interface, such as the widening or narrowing of canals or the addition of man holes for drainage purposes.

The user interacts with the user interface via a touch table Figure 4-2. This is conducive to the workshop participants' direct involvement in the use of the interactive model. The operation of the model on the technical level was carried by a model specialist.

The speed and easiness in which all aspects of the model can be adapted by nonmodel experts are the core innovative aspects of this interface. In conventional model interfaces mentioned above, adaptions can only be made by model specialists. Making adaptation in these conventional models, together with the accompanying computation time of an adapted model scenario, takes several hours and can therefore not be carried during work sessions.

\section{Realistic visualization of model outputs}

The model output is visualized in a virtual three-dimensional environment. This environment is based on data from Laser Imaging Detection and Ranging (LIDAR), measured by aerial scanning with helicopters. This technology provides the opportunity to capture the surface of an area in dots, all having an $\mathrm{x}-\mathrm{y}$ - and $\mathrm{z}-$ coordinate. The LIDAR data that is available in the study area consist of approximately 15 dots per square meter. This 'point cloud' was colored according 
to the aerial photographs which were also available in the study area. By applying big data processing technology (De Haan 2009) these data are presented in a virtual environment comparable with flight simulators. In this virtual environment, the model output of the Interactive Water Simulation Model were presented (see Figure 4-3). More details on this technology can be found in Kehl and De Haan (2012).

The core innovative aspect of this realistic visualization of model outputs, in comparison to usual two dimensional flood maps, is that users can assess the inundation depths in relation to real objects, such as houses, trees and cars. Therefore, no legend with color codes is necessary, which makes the assessment of model outcomes better accessible for users that are not used to work with maps.

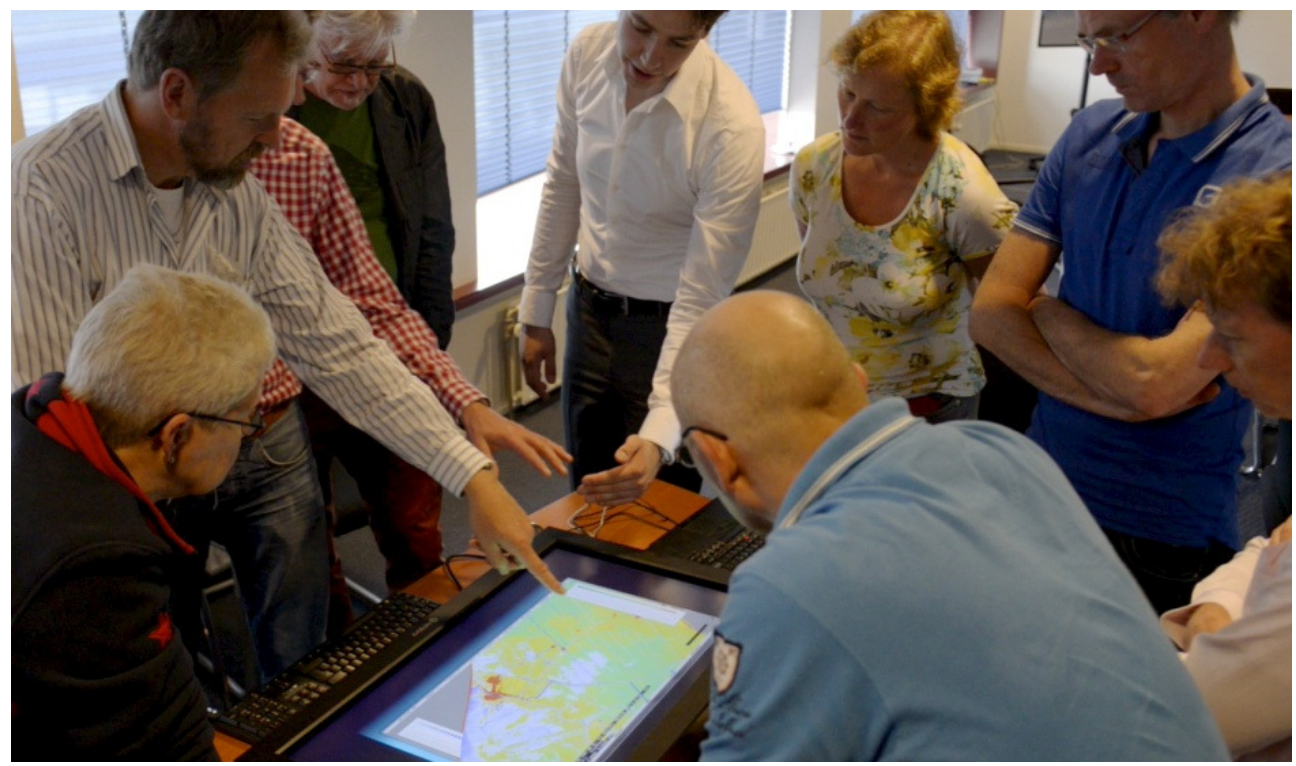

Figure 4-2: Use of the Interactive Water Simulation Model for workshop Watergraafsmeer 


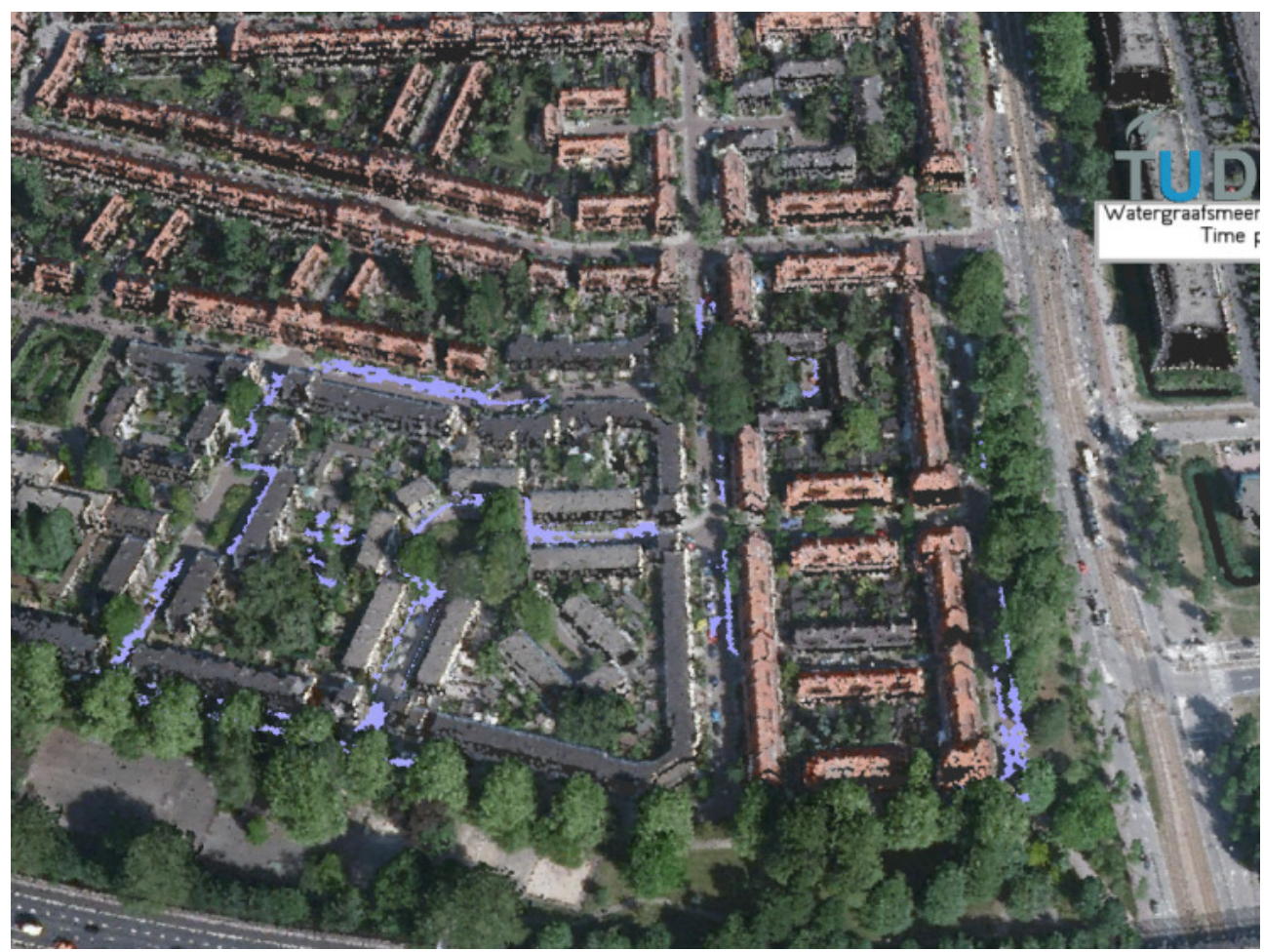

Figure 4-3: Visualization of model outcomes in 3D environment

\subsection{Methodology}

\subsubsection{General}

To reach our goal we carried out a case study in Amsterdam, consisting of two workshops in which the Interactive Water Simulation Model was applied. In the first workshop 20 people participated and in the second workshop 22 other people participated.

To assess whether the interactive model improved the decision-making process (i.e. the first part of our goal of research) we choose three different criteria. These criteria are related to our perspective on decision-making processes as a sequence of work sessions in which various participants diagnose problems, redefine issues, elaborate suggested solutions and finally chose for a satisfying solution. First, we focused on how the model helped the various participants to understand the existing problem. Second, how the model influenced the process of generation of possible solutions. Third, how the model helped in the selection of solutions. To assess the acceptance of the model (i.e. the second part of our goal of research) we focused on the questions whether participants considered the model as reliable 
(Brugnach, Tagg et al. 2007) and whether they would apply an interactive model in future work sessions.

These criteria were further elaborated in a questionnaire that was send to the participants and were used in group evaluations after the workshops. The content of the workshop, the group evaluation and the questionnaire is further explained in the following sub sections.

\subsubsection{Set-up of workshops}

Two work sessions with a similar set-up were organized to define a set of measures to make Amsterdam resilient for extreme rainfall events of $60-100 \mathrm{~mm}$ in one hour, which may be expected to occur more often as a result of climate changes (Hanel and Buishand 2010). The workshops focused on two districts in the region of Amsterdam: (1) Watergraafsmeer and (2) Purmerend. The workshop in the district Watergraafsmeer was carried out within a Dutch national research program called Knowledge for Climate, Climate Proof Cities 3.3. The workshop in Purmerend was carried out within the Urban Water Plan Purmerend 2015.

The following program was followed in both workshops:

1. Introduction of the technical background for the Interactive Water Simulation Model.

2. Demonstration of the effects of a rainfall event of $100 \mathrm{~mm}$ in one hour in the Interactive Water Simulation Model.

3. Demonstration of various previously prepared scenarios in the model, based on the expert knowledge of urban water specialists of the municipality. As sewer systems are not designed for rain events of $100 \mathrm{~mm}$ in one hour, the focus was on measures above the surface, i.e. measures in the spatial planning of the city. This included permeable parking lots, squares with the ability to store rainwater and water storage on green roofs (MacKenzie 2010).

4. Application of the Interactive Water Simulation Models. The effectiveness of the prepared scenarios was presented directly in the model to the participants in groups of around ten people. Due to the short computation times and the flexibility to change the model, the participants of the workshops could test various other solutions such as elevated roads or widened gutters.

\subsubsection{Group evaluation and questionnaire}

The group evaluations were carried out after the application of the Interactive Water Simulation Model during the workshops. All participants were asked to express their opinions about if and how the application of the Interactive Water Simulation Model improved the decision-making process during the workshop, and 
how it can improve future decision-making processes. These opinions were recorded and minutes of meeting were made, consisting of representative comments expressed by the participants.

After the workshop, the participants were asked to respond to a questionnaire. In this questionnaire the respondents were asked to give a score to different statements pertaining to their appreciation of the use of an interactive water model during work sessions. The participants were asked to give a score on a scale from 1 (totally disagree) to 5 (totally agree) on the following questions:

1. Work sessions are necessary links in a decision-making process

2. Work sessions are important to understand each other's perspectives on the problem

3. In work sessions substantive decisions are being made

4. The interactive water model helped me to better understand the problem

5. The interactive water model helped me to better understand the effectiveness of suggested measures

6. The outcomes of the model were reliable

7. The outcomes of the interactive water model were understandable

8. I would apply the interactive water model in future work sessions

\subsection{Results}

\subsubsection{Workshops}

The workshops were attended by policy makers from the municipality, regional water board, province and fire department, all involved in spatial planning as it relates to Urban Water Management. Workshop 1 (Watergraafsmeer) was held on May 22, 2013. It was attended by 20 participants. Workshop 2 (Purmerend) was held on September 5, 2013 and was attended by 22 other participants.

\subsubsection{Outcomes group evaluations}

In general, the Interactive Water Simulation Model was positively received during the work sessions. The participants agreed that the water model gave them understanding of the problems that heavy rainfall can cause in the study areas and which solutions can solve these problems. The following quotations were representative for the general opinion during the group evaluations:

"The model gave me a new understanding of the consequences"

"This makes clear which options we have to choose from" 
Besides a better understanding in problems and solutions among non-expert participants, the interactive water model also improved the engagement of the participants in the decision making process. The participants appreciated their involved in the diagnosis of the problem and the generation of possible solutions positively:

"It triggered me to get a better technical understanding of the problem

"It gave me much inspiration for new work sessions"

"This connects different people and disciplines"

Most of the participant intended to use the interactive water model in future work sessions. This was illustrated by the following quotations:

"All policy makers involved in water management need to use this instrument"

"The model should be used to test the effect of new spatial developments on urban water problems during heavy rainfall"

The main concern, expressed during the group evaluations, was that the use of an interactive water model during work sessions can lead to a trial and error approach. The risk of such a trial and error approach is that solutions that are preferred on beforehand can retrieve all attention, whereas other possible solutions become underexposed. To limit this risk of a biased selection and elaboration of alternatives, the importance of a good process design of work sessions in which interactive models are applied was stressed by the participants:

"The use of the model was too much 'trial and error'. We need a more structural approach in the use of the model".

"A process design to use the model is required. Otherwise the use remains trial and error"

Another concern was how an underpinned weighing of alternatives can be organized under the fast generation of possible solutions during a work session. The use of indicators, such as applied in multi-criteria analysis, was suggested for this:

"The model should prioritize the effectiveness of measures based on indicators considered important by the participants, such as damages, costs of measures, cost allocation and responsibilities of the different stakeholders".

This quotation also indicates the importance to link the outcomes of the model with the different legal responsibilities and available funds of the organizations 
involved in work session the participants in the work session had. During the evaluations, the participants indicated that outside the work session these responsibilities and available funds can be decisive for the final solution that is selected.

\subsubsection{Outcomes questionnaires}

15 out of the 42 participants of the workshops responded to the questionnaire. The results per question are shown in Table 4-2. Although the number of responses is limited and therefore no significant conclusions can be drawn, the outcomes of the questionnaire confirm the outcomes of the group evaluations on the following points:

- A majority agrees that the Interactive Water Simulation Model helped them to better understand the problem during the workshops.

- Half of the respondents agreed or fully agreed that the Interactive Water Simulation Model helped to better understand the effectiveness of suggested measures, whereas 5 respondents where neutral and a minority of 2 respondents disagreed.

- A majority of the respondents would apply the interactive water model in future work sessions

The first three questions, regarding the appreciation of work sessions in general, show that work sessions are considered as important to understand each other's perspectives on the problem. Although, no substantive decision are being made in current work sessions they strongly influence the selection of possible solutions and therefore the final outcomes of a decision-making process. 
Table 4-2: Outcomes questionnaire among participants of workshop 1 and 2

\begin{tabular}{|c|c|c|c|c|c|c|c|}
\hline & & $\begin{array}{l}\text { Total } \\
\text { responses }\end{array}$ & $\begin{array}{l}\text { Fully } \\
\text { agree }\end{array}$ & Agree & Neutral & Disagree & $\begin{array}{l}\text { Fully } \\
\text { disagree }\end{array}$ \\
\hline 1 & $\begin{array}{l}\text { Work sessions are } \\
\text { necessary links in a } \\
\text { decision making process }\end{array}$ & 15 & 3 & 3 & 6 & 3 & 0 \\
\hline 2 & $\begin{array}{l}\text { Work sessions are } \\
\text { important to understand } \\
\text { each other perspectives on } \\
\text { the problem }\end{array}$ & 15 & 8 & 7 & 0 & 0 & 0 \\
\hline 3 & $\begin{array}{l}\text { In work sessions } \\
\text { substantive decisions are } \\
\text { being made }\end{array}$ & 15 & 0 & 2 & 3 & 5 & 5 \\
\hline 4 & $\begin{array}{l}\text { The interactive } 2 \mathrm{D} \text { model } \\
\text { helped me to better } \\
\text { understand the problem }\end{array}$ & 15 & 5 & 7 & 2 & 1 & 0 \\
\hline 5 & $\begin{array}{l}\text { The interactive } 2 \mathrm{D} \text { model } \\
\text { helped me to better } \\
\text { understand the } \\
\text { effectiveness of suggested } \\
\text { measures }\end{array}$ & 15 & 2 & 5 & 5 & 3 & 0 \\
\hline 6 & $\begin{array}{l}\text { The outcomes of the model } \\
\text { were reliable }\end{array}$ & 15 & 0 & 6 & 8 & 1 & 0 \\
\hline 7 & $\begin{array}{l}\text { The outcomes of the } \\
\text { interactive } 2 \mathrm{D} \text { model were } \\
\text { understandable }\end{array}$ & 15 & 9 & 6 & 0 & 0 & 0 \\
\hline 8 & $\begin{array}{l}\text { I would apply the } \\
\text { interactive } 2 \mathrm{D} \text { model in } \\
\text { future work sessions }\end{array}$ & 15 & 4 & 5 & 5 & 1 & 0 \\
\hline
\end{tabular}

\subsection{Discussion}

The workshops and accompanying questionnaires and evaluations showed that the Interactive Water Simulation Model was positively received and improved the decision-making process on at least three aspects. First, the realistic visualization of results helped the participants, who had various backgrounds and were no water specialists, to be able to understand the problem technically. This improved their engagement in the decision making process. Second, the easy adaptable interface improved the involvement of the participants in the generation of possible solutions. This ensured that alternative solutions were generated from different 
perspectives on the problem. Third, given the short computation times of the model, multiple suggested solutions could be evaluated and enhanced within the time horizon of a work session. Either this can shorten the decision-making process as a whole or, under a fixed time horizon of a project, more iterations can be made on suggested solutions for finding the most attractive solution.

The workshops in which the participants used the Interactive Water Simulation Model consisted of a general exploration and selection of solutions. As this exploration had, on the short term, no direct financial or political consequences, the direct impact of the decisions were therefore low. One should therefore be careful in drawing conclusions from the outcomes of the evaluation of these workshops about the acceptance of interactive models in general. It is expected that an interactive model will be used differently when consequences on the short term are high, for example during disaster planning (Janis and Mann 1977; Morss, Wilhelmi et al. 2005).

A poor communication of the uncertainty in model outputs is often mentioned in literature as one of the reasons why decision-makers do not trust model outputs (Brugnach, Dewulf et al. 2008; Timmerman, Beinat et al. 2010; Voinov and Bousquet 2010). We expect that interactive modelling can contribute to a better understanding of uncertainties in model outputs among decision-makers as they can directly examine if current data were used in the model set-up. They can also see how suggested solutions are translated into the model and therefore better understand the scope of the outcomes. Still, the reliability of the outcomes was mentioned in the evaluations as a point that requires further improvement. In common modelling practices, a validation with real measured data is applied for this. However, in environmental problems related to climate changes, the future is unpredictable and the nature of the relationship between processes is sometimes unknown. In these cases, different model concepts or variation in input data in ensemble calculations can be considered (Bankes 1993; Demeritt, Nobert et al. 2010; Kwakkel, Walker et al. 2010).

Technical developments used to develop the Interactive Water Simulation Model are also used in the development of serious games. Serious games are simulation models comparable with flight simulators, in which users can assume the roles of different participants so as to produce a better understanding of each other's perspectives on the problem as well as the accompanying solutions or else for training purposes (Haasnoot, Middelkoop et al. 2009; Voinov and Bousquet 2010). However, current serious games often contain prepared model scenarios for a limited number of solutions and do not support iterative processes that engage participants in optimizing suggested solutions (White, Wutich et al. 2010). We 
believe that interactive models can therefore further improve serious games. The Interactive Water Simulation Model, as developed in our research enables users to simulate most of the possible solutions and it supports iterative processes. An advantage of this approach is that the same model can also be used for other types of work sessions during the decision-making process. Participants are therefore always informed by the same model information over the course of the whole decision-making process.

\subsection{Conclusions}

The question addressed in this paper was whether interactive models can improve a decision-making process in urban water management and how they are accepted by decision-makers, in respect to non-interactive models that are only applied in the preparation of work sessions.

The interactive water model we applied consisted of three core innovative aspects: (1) a short computation times in combination with a high spatial resolution and an accurate physical representation of all relevant processes, (2) ease of model adaptability to test suggested measures and (3) a realistic visualization of model outputs.

We assessed the improvement of the decision-making process in two workshops focusing on three criteria. First, how it helped the various participants to understand the existing problem. Second, how it influenced the process of generation of suitable alternatives. Third, how the model helped in the selection of alternatives. To assess the acceptance of the model we focused on the questions whether participants considered the model as reliable and whether they would apply an interactive model in future work sessions.

Regarding the improvement of the decision-making process the following conclusions can be drawn, based on the workshops and accompanying questionnaires and evaluations:

- The realistic visualization of results helped the participants, who had various backgrounds and were no water specialists, to better understand the consequences of heavy rainfall in urban area in respect to existing methods. This improved their engagement in the decision making process.

- The easy adaptable interface helped answering questions pertaining to the diagnosis of a problem, the interrelations and interdependences between different topics of the problem and the effectiveness of solutions. It therefore improved the involvement of the participants in the generation of possible solutions. This ensured that alternative solutions were generated from different perspectives on the problem. 
- The short computation times of the model helped to focus dialogues and negotiations during work sessions on effective alternatives, as technically ineffective solutions were directly identified and discarded.

- The short computation times provided the opportunity to evaluate and enhance measures more often within work sessions. Either this can shorten the decision-making process as a whole or, under a project's fixed time horizon, more iterations can be made on suggested solutions to find the most attractive solution.

Regarding the acceptance of interactive models we are careful to draw conclusions, as this highly depends on how a model is technically elaborated in terms of the user requirements and how its outcomes are validated. In our case, the willingness to apply the interactive water model in future decision-making processes was large. Independently of the outcomes of a model, participants can have other motivations to value one solution above the other, such as former personal or political experiences with other participants in a work session (March 1978; Simon 1987). It can therefore not be expected that the outcomes of interactive models that are applied during work sessions will always be accepted by the participants. However, during the workshops and their evaluations, we did not observe the participants refusing to accept model outcomes when these outcomes did not meet their expectations or preferences. For example, various participants came back from their initial preference for green storage roofs when the Interactive Water Simulation Model showed that the effectiveness of this measure was low. Still, this does not mean that participants in workshops in Urban Water Management will always renounce their preferences when a model shows the ineffectiveness of the proposed solutions. During the evaluations, the participants indicated that outside the work session the legal responsibilities of the different organizations and the available funds can be decisive (Levin and Cross 2004). Therefore, the application of interactive models during work sessions can be more useful when formal responsibilities and available funds are considered alongside the use of the model. In the evaluations of the workshops, several participants remarked that the use of an interactive water model can lead to a trial and error approach, which can result in a non-coherent package of individual measures suggested by participants in the work sessions. This emphasizes the importance to apply an interactive water model within the context of a sophisticated process design. In our case, the preparation of different general main solutions that can be used for further iterations during work sessions was applied. We consider also a good follow-up to the work sessions by specialists, for example to investigate the technically feasibility and coherence of the proposed solutions. 
In this paper we showed how new model technology (i.e. fast and flexible computation algorithms and realistic visualizations) that is applied in work sessions can bridge the gap between de modelers' domain and the decision-makers' domain in the field of Urban Water Management. Comparable case studies are limited, since this model technology has only become most recently available. We encourage further research in other fields of water management, such as structural planning or flood disaster management, to see if the findings presented in this paper are also valid for these disciplines. Also other types of Interactive Modelling Environments need further exploration, for example in meetings with civilians or in the setting of a serious game. 


\section{Evaluation of the influence of an interactive use of models on the collaborative knowledge construction process}

This chapter has been submitted as journal paper to the Journal of Environmental Modelling and Software (currently under review)

\subsection{Abstract}

There is an increasing use of interactive flood simulation models in work sessions with practitioners, which is supposed to be more effective than feeding static model results from conventional simulation models into the decision-making process. These interactive simulation models rely on fast and flexible computation algorithms and realistic visualizations and are therefore accessible for practitioners during work sessions, allowing demand-driven flood simulations together with domain experts.

In this paper we present a method to assess what is actually the influence of applying interactive models on the decision-making process in a work session when compared to the use of static maps and animations prepared in advance of the work session. Specifically, we monitor the properties of the process of collaborative knowledge construction as it evolves in multi-stakeholder work sessions. Our method was adopted from education sciences and adapted for the use in multiactor work sessions. In this method, all conversations are recorded by video, fragmented in individual statements and classified on different properties of collaborative knowledge construction. We tested the applicability and usefulness of our method in a flood disaster experiment in which we monitored two cases: the use of conventional static flood maps and the application of an interactive flood simulation model.

We conclude that focusing on collaborative knowledge construction is a helpful perspective for assessing the influence of an interactive use of models on the 
decision-making process in work sessions. Our method reveals how model outputs become integrated in the knowledge construction process of practitioners in a flood disaster setting and promises to be a usable method for future evaluations of the influence of interactive models in a larger number of experimental settings and in real-world situations.

\subsection{Introduction}

Since the 1990s, computer simulation modelling has become increasingly important in the production of knowledge relied upon in the management of flood risks (Porter and Demeritt 2012; Landström and Whatmore 2014). The simulation models central to flood risk management originate in hydrological and engineering sciences, where computer simulation have made it possible to explore complex natural systems (Hesselink, Stelling et al. 2003; Stelling 2012). In these models, hydrological and hydraulic processes are digitally schematized and applied to a certain problem area. In the management of flood risks, simulation models are used for various purposes, for example to build understanding about floods, to predict future floods or to explore the effect of adaptation or mitigation measures (Brugnach and Pahl-Wostl 2007). Outputs of these simulations are usually communicated by using flood hazard maps that show the spatial pattern of floods including inundation depths or damages.

It is often concluded in literature that a gap exists between the knowledge produced by model specialists (i.e. domain experts) and the use of this knowledge by decision-makers, policy analysts and other practitioners outside the domain of experts (Seijger, Dewulf et al. 2013; Leskens, Brugnach et al. 2014; Giebels, van Buuren et al. 2015). The interactions between domain experts and practitioners are often based on a one-way approach, with knowledge transfer largely originating from the domain experts, and involving the domain experts as the producers of knowledge and the practitioners as the users (Leskens, Brugnach et al. 2014; LópezRodríguez, Castro et al. 2015). This one-way approach may fail to match the expectations of practitioners of flood policy decision-making and it may be used differently than was expected or intended. Moreover, the expert domain is fragmented across disciplines (Herrick and Sarewitz 2000) and the interaction between experts and practitioners is difficult due to differences in problem perceptions, time frames, reward structures, goals, process cycles, criteria for judging the quality of knowledge and discourse (Bouwen 2001; Morss, Wilhelmi et al. 2005; Brugnach, Dewulf et al. 2011; Hegger, Lamers et al. 2012; Leskens, Brugnach et al. 2014; Leskens, Brugnach et al. 2014). As a consequence, model outputs prepared by domain experts are often not part of the considerations and discussions among practitioners of flood policy decision-making and do not 
influence the analysis of the situation at hand and possible measures (Leskens, Brugnach et al. 2014).

There is a growing recognition in the field of policy research that model outputs and other knowledge produced by domain experts (e.g. scientists, modellers, engineers) can be more effectively used when interactive ways of knowledge production are applied (Seijger, Dewulf et al. 2013). Instead of a one-way supply of information from the experts' domain to the practitioners' domain, knowledge is jointly constructed by obtaining perspectives of domain experts, practitioners and other stakeholders involved in the complex problems that are being studied. This is also indicated in literature as the co-production of knowledge (Armitage, Berkes et al. 2011; Mauser, Klepper et al. 2013). Such interactive approaches are expected to result in a better inclusion of different inputs, more socially robust knowledge (i.e. knowledge production that has taken place in its context of application) and increased ownership and accountability for decisions (Gibbons 1999; Cash, Clark et al. 2003; Cornell, Berkhout et al. 2013; Mauser, Klepper et al. 2013).

Following this development towards knowledge that is jointly constructed among domain experts and practitioners, flood simulation models have recently been developed that can be used during the work sessions in which practitioners and domain experts gather (see Figure 4-2). These so-called interactive models are expected to be more effective than static maps from conventional simulation models in feeding model results into the decision-making process. Interactive models rely on fast and flexible computation algorithms and realistic visualizations and are therefore accessible for practitioners so that they can carry out flood simulations together with domain experts in work sessions (Leskens, Kehl et al. 2015). Interactive models can, for example, be used during work sessions to assess the impact of storm surges or dam breaches or to analyze the effects of suggested measures, such as elevating levees by sandbags in conditions of flood disaster management or developing water storage basins in urban areas. Other than 'participatory modelling' (Castelletti and Soncini-Sessa 2007; Whatmore, Lane et al. 2011), where a model itself is created together with practitioners or other stakeholders, interactive models are largely prepared beforehand but can be adapted during a work session, for example, to add missing data or to set the conditions for different scenarios. The technical feasibility of using an interactive model in multi-actor work sessions in flood management has already been demonstrated in various cases. Leskens et al (2014) concluded in two case studies that the interactive use of a flood simulation model during multi-actor work sessions was appreciated by its participants and was seen as an improvement when compared to the use of static flood maps made in advance of a work session. 
Although the first application of interactive models shows that their use can be helpful to provide useful model information to practitioners, these observations are based on the personal opinions of only a small number of users in the specific context of a limited number of work sessions. Therefore, there is a need for a more systematic evaluation of what is actually the influence of applying interactive models on the process and outcome of a work session, when compared to the use of static maps and animations prepared in advance of a work session. Retrieving more insight in this is necessary as multi-actor work sessions in which interactive model tools are used are increasingly applied, for example during flood disasters (Leskens, Kehl et al. 2015), urban planning (Leskens, Brugnach et al. 2014) or in serious games in which participants can play the role of different stakeholders in a virtual environment (Hummel, van Houcke et al. 2011).

The goal of this paper is to present a method to assess if and how an interactive use of simulation models leads to an integration of model outputs in the knowledge construction process of practitioners in flood policy decision-making. We present a theoretical framework as a basis for this method and operationalize this into measurable metrics. We test the method in an experiment in which we compare two cases: one with the use of an interactive model and one without. We discuss the usefulness and applicability of our method and propose directions for further research. By introducing an assessment method we want to set the agenda for a more systematic evaluation of the influence of various interactive models and tools applied in current and future flood policy decision-making.

\subsection{Theoretical framework}

A common method of investigating the influence of model information on the knowledge construction process of practitioners of flood policy decision-making is to focus on the question whether the supply of model information actually fits with the information demands of the practitioners (Faulkner, Parker et al. 2007; Janssen, Hoekstra et al. 2009). With the use of non-interactive models, these investigations focused on how model outputs, produced in advance of a work session, can optimally support the information demand of decision-makers during a work session (Timmerman, Beinat et al. 2010). These investigations focused on defining the information requirements of decision-makers and, subsequently, matching the content and presentation of model outputs (e.g. maps, animations or numbers) to these requirements. This has resulted in different methods to communicate model outputs, such as communicating model uncertainties in ranges (Demeritt, Nobert et al. 2010), summarizing model outcomes in different key performance indicators (Balica, Popescu et al. 2013) or embedding model outputs in multi-criteria analyses (Zagonari and Rossi 2013). 
With the availability of interactive models, model outputs are no longer 'produced' by model specialists in advance of work sessions and 'used' by practitioners.

Instead, interactive models are used to support a joint construction of knowledge (i.e. co-production of knowledge) among domain experts and practitioners (Gibbons 1999; Mauser, Klepper et al. 2013). The outputs of interactive models are not static anymore, as feedback on the model outputs can be taken into account during work sessions and the outcomes can be adjusted to useful feedback in an iterative way (Leskens, Brugnach et al. 2014) (Figure 5-1).

Therefore, to investigate how model information from interactive models influence the knowledge construction process of practitioners in flood policy decision-making (i.e. the goal of our research) we chose a different approach compared to earlier research. In line with the interactive character of interactive models, our approach focuses on how participants in a work session interact with the model and how the outputs of the model actually become part of the knowledge that is collaboratively constructed within a work session. This depends on how participants of a work session are able to discuss and deliberate about model outputs, on whether they can give feedback on this information and whether this information challenges their prior ideas and perspectives (Weick 1995; Bouwen 2001).

The concept of collaborative knowledge construction describes this real-time process of how different participants in a decision-making process exchange knowledge and experiences and use external information sources to create shared knowledge when decisions are made (Fischer, Bruhn et al. 2002). It emphasizes the ongoing learning process of participants in at times disturbed, uncertain and high-tempo environments (Keller, Ansell et al. 2012). Collaborative knowledge construction is to a large extent measurable through real-time observation, which helps us to assess the influence of interactive models on decision-making. These real-time observations are usually done by video analysis in which the conversations during the process are fragmented into individual statements that are expressed by the participants (Fischer, Bruhn et al. 2002; Derry, Pea et al. 2010). Following this, these individual statements can be characterized on different properties of collaborative knowledge construction, for example by the topics that are being mentioned, the rate of participation of different actors and the extent to which participants refer to each other's statements (see further method section). Examples of real-time observation of collaborative knowledge construction processes in groups can be mostly found in educational research, for example to investigate the process of collaborative knowledge construction in the context of class rooms, digital bulletin board systems or internet forums (Banks 1993; Brandon and Hollingshead 1999; Pena-Shaff and Nicholls 2004). We will make use of this experience for our purpose. 
Conventional modelling:

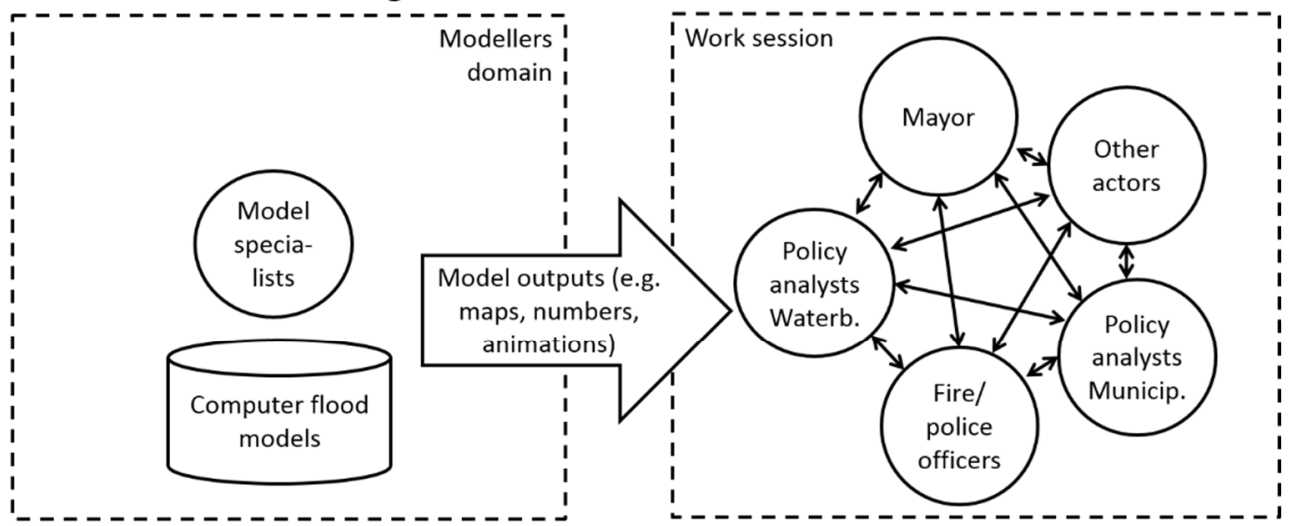

\section{Interactive modelling:}

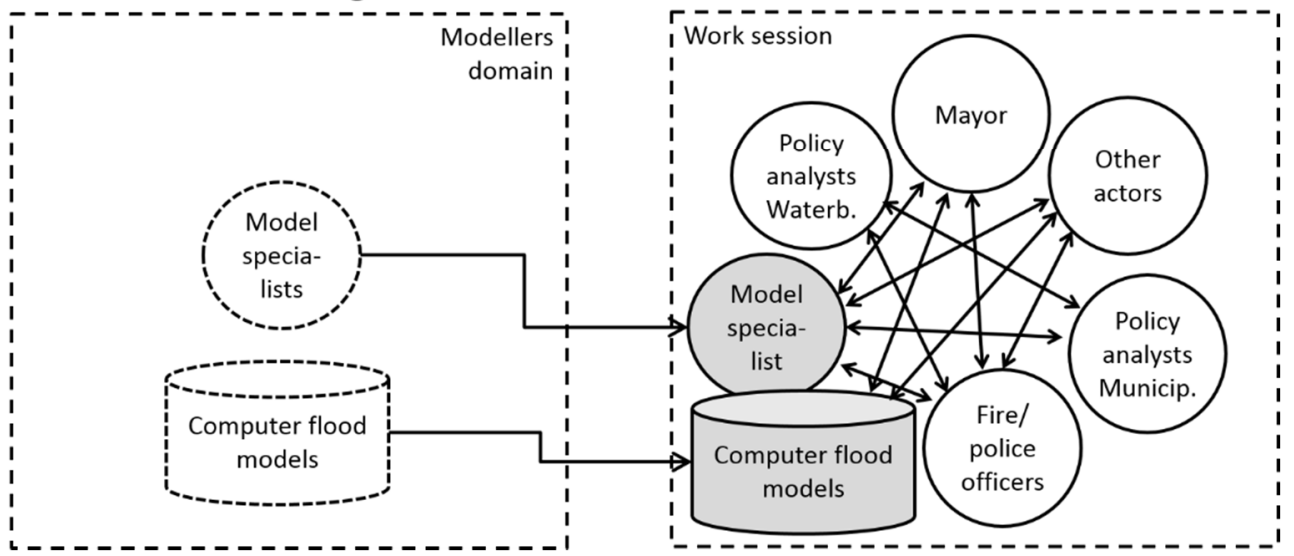

Figure 5-1: The conventional use of model outputs versus the application of an interactive model

Related to the concept of collaborative knowledge construction is the concept of social learning, here defined as the process in which individuals or groups learn and adapt to disturbances and uncertain social-ecological conditions (Argyris and Schön 1978; Armitage, Berkes et al. 2011). The social learning process takes place on wider time and group scales than multi-actor work sessions that have a time horizon of approximately two hours (i.e. our unit of analysis). Social learning is assumed to happen on at least three time and group scales (Pahl-Wostl, Craps et al. 2007): 1) on short to medium time scales at the level of processes between collaborating stakeholders in collaboration processes, 2) on medium to long time scales at the level of change in actor networks, and 3) on long time scales at the level of change in governance structure (formal and informal institutions and cultural values, norms, and paradigms). The first level best corresponds with the 
process of collaborative knowledge construction in work sessions we are focusing on in this article.

\section{$5.4 \quad$ Method}

\subsubsection{Assessment method}

With our assessment method we aim for a more systematic evaluation of the influence of interactive models and tools applied in current and future flood policy decision making. As this will require a number of cases to be investigated and compared, we aim for a method that can be easily applied, focusses on measurability, but still captures the major aspects of the process of collaborative knowledge construction when an interactive model is used. To this end, we adopt indicators that have often been used for the same purpose but in another context, namely educational settings in classrooms or forums. We adapt these indicators to the situation of multi-stakeholder processes in flood policy decision making. In this research we assess the collaborative knowledge construction process by using indicators related to three commonly used properties of collaborative knowledge construction: (1) content, (2) process, and (3) outcomes (Fischer, Bruhn et al. 2002; Pena-Shaff and Nicholls 2004; Jensen 2007).

\subsubsection{Content}

The collaborative knowledge construction process depends on the content that is available in the multi-stakeholder work sessions, brought in by prior knowledge and experiences of the various stakeholders or by external information sources available such as flood maps or models (Hiltz 1993; Fischer, Bruhn et al. 2002). More content means that more input is available to collaboratively construct shared knowledge.

One can assess this content with the following indicators:

1. The scope of prior knowledge and experiences among the participants, measured by a questionnaire with questions about what organization the participant represents, their task in this organization, prior experience and knowledge related to the topic of the work session, planned contribution in work session and expected results of work session.

2. The amount of relevant external information available, such as maps, factsheets or databases.

\subsubsection{Process}

Besides the available content in a group, collaborative knowledge construction depends on how this content is exchanged among the different participants and how this exchange of content leads to constructed knowledge of the group (Gergen 
and Thatchenkery 1996). Social interaction plays an important role in this (Bouwen and Taillieu 2004). Weinberger and Fischer (2006) provide a framework to further analyze this process of social interaction in detail. This framework was applied in research about computer supported collaborative learning in educational settings. Regarding the process of collaborative knowledge construction, the framework focuses on the degree to which different participants of work sessions participate and on the level of social co-construction, measured by the extent to which participants refer to contributions (i.e. statements) of other participants (Fischer, Bruhn et al. 2002).

Four levels of social co-construction can be discriminated (Newman, Webb et al. 1995; Pena-Shaff and Nicholls 2004), from low to high: (a) externalization of knowledge, in which participants bring individual prior knowledge into the situation; (b) elicitation of knowledge, in which participants are causing each other to express knowledge; (c) conflict-oriented knowledge construction, in which different interpretations are confronted and knowledge structures are modified; and (d) integration-oriented knowledge construction, in which individual perspectives of participants are integrated in common knowledge.

The different levels of social co-construction can be recognized by the type of statements that participants make, such as questions, replies, clarifications, interpretations or reflections. For example, asking for clarification about the statement by another participant can be considered as the second level of social coconstruction (i.e. elicitation), whereas debating the statement of another participant refers to the third level (i.e. conflict-oriented knowledge construction). In Table 5-1 we link different types of statements, as distinguished by Pena-Shaff and Nichols (2004), to the four levels of social co-construction. 
Chapter 5: Evaluation of the influence of an interactive use of models on the collaborative knowledge construction process

Table 5-1: Levels of social co-construction of knowledge linked to different types of statements used in conversations

\begin{tabular}{|c|c|}
\hline $\begin{array}{l}\text { Levels of social co- } \\
\text { construction of } \\
\text { knowledge } \\
\text { (Weinberger and } \\
\text { Fischer 2006) }\end{array}$ & Types of statements (Pena-Shaff and Nicholls 2004) \\
\hline \multirow[t]{4}{*}{$\begin{array}{l}\text { 1. Externalization of on- } \\
\text { topic knowledge }\end{array}$} & Clarifications: Identifying and elaborating on ideas and thoughts \\
\hline & Replies: Responding to other participants' questions or statements. \\
\hline & $\begin{array}{l}\text { Interpretations: using inductive and deductive analysis based on facts } \\
\text { and premises posed, making predictions and building hypotheses }\end{array}$ \\
\hline & $\begin{array}{l}\text { Reflections: Acknowledging learning something new, judging } \\
\text { importance of discussion topic in relation to their learning }\end{array}$ \\
\hline $\begin{array}{l}\text { 2. Elicitation of on-topic } \\
\text { knowledge }\end{array}$ & $\begin{array}{l}\text { Questions: Gathering unknown information, inquiring, starting a } \\
\text { discussion or reflecting on the problems raised. }\end{array}$ \\
\hline \multirow[t]{3}{*}{$\begin{array}{l}\text { 3. Conflict-oriented } \\
\text { knowledge construction }\end{array}$} & $\begin{array}{l}\text { Judgment: Making decisions, appreciations, evaluations and criticisms } \\
\text { of ideas, facts and solutions discussed }\end{array}$ \\
\hline & Conflict: Debating other participants' points of view \\
\hline & $\begin{array}{l}\text { Assertion: Maintaining and defending ideas questioned by other } \\
\text { participants }\end{array}$ \\
\hline \multirow[t]{2}{*}{$\begin{array}{l}\text { 4. Integration-oriented } \\
\text { knowledge construction }\end{array}$} & $\begin{array}{l}\text { Consensus building: Trying to attain a common understanding of the } \\
\text { issues in debate }\end{array}$ \\
\hline & $\begin{array}{l}\text { Support: Establishing rapport, sharing feelings, agreeing with other } \\
\text { people's ideas either directly or indirectly, and providing feedback to } \\
\text { other participants' comments }\end{array}$ \\
\hline
\end{tabular}

Following the aforementioned literature, the process can be assessed by the following indicators:

3. The degree of participation, measured by the number of statements per participant (Hiltz 1993; Fischer, Bruhn et al. 2002). To make sure that the statements are actually part of a participation process, they are only counted if they are a response to earlier statements and have the full attention of the group. 
4. The degree to which the discussed topics were socially co-constructed. This is measured by the number of statements per topic, sorted out by the four different levels of social co-construction. To ensure that the statements are actually part of a shared knowledge construction process, they are only counted again if they are a response to earlier statements and have the full attention of the group.

\subsubsection{Outcomes}

A third aspect to assess the process of collaborative knowledge construction is to focus at its outcomes. Outcomes are the follow-up actions of a work session, such as a redefinition of the issue, definition of further research, the involvement of other actors, an elaboration of selected solutions or, the selection of a certain solution (Hage 1980).

The outcomes are strongly related to the content and the process of collaborative knowledge construction. For example, when a lot of content (i.e. prior knowledge and experience of participants or external information sources) is available in a work session and the process has a high quality (i.e. a high participation rate and high levels of social co-construction), one can expect good outcomes, for example with high effectiveness, sustainability or efficiency. However, this will not always be the case. One can also imagine the case in which the responsive decision-makers neglect the outcomes of a high-quality collaborative knowledge construction process and implement other decisions. Therefore, the outcomes of a collaborative knowledge construction process can be assessed by the consistency between the intended follow-up actions of the participants in the work session and the actually implemented measures. Related to this, Bouwen and Taillieu (2004) consider the social relational qualities of outcomes, related to the level of ownership of solutions by the stakeholders. This will be mainly proved after a work session and can be measured by the extent to which outcomes are committed to in follow-up actions, the participation of the stakeholders in follow-up work sessions, and the degree to which the participants show ownership of and feel responsible for agreed actions.

One can assess outcomes by the following indicators:

5. The degree of consistency of the implemented follow-up actions and the intended follow-up actions during a work session. We measure this in a qualitative way by comparing both.

6. The degree of ownership of the follow-up actions by the participants and their feeling of responsibility to undertake actions. We measure this by the participation (i.e. number of statements) of the participants in the definition of the follow-up actions and by monitoring the engagement of participants after 
the work session, for example by their interest to participate in new work sessions.

\subsection{Experimental set-up}

\subsubsection{Objective}

The objective of the experiment was to test the usefulness and applicability of our method in measuring the differences in collaborative knowledge construction when an interactive model is applied compared to the case of using static model outputs. To this end we applied our method in two cases. In one case, the participants had the availability of static flood maps, showing floods on several dam breach location, and a digital elevation map and a topographical map. In the other case, the participants had the availability of the same maps. Additionally, they could make use of an interactive flood simulation model. The static flood maps that were available in both cases were created by using the interactive flood simulation model beforehand.

\subsubsection{Setting of the experiment}

In both cases a similar multi-stakeholder work session during a flood disaster was simulated, characterized by a content-driven, high tempo decision-making process (Leskens, Brugnach et al. 2014). We chose the setting of flood disasters as in this setting the information sources such as maps and models are only used when they are directly applicable, since there is little time to process complex information (Morss, Wilhelmi et al. 2005). In other settings, where more time is available and specialists have more room for explanation and answering questions, the differences in collaborative knowledge construction between cases with and without the use of an interactive model may be less significant. Another reason to choose this setting was that flood disasters are usually managed though temporal organizations existing of representatives of involved stakeholders (e.g.. water boards, municipalities, fire departments or police departments) who have no particular shared history of deciding together or having personal relations (Leskens, Brugnach et al. 2014). This may minimize the influence that social relations and a shared history among participants can have on the collaborative knowledge construction process (Wenger 2000).

\subsubsection{Script of the experiment}

The area of concern was the town Hoorn (in North Holland) that was threatened by a flood due to a storm on the adjacent lake named Markermeer. Each case had eight participants. The decision task of the participants in both cases was to decide about which neighborhoods of the town Hoorn had to be evacuated due to the threatening flood. The experiment took 30 minutes. At the start of each round of 10 minutes, the participants were given new information about the impending 
flood. After each round they had to make a decision. The disaster script that was followed is shown in Table 5-2 and was similar for both cases. On beforehand, the participants where thoroughly briefed about the general time planning, their roles, the maps and the interactive flood simulation model. Since this was an experimental setting, indicator 5 (i.e. the consistency of the intended follow-up actions and the implemented follow-up actions) was not measured.

Table 5-2: Disaster script

\begin{tabular}{|c|c|c|}
\hline Round & Announcement & Decision task \\
\hline 1 & $\begin{array}{l}\text { A storm surge in combination with high water } \\
\text { levels in the Markermeer. As a consequence, } \\
\text { the water levels at the protecting dikes of } \\
\text { Hoorn are at alarm level }\end{array}$ & $\begin{array}{l}\text { Should there be any neighborhoods } \\
\text { evacuated and, if so, which } \\
\text { neighborhoods should be evacuated first } \\
\text { (with a maximum of four). Answer } \\
\text { within } 10 \text { minutes }\end{array}$ \\
\hline 2 & $\begin{array}{l}\text { Dike deformations are reported at three } \\
\text { locations }\end{array}$ & Idem \\
\hline 3 & $\begin{array}{l}\text { Flood gate in the harbor of Hoorn is about to } \\
\text { breach }\end{array}$ & Idem \\
\hline
\end{tabular}

\subsubsection{Participants}

The experiment was held during a conference about water information systems called 'Lizard Experience' on the $19^{\text {th }}$ of November 2014. 17 people participated our experiment (14 male and 3 female, aged between 40 and 65). While they were not familiar with the experiment, they all knew the context of flood management organizations and had experience working with maps. The participants were randomly distributed over both cases. All individual statements during the experiment in both cases where recorded and scored according to the assessment method as described in the former section.

\subsubsection{Roles}

Each participant was informed beforehand of the experiment about his/her role and prior preferences for solutions. However, it was emphasized that this preference was allowed to change during the experiment due to new insights. Indicator 1 (i.e. the scope of prior knowledge and experiences among the participants) was not measured, since it was similar in both cases. 
The following four roles where identified and each role was represented by two participants:

1. Mayor: has the perspective of 'better safe than sorry' and wants to evacuate as much and as soon as possible

2. Water board director: Since the strength of the dikes are the responsibility water board director, he advocates that evacuation is not necessary

3. Fire department officer: Due to earlier experiences, the fire department advocates for vertical evacuation, which means that the people move to higher floors instead of leaving the area

4. Police department officer: Prefers the neighborhoods that are feasible to evacuate in relation to available evacuation routes

\subsubsection{Available information}

Each group had the availability of the following information:

- Six inundation maps, each showing the flooded area after six hours as the consequence of a dam breach (Figure 5-2).

- Digital elevation map of the area

- Topographical map of the area, showing the main roads and the neighborhoods

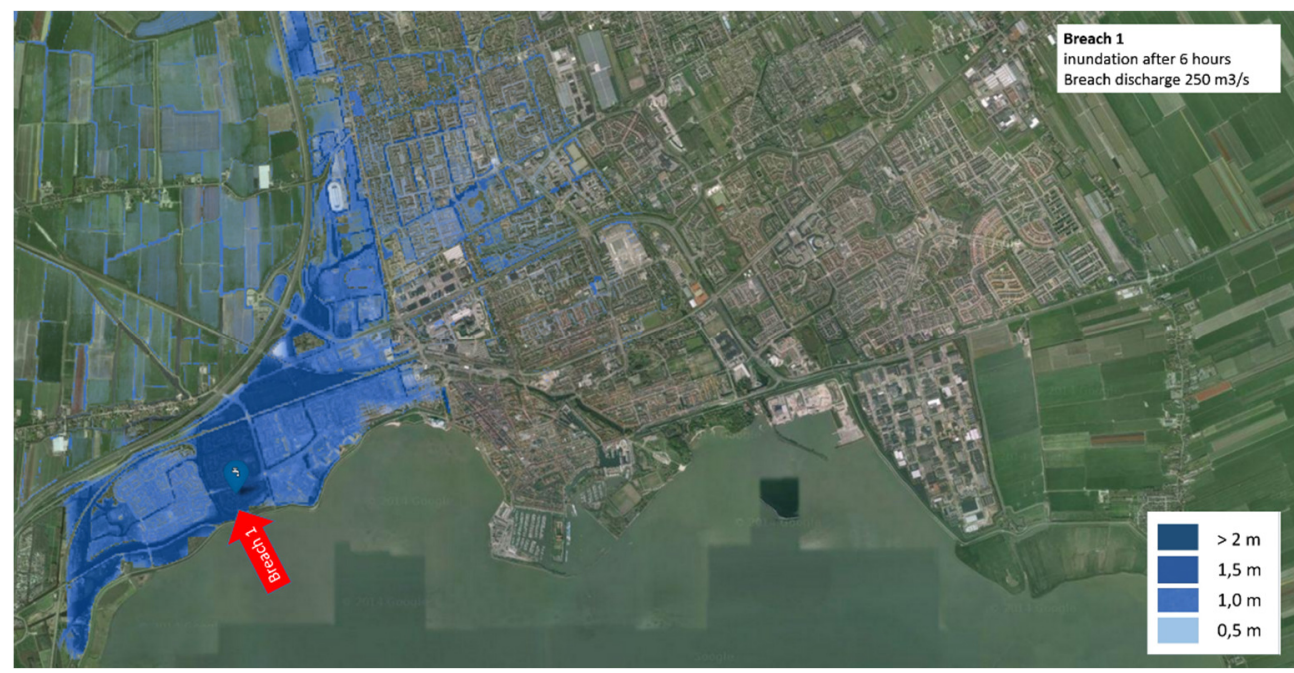

Figure 5-2: One of the six flood maps showing the flooded area after six hours at several dam breach locations. The flood maps where created with the same model as the one that was used interactively.

\subsubsection{Interactive flood simulation model}

The interactive flood simulation model that was applied was the 3Di model (Deltares, Nelen\&Schuurmans et al. 2015). The graphical user interface of 3Di consists of a digital topological map or satellite image of the area, projected on a 
touch table (Figure 5-3). Dam breaches can be simulated by clicking on the screen. Either a fixed discharge or an initial width could be assigned to a dam breach location.

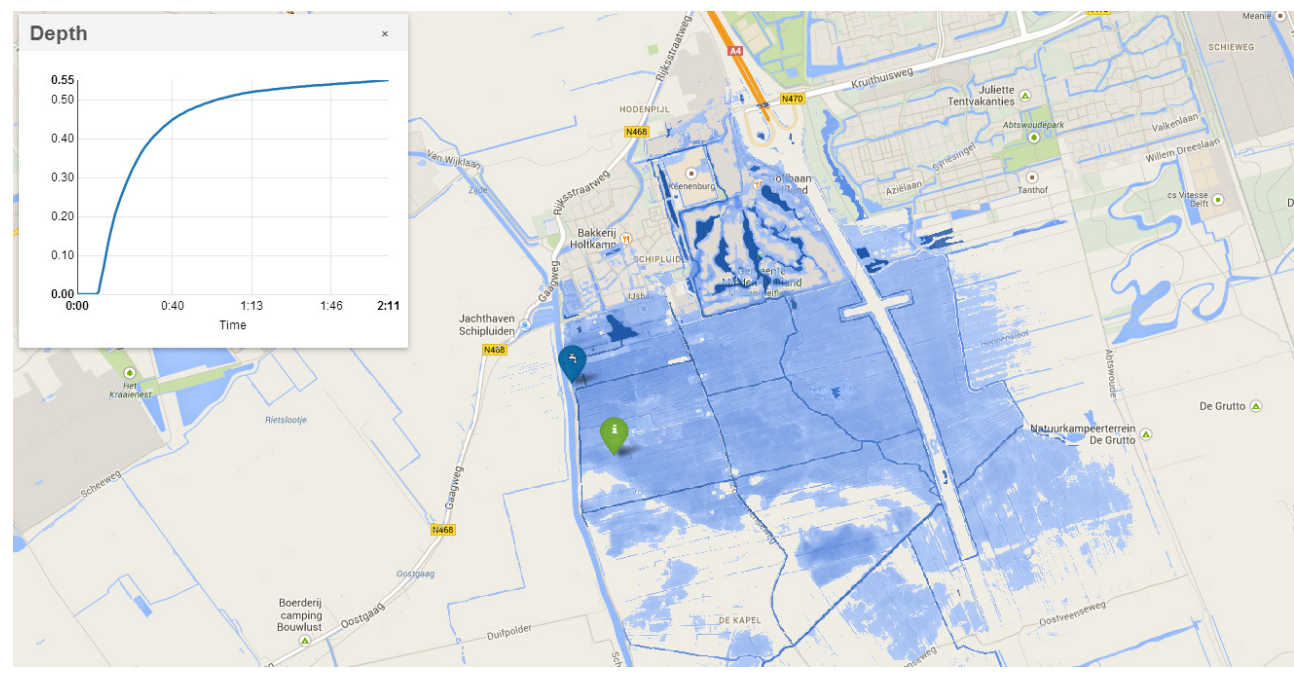

Figure 5-3: Display of interactive model 3Di

The speed and ease with which dam breaches could be simulated and the area could be adjusted without the help of model experts are the core innovative aspects of this interface. In conventional model interfaces, such as Sobek (Deltares 2015) or Mike11 (DHI 2015), adaptions can only be made by model specialists. Making adaptations in these conventional models, together with the accompanying computation time of an adapted model scenario, takes several hours and can therefore not be carried out during stakeholder meetings. A further explanation about which processes were included in the model and which computation algorithms were used to ensure the short computation times is given in the appendix.

\subsection{Results}

\subsubsection{General comparison}

In total, 444 statement were counted in the case with the use of an interactive model and 371 statements were counted in the case without the use of an interactive model. To be able to score the indicators as explained in the method section, for each statement the following five properties were scored: (1) the number of people that paid attention to a statement, (2) whether it was a response to a former statement, (3) the type of statement and the levels of social coconstruction, (4) the topic of the statement and (5) whether it was a statement in 
which follow-up actions were formulated. A summary of these properties is given in Table 5-3.

Table 5-3: General properties of the process in both cases (with and without the use of an interactive model)

\begin{tabular}{|l|l|l|}
\hline Discussion properties & With & Without \\
\hline Total number of statements & 444 & 371 \\
\hline Statements that were a reaction on former statements & $78 \%$ & $81 \%$ \\
\hline Statements to which all participants paid attention & $72 \%$ & $85 \%$ \\
\hline Statements in level 1 of social co-construction (externalization) & $56 \%$ & $54 \%$ \\
\hline Statements in level 2 of social co-construction (elicitation) & $11 \%$ & $12 \%$ \\
\hline Statements in level 3 of social co-construction (conflict) & $13 \%$ & $10 \%$ \\
\hline Statements in level 4 of social co-construction (integration) & $12 \%$ & $17 \%$ \\
\hline Statements in which follow-up actions where formulated & $7 \%$ & $6 \%$ \\
\hline
\end{tabular}

\subsubsection{Comparison on content}

Since an experimental setting was created, to compare the use of an interactive model with the conventional use of model information on maps, the content in both cases was equal, except from the interactive model that was used in one of the cases. In real-world applications, indicator 1 would be measured by a questionnaire and indicator 2 would be measured by an inventory of the available external information.

\subsubsection{Comparison on process}

The scores on indicator 3 (i.e. the degree of participation of the different participants) are shown in Table 5-4. The scores shows that the total number of statements and the distribution of the statements over the different stakeholders is comparable in both cases. Accordingly, no significant differences of the degree of participation between the case with and without the use of an interactive model can be observed. 
Chapter 5: Evaluation of the influence of an interactive use of models on the collaborative knowledge construction process

Table 5-4: Indicator 3: Participation of different stakeholders with and without the use of an interactive model, monitored by the number of statements per stakeholder. Statements were only counted if they were a response on earlier statements and had had full attention of the group

\begin{tabular}{|l|l|l|}
\hline Sender & With & Without \\
\hline Municipality & 64 & 70 \\
\hline Water board & 71 & 26 \\
\hline Police department & 52 & 58 \\
\hline Fire department & 62 & 84 \\
\hline Total & 249 & 238 \\
\hline
\end{tabular}

The results on indicator 4 (i.e. the degree in which the discussed topics where socially co-constructed) are shown in Table 5-5. The following conclusions can be drawn from this table:

- The distribution of the statements over the different levels of social coconstruction are comparable in both cases (see the last row of the table)

- More topics where discussed in the case without the use of an interactive model

- The participants in the case with the use of an interactive model have more focus on technical topics, represented by the type of topics (e.g. discussing the live model results, necessity of evacuation, the time to inundation and the routes of evacuation) and the intensity in which these topics were discussed

- The participants in the case without the use of an interactive model show a higher variety of topics discussed, such as different actions to decrease the consequences of floods and different options for evacuation (i.e. shelter on dike, improving self-reliance, evacuating cattle). 
Chapter 5: Evaluation of the influence of an interactive use of models on the collaborative knowledge construction process

Table 5-5: Indicator 4: The degree in which the discussed topics where socially co-constructed. This was measured by the number of statements per topic, sorted by the four different levels of social coconstruction. To make sure that the statements were actually part of a shared knowledge construction process, they were only counted if they were a response on earlier statements and had had full attention of the group

\begin{tabular}{|c|c|c|c|c|c|c|c|c|}
\hline \multirow[b]{2}{*}{ Level of social co-construction } & \multicolumn{4}{|c|}{ With } & \multicolumn{4}{|c|}{ Without } \\
\hline & 1 & 2 & 3 & 4 & 1 & 2 & 3 & 4 \\
\hline \multicolumn{9}{|l|}{ Topics discussed in both cases (10): } \\
\hline Areas to evacuate & 17 & 4 & 12 & 9 & 11 & 3 & 11 & 13 \\
\hline Assignment & 1 & & & & 2 & & & \\
\hline Elevation of area & 4 & & & & 11 & 2 & 1 & 7 \\
\hline Follow-up actions & 1 & 2 & 8 & 6 & 4 & 2 & 5 & 13 \\
\hline Land use & 1 & & & & 1 & & & 1 \\
\hline Location of sluice/breach & 11 & 4 & & & 12 & 2 & & \\
\hline Necessity to evacuate & 6 & 1 & 11 & 13 & 4 & 1 & 3 & 1 \\
\hline Route to evacuate & 34 & 4 & 7 & 6 & 4 & 1 & 1 & 2 \\
\hline Self-reliance in evacuation & 1 & & & & 4 & & 2 & 5 \\
\hline Time to evacuate & 3 & & & 2 & 1 & & & \\
\hline \multicolumn{9}{|l|}{$\begin{array}{l}\text { Topics only discussed in the group with the } \\
\text { use of an interactive model (9): }\end{array}$} \\
\hline Areas to warn & 5 & & 2 & 5 & & & & \\
\hline Horizontal or vertical evacuation & & 1 & & & & & & \\
\hline Interpretation results of model & 2 & & & 1 & & & & \\
\hline Live model results & 31 & 2 & 1 & 2 & & & & \\
\hline Model application & 6 & 1 & 1 & 2 & & & & \\
\hline Model scenario set-up & 8 & 4 & & & & & & \\
\hline Prepare or inform people about evacuation & & 1 & 1 & & & & & \\
\hline Support & & & 1 & & & & & \\
\hline Topography & 9 & & & & & & & \\
\hline \multicolumn{9}{|l|}{$\begin{array}{l}\text { Topics only discussed in the case without } \\
\text { the use of an interactive model (18): }\end{array}$} \\
\hline Actions to block channel & & & & & 10 & 1 & & 2 \\
\hline Actions to decrease consequences & & & & & 7 & 1 & 2 & \\
\hline Adaptive building techniques & & & & & & & & 1 \\
\hline Consequences of breach & & & & & 14 & 3 & & 9 \\
\hline Consequences of breach in relation to water level & & & & & 2 & & 1 & \\
\hline Content of flood maps & & & & & 11 & 1 & 2 & 1 \\
\hline Dike as place to evacuate to & & & & & 5 & & 2 & \\
\hline Discharge through breach & & & & & 7 & 2 & & \\
\hline Elevation map & & & & & 1 & 1 & & \\
\hline Evacuation cattle & & & & & 4 & 1 & 1 & 2 \\
\hline Evacuation to higher areas & & & & & & & 1 & 1 \\
\hline Number of sluice gates & & & & & 2 & 1 & & \\
\hline Observation on map & & & & & 12 & & & 2 \\
\hline Preparation of involved organizations & & & & & & & & 1 \\
\hline Role of mayor & & & & & 2 & 1 & & \\
\hline Roles & & & & & 1 & 1 & & \\
\hline Unclear & & & & & 1 & & & \\
\hline Water level & & & & & 1 & & & \\
\hline Totals: & 140 & 24 & 44 & 46 & 134 & 24 & 32 & 61 \\
\hline
\end{tabular}


Chapter 5: Evaluation of the influence of an interactive use of models on the collaborative knowledge construction process

\subsubsection{Comparison of outcomes}

After each round - each round started with the provision of new information - the participants in both cases had to formulate follow-up actions. The follow-up actions after each round are listed in Table 5-6, showing the following general points:

- The participants in both cases (in round 1 and 2) focus on the same neighborhoods, whereas in round 3 the focus was different. Here, the participants in the case with the use of an interactive model could directly examine the consequences of a breach of the flood gate in the harbor of Hoorn. Since this dam breach location was not described on one of the six static flood maps, the participants in the case without the use of an interactive model had to estimate the potential flooded area.

- The participants in the case with the use of an interactive model took the elements of depth and time to inundate more into consideration. This results in follow-up actions about vertical evacuation instead of evacuation out of the area, prioritizing neighborhoods that could be flooded early after a breach and providing inhabitants information about the time to inundation.

- The participants in the case without the use of an interactive model covered a wider range of topics in their follow-up actions, such as concerns about invalid people, warning cattle farmers and leave evacuation routes open.

Table 5-6: The follow-up actions that were decided upon after each round with and without the use of an interactive model. The letters of the neighborhoods correspond to the topographical map that was available in both cases

\begin{tabular}{|l|l|l|}
\hline Rounds & With & Without \\
\hline 1 & $\begin{array}{l}\text { Prepare for vertical evacuation of } \\
\text { neighborhoods T, U, V and W }\end{array}$ & $\begin{array}{l}\text { Prepare neighborhoods T, U, V and W for } \\
\text { evacuation out of the area }\end{array}$ \\
\hline 2 & $\begin{array}{l}\text { Prepare for vertical evacuation of } \\
\text { neighborhoods T, U, V and W. If only } \\
\text { one floor, than horizontal evacuation }\end{array}$ & $\begin{array}{l}\text { Prepare neighborhoods U, V and W for } \\
\text { evacuation out of the area. Warn cattle } \\
\text { farmers. Evacuate invalid people. Leave } \\
\text { evacuation routes open }\end{array}$ \\
\hline 3 & $\begin{array}{l}\text { Vertical evacuation for half R, Q and Y. } \\
\text { Prepare other areas. Inform about time } \\
\text { to inundate }\end{array}$ & $\begin{array}{l}\text { Evacuate Y directly out of the area, } \\
\text { prepare U, V, W. Warn cattle farmers }\end{array}$ \\
\hline
\end{tabular}

Indicator 5 (i.e. the consistency of the intended follow-up actions and the implemented follow-up actions) was not measured, as, due to the experimental setting, no implementation of follow-up actions took place. 
The results of indicator 6 (i.e. the degree of ownership of the follow-up actions by the participants) are shown in Table 5-7. This ownership was measured by counting the number of statements per stakeholder regarding the formulation of follow-up actions. No clear differences between both cases can be observed. Notable is the high engagement of the municipality in both cases, which might be related to their preference of evacuating as many neighborhoods as possible. Since our experiment included a simulated environment, the real engagement afterwards could not be examined. In real-world applications, this would be an important indicator for the ownership of the follow-up actions (Bouwen and Taillieu 2004).

Table 5-7: Involvement of different stakeholders in the formulation of follow-up actions after each round with and without the use of an interactive model, monitored by the number of statements per stakeholder

\begin{tabular}{|l|r|r|r|r|r|r|r|r|}
\hline Sender & \multicolumn{3}{|c|}{ With } & \multicolumn{3}{c|}{ Without } \\
\hline & Round 1 & Round 2 & Round 3 & Tot. & Round 1 & Round 2 & Round 3 & Tot. \\
\hline Municipality & 2 & 5 & 3 & 10 & 1 & 5 & 6 & 12 \\
\hline Water board & 4 & 1 & 2 & 7 & 2 & 0 & 1 & 3 \\
\hline Police department & 1 & 3 & 1 & 5 & 1 & 2 & 2 & 5 \\
\hline Fire department & 2 & 5 & 1 & 8 & 1 & & 2 & 4 \\
\hline
\end{tabular}

In summary, the collaborative knowledge construction process in the case with the use of an interactive model concentrated more on the technical properties of the threatening flood, such as critical depths and time to inundation. The outcomes on participation, social co-construction and ownership of the outcomes where comparable in both cases. This resulted in follow-up actions about vertical evacuation instead of evacuation out of the area, prioritizing neighborhoods that could be flooded early after a breach and providing inhabitants information about the time to inundation. On the other hand, the case without the use of an interactive model 'spent' its collaborative learning capacity more on developing more integral follow-up actions, taking concerns about invalid people, warning cattle farmers and accessibility of evacuation routes into account.

\subsection{Discussion}

The applied assessment method proves to be useful to identify differences in the knowledge construction process in work sessions with and without the use of an interactive model. We showed that a focus on the process of collaborative knowledge construction is a useful perspective to understand how model outputs 
become integrated with the knowledge of practitioners towards a shared understanding about the situation at hand. Our method is therefore a contribution with respect to conventional methods to assess the usefulness of models, mostly discriminating between 'produced' knowledge by domain experts and the use of this knowledge by practitioners and not capturing the collaborative process of knowledge construction.

Recording, fragmenting and classifying the conversations during the work sessions took around 8 hours per case. Therefore, we succeeded in presenting a method that can be easily applied, focusses on measurability, but still captures important aspects of the process of collaborative knowledge construction when an interactive model is used. Given our experimental set-up, we were not able to test indicator 1 (conducting a questionnaire to measure the prior knowledge and experience of participants), indicator 2 (making an inventory of the amount of relevant external information available) and indicator 5 (comparing the follow-up actions and the implemented follow-up actions). Since these activities can be seen as common research activities, we did not find it necessary to test the usefulness and the practical applicability of these indicators.

Given the results of our experiment, our method promises to be usable for future evaluations of the influence of interactive models in a larger number of experimental settings and in real-world situations. Learning from our first application of the method, we stress the importance of two factors that may be taken into account in future applications of our method. First, personal characteristics of the people involved such as creativity, leader capacity or extroversion may importantly influence the collaborative knowledge construction process. Although the participants in our experiment were instructed about their role and preferences on beforehand, this personal characteristics can influence the number of statements and the topics that are mentioned. The experimental setting could be improved by including a selection of similar personal characteristics in the two cases. Second, nonverbal communications can significantly influence the interactions that, subsequently, influence collaborative knowledge construction (Kittleson and Southerland 2004). For example, when the attitude of a participant shows his disagreement this is not captured as a statement in our method. While we did not observe strong signs of nonverbal communication that deviated from the verbal communication that was already captured in our method, we recommend to monitor the nonverbal communication alongside the application of the proposed method.

The topic of model uncertainty was hardly mentioned by the participants of our experiment, which is usually an important issue in the use of model results 
(Brugnach, Tagg et al. 2007). A possible reason for this might be that the use of an interactive model contributes to a better understanding of uncertainties in model outputs among practitioners as they can directly examine if accurate data was used in the model set-up. Given the transparency of the model structure and how suggested solutions are translated into the model, including the various assumptions that are made, practitioners are therefore better able to understand the scope of the outcomes. Still, a calibration and validation with real measured data, as applied in common model practices, is always advisable.

\subsection{Conclusions}

In this paper we investigated how the use of an interactive model influences the decision-making process in multi-actor work sessions in flood policy decisionmaking. Specifically, we focused on the properties of the collaborative knowledge construction process in the situation of flood disaster decision making. To make the influence of the use of an interactive model measurable, we presented a method including six indicators to monitor the content, process and outcomes of the collaborative knowledge construction process.

We demonstrated the practical applicability of our method in a comparative experiment, in which we compared the collaborative knowledge construction process in a case with and a case without the application of an interactive model. Our method reveals how model outputs become integrated in the knowledge construction process of practitioners in a flood disaster setting. In our experiment we found that the collaborative knowledge construction process in the case with the use of an interactive model concentrated more on the technical properties of the threatening flood, such as critical depths and time to inundation, than in the case without an interactive model. The outcomes regarding participation, social coconstruction and ownership of the outcomes where comparable in both cases.

Our method promises to be usable for a more systematic evaluation of the influence of interactive models in a larger number of experimental settings and in real-world situations. Improvements of the method that should be considered in future research are the inclusion of personal characteristics of participants that influence the collaborative knowledge construction process, such as leadership capacity and extroversion, and nonverbal communication. Situational aspects, such as relations among participants and shared history are expected to highly influence how participants interact and therefore influence the collaborative knowledge construction process. Further application of this method will therefore only be relevant in contexts where these aspects do not play an important role. An example of such a context is the context of flood disasters, as this is a content-driven, high tempo and temporal decision environment in which participants do not know each 
other on beforehand. In practice, our method can be applied to test the effect of different set-ups of multi-stakeholder work sessions in which interactive models are being used, for example by different guidance styles or different agendas. Further, the method can function as a benchmark in comparing different interactive models or other interactive analysis tools applied in flood management. 


\section{Conclusions and recommendations}

\subsection{General}

Our results show that it is feasible to organize work sessions with practitioners of flood policy decision-making and domain experts in which flood simulation models are interactively applied. It was shown that practitioners of flood policy decisionmaking appreciated the interactive use of flood simulation models. It gave them a better understanding of the problems at hand, involved them in the generation of alternative measures and helped them to explore the effectivity of measures. By video recording of work sessions and classifying all individual statements made during these work sessions with respect to the different properties of collaborative knowledge construction, we revealed how model outputs become integrated in the knowledge construction process as it evolves during work sessions. This assessment method promises to be usable for future evaluations of the influence of interactive models in a larger number of experimental settings and in real-world situations.

The remainder of this chapter summarizes the answers given to each of the four research questions provided in the introduction. Thereafter, a discussion on these conclusions is given. This chapter also summarizes the contribution this research makes to science and its societal relevance. In the last section, directions for future research are proposed.

\subsection{Answers to research questions}

\subsubsection{Potential for an interactive use of models}

The first research question addressed in this thesis is: "What are the main reasons for the gap between the knowledge produced by domain experts and the use of that expert knowledge by practitioners in flood policy decision-making and is there a potential to fill this gap with an interactive use of flood simulation models?" To answer this question, we focus in Chapter 2 on a real situation of decision-making (i.e. Flood Disaster Management) and present the results of a document review, social network analysis and flood disaster exercise. 
This provided new insights in the reasons for the poor use of model outputs by practitioners in flood disaster management. Besides the discrepancy between what information is demanded by practitioners and what flood simulation models can actually offer in terms of output and related uncertainties, also delays and constraints that emerge in the exchange of model information through the network of participants influence the use of model outputs by practitioners. These delays and constrains result from both technical limitations of the current models and organizational limitations. Technical limitations imply that current models are too inflexible to adapt to the current situation or to predict the effect of responses and have a too long calculation time to keep up the frequency in which decisions are made. Therefore, model information provided to practitioners is often outdated, which makes it unusable. Organizational limitations imply that the exchange of situational information and model information gets delayed by the various intermediaries it has to pass. Model experts are also hesitant to provide model information to others in the network, as they are afraid that this information will be used wrongly. Given the division of tasks and responsibilities, they lose the opportunity to explain the applicability of their predictions while, in the same time, they are considered fully accountable for the accuracy of these predictions.

Both the technical limitation of current models and the organizational limitations could potentially be solved by models that can be used interactively in work sessions of practitioners. Such models should be fast enough to be able to keep pace with the frequency in which decision are made and directly applicable in work sessions with practitioners to avoid the delays that emerge through the exchange of model information.

\subsubsection{Technical feasibility of an interactive use of models}

The second research question addressed in this thesis is: "Can flood simulation models, as recently made available, be made accessible to practitioners of flood policy decision-making and be used by them to carry out flood analyses together with domain experts in work sessions?" In Chapter 3, we configure a flood simulation model for a study area in the Netherlands that could be interactively used, based on prototype modelling software named 3Di, and evaluate its accessibility and usefulness in individual user test and in a multi-stakeholder work session.

We found that practitioners who were no model experts were able to apply the simulation model without the support of a domain expert. The work session showed that the simulation model could also be used collaboratively by both domain experts and practitioners during a multi-stakeholder work session to support the process of assessing flood risks and choosing flood adaptation and 
mitigation measures. We concluded that, despite the complexity of the flood simulation model and the size of the involved data sets, a process can be set up in which practitioners of flood management can carry out flood simulations together with domain experts in an interactive work session.

\subsubsection{Interactive use of models in real-world applications}

The third research question addressed in this thesis is: "Is an interactive use of flood simulation models during work sessions accepted by practitioners in realworld decision-making processes and do they perceive this as an improvement, compared to static flood maps that are prepared in advance of a work session?" In Chapter 4 we describe two work sessions that were part of real decision-making processes. For both work sessions we configured a flood simulation model in the prototype 3Di software that was used interactively during the work sessions. We carried out group evaluations and completed questionnaires to investigate whether the participants of the workshops accepted the interactive use of a model during work sessions and whether they perceived this as an improvement when compared to static flood maps that are prepared in advance of a work session.

Regarding how the participants perceived the interactive use of the model, four conclusions can be drawn based on the work sessions and related questionnaires and evaluations: (1) The realistic visualization of results helped the participants, who had various backgrounds and were no water specialists, to better understand the consequences of heavy rainfall in urban areas in respect to existing methods. This improved their engagement in the decision-making process. (2) The easy adaptable interface helped answer questions pertaining to the diagnosis of a problem, the interrelations and interdependences between different topics of the problem and the effectiveness of solutions. It, therefore, improved the involvement of the participants in the creation of possible solutions. This ensured that alternative solutions were created from different perspectives on the problem. (3) The short computation times of the model helped to focus dialogs and negotiations during work sessions on effective alternatives, as technically ineffective solutions were directly identified and discarded. (4) The short computation times provided the opportunity to evaluate and enhance measures more often within work sessions. In both cases, the willingness to interactively apply models during work sessions in future decision-making processes was extensive.

Based on the experiences in both work sessions and the results of the questionnaires and group evaluations, we were also able to provide recommendations for the set-up of work sessions in which models are interactively used. In our case, the preparation of different general main solutions that can be used for further iterations during work sessions was helpful. We also recommend a 
good follow-up to the work sessions by specialists, for example, to investigate the technical feasibility and coherence of the proposed solutions.

\subsubsection{Influence of interactive use of models on the process of collaborative knowledge construction}

The fourth research question addressed in this thesis is: "How can systematically be assessed if and how an interactive use of simulation models leads to an integration of model outputs in the knowledge construction process of practitioners in flood policy decision-making?" In Chapter 5 we introduce a method to monitor the process of collaborative knowledge construction as it evolves in multi-actor work sessions. Our method was adopted from education sciences and adapted for the use in multi-actor work sessions. We tested the applicability and usefulness of this assessment method in a flood disaster experiment in which we made a comparison between two cases: the use of conventional static flood maps made in advance of a work session and the application of a flood simulation model that could be interactively used during a work session.

Our method reveals how model outputs became integrated in the knowledge construction process of practitioners in a flood disaster setting. In our experiment, we found that the collaborative knowledge construction process focused more on the technical properties of the threatening flood when an interactive model was used, such as critical depths and time to flood, rather than in the case without an interactive model. The outcomes regarding participation, social co-construction and ownership of the outcomes where comparable in both cases.

Our method promises to be usable for a more systematic evaluation of the influence of interactive models in a larger number of experimental settings and in real-world situations. Improvements of the method that should be considered in future research are the inclusion of personal characteristics of participants that influence the collaborative knowledge construction process, such as leadership capacity and extroversion, and nonverbal communication. As relations among participants and shared history are expected to highly influence how participants interact and, therefore, influence the collaborative knowledge construction process, application of this method will, consequently, only be relevant in contexts where these aspects do not play an important role. In practice, our method can be applied to test the effect of different set-ups of multi stakeholder work sessions in which interactive models are being used, for example, by different guidance styles or agendas. The method can also be used as a benchmark when comparing different interactive models or other interactive analysis tools applied in flood management 


\subsection{Discussion}

\subsubsection{Changing role of the expert}

Shifting from a one-way approach of presenting expert knowledge to practitioners toward an interactive approach that is supported by an interactive use of models in work sessions requires a different role for domain experts. Besides being a domain expert in the technical aspects of the issue at hand, domain experts should also be capable to interact with practitioners while using a simulation model and to facilitate the inclusion of technical knowledge generated with the model in the collaborative knowledge construction process. This changing role may be difficult since the actual domains of modelers and practitioners are two separate domains that have their own idioms, appropriate forms of communication and related action (i.e. discourse) (Gergen and Thatchenkery 1996). However, we believe that this interaction is in many cases necessary to collaboratively construct shared knowledge between domain experts and practitioners about the issues at hand, for example, in flood disaster management. Another role of experts that remains very important is to safeguard the validity of the model outcomes. Without this expert input, vivid imagery from simulation models can easily lead to an overestimation of the accuracy of outcomes (Sunstein 2002) and quickly obtained outcomes of models can be interpreted wrongly (Weick and Sutcliffe 2005).

\subsubsection{The group sets the standard of quality}

Our conclusions do intentionally not give a classification about what are good or bad decisions and whether this depends on the quantity of technical information that is included in the knowledge that is collaboratively constructed when decisions are made. In general, it is hard to develop a shared frame of reference to decide about the quality of decisions as participants in a process of collaborative knowledge construction can initially have different ideas about what are good decisions. For example, domain experts generally make their assessments using scientific knowledge and expertise and assume that, with more detailed model information, analysis will improve and better decisions can be made. Political decision-makers, on the other hand, can have political reasons such as legal responsibilities or available funding that might be decisive for the decision they prefer. However, through a process of social interaction (Bouwen and Taillieu 2004), a shared meaning toward the issue at hand can be developed which will also include a shared classification about what are good and bad decisions.

The quality of a decision is, therefore, set by the group itself. However, an external observer who is not a member of the group can assess the diversity, the extent of inputs in the collaborative knowledge construction process or the level in which this content was exchanged. For example, a decision based on a high diversity of 
inputs, which can include the technical information from models, and a high level of social interaction about these inputs might be preferred above a decision based on one source of information without any debate. An external observer might also be able to assess whether information that is relevant for the issue at hand was available in the work session in which the decisions were made.

\subsubsection{The issue of model uncertainty}

It has often been mentioned in the literature that one of the reasons for the limited use of model outputs by practitioners is their inability to deal with the uncertainties in model outputs (Brugnach, Tagg et al. 2007; Faulkner, Parker et al. 2007). However, in our case studies, we observed that the issue of model uncertainty was hardly mentioned by the participants. Although we did not focus on the issue of model uncertainty, this suggests that an interactive use of a model changes the way how practitioners deal with model uncertainties. Here we indicate three changes that are our conclusions from our experiences in the different case studies. First, the interactive character of the model allows practitioners to directly examine if accurate data is used in the model set-up. Second, the interactive use gives practitioners ample opportunity to get direct feedback on their questions concerning model uncertainty and to discuss this with domain experts or other practitioners. Third, practitioners can see how suggested solutions are translated into the model, including the various assumptions that were made, and can, therefore, better understand the scope of the outcomes. In short, an interactive use of models increases the transparency of model uncertainties and the ability to discuss this with others, which improves the possibility for practitioners to assess if the model outputs can be trusted.

\subsection{Contribution to science}

We contributed to the scientific understanding by showing that new model technology can support interactive approaches of knowledge production on the science-policy interface. We specified this influence in terms of collaborative knowledge construction, which proved to be a usable perspective. We operationalized collaborative knowledge construction in a method consisting of six measureable parameters, derived from educational science literature and adapted to the situation of decision-making processes in multi-actor work sessions. This new method can be used to assess the collaborative knowledge construction on content, process and outcomes in real-time decision-making processes during work sessions. Although we applied this method to make a comparison between the collaborative knowledge construction in a case with and a case without the interactive use of a model, it is also applicable to investigate collaborative knowledge construction in other cases of multi-actor decision making. We do not only provide insight in how 
model outputs are used in the knowledge construction process within a work session, but also how model information flows through organizations. We applied a Social Network Analysis for this, which proved to be a helpful method to structurally analyze this exchange of information through the network of participants in organizations.

With our results, we further provide the scientific community of environmental modelling and software with a method to gain better insight into the usefulness of their innovations with regard to how they are actually supporting the collaborative knowledge construction process during decision-making. We demonstrated this by configuring a simulation model that can be interactively used and is accessible to practitioners and we applied this system in test cases and real-world decisionmaking processes. We gave a systematic overview of the applied model technology, existing of algorithms for high detailed and fast computations, an interface that allows real-time interaction with the model during simulations and algorithms for realistic $3 \mathrm{D}$ visualization with large data sets.

Besides contributions on specific fields of science, this research also shows the value of an interdisciplinary approach. We combined theory from educational science, policy-making science and environmental modelling and software science to successfully obtain a better understanding of the gap between the knowledge that is produced by domain experts and the use of that expert knowledge results by practitioners and to investigate if and how an interactive use of models can contribute to fill this gap.

\subsection{Societal relevance}

Our results show that an interactive use of a simulation model together with decision-makers and domain experts can be an effective instrument to feed model simulation results into the collaborative knowledge construction process when decisions are made. Although we recognize that decisions are only partially based on technical knowledge, we believe that available expert knowledge should at least be accessible to practitioners of flood policy decision-making. By using this information, decision-makers can be more technically informed about the issues at hand. This has great societal relevance, for example, in cases of flood disasters where decision-makers can use this information to better decide what the urgency is for evacuation, which people should be evacuated and how this can be achieved. Also in cases of planning, an interactive use of models gives decision-makers a better understanding of the technical content of the issue at hand and can help them gain insight into the technical effectiveness of suggested solutions. 
It can be expected that political decision-making will be more and more supported by new developed real-time and interactive model set-ups. Examples are dynamic map tables and serious games. Our method to monitor collaborative knowledge construction can be used to test the effect of these different models set-ups or to test different methods to use models interactively, for example, by different guidance styles or agendas. The method can also be used as a benchmark to compare different models or other interactive analysis tools.

Our work provides practitioners and domain experts in flood policy decisionmaking practical insight into how to set-up simulation models that can be interactively used. Moreover, we give practical guidelines for organizing interactive work sessions with models. Regardless of the choice of whether to apply a model interactively, we showed the importance to organize the right content around the table (i.e. prior knowledge and experiences of participants and external information) and support a social interaction process among the participants that is aimed at creating shared knowledge as the basis for further actions.

\subsection{Recommendations for further research}

To gain a deeper understanding of the effects of an interactive use of models on the collaborative knowledge construction process, we recommend the application of our assessment method as presented in Chapter 5 in a larger number of experimental settings and in real-world situations. Learning from our research, we stress the importance of two factors that may be taken into account in future applications of our assessment method. First, personal characteristics of the people involved such as creativity, leadership capacity or being an extrovert may significantly influence the collaborative knowledge construction process. Although the participants in our experiment in Chapter 5 were instructed about their role and preferences beforehand, their personal characteristics can influence the number of statements and the topics that are mentioned. The experimental setting could be improved by including a selection of similar personal characteristics in the two cases. Second, nonverbal communications can importantly influence the interactions that influence collaborative knowledge construction (Kittleson and Southerland 2004). For example, when the attitude of a participant shows his disagreement, this is not captured as a statement in our method. While we did not observe strong signs of nonverbal communication that deviated from the verbal communication that was already captured in our method, we recommend monitoring the nonverbal communication alongside the application of the proposed method.

Situational aspects such as relations among participants and shared history are expected to highly influence how participants interact and, therefore, influence the collaborative knowledge construction process. Either these aspects should be taken 
into account in further research or further research should focus on contexts where these aspects do not play an important role. An example of such a context is flood disasters as this is a content-driven, high-tempo and temporal decision environment in which participants do not know each other beforehand.

In this research we applied one flood simulation model (i.e. 3Di) and configured this software for the various case study areas. The model was based on user requirements derived from a user study (see Chapter 3) and was further developed by software specialists of Deltares, the Delft University of Technology and Nelen \& Schuurmans. However, different design choices would have resulted in another model with, possibly, different effects on the collaborative knowledge construction process. The development of models that is aimed at an interactive use is, therefore, a topic for further research, including how different design choices will affect the collaborative knowledge construction process. 



\section{Appendix}

An explanation about which physical process are included in the Interactive Water Simulation Model 3Di and which computation algorithms are used to ensure the short computation times is given in this appendix.

\section{Included physical processes in the model}

Groundwater flow processes are taken into account, based on the CAPSIM method (Wesseling 1991). This method consists of several interacting reservoirs:

- Interception, referring to precipitation that does not reach the soil, but is instead intercepted by the leaves and branches of plants and by the floor. Interception in each sub-grid cell is defined by an amount of millimeters that can be derived from land cover information.

- Unsaturated zone, referring to the soil moisture above the groundwater level. The unsaturated zone is defined by infiltration capacity and porosity of the soil.

- Groundwater, defined by a permeability factor and fixed seepage or infiltration rates with deeper aquifers.

- $\quad$ Surface water, referring to the amount of water that is stored on the surface.

Between these reservoirs, interaction takes place both vertically and horizontally. Here, the following common hydrological processes are included (see Figure 6-1):

1. Interception of rainfall

2. Infiltration from surface to the unsaturated zone

3. Evaporation and transpiration from interception layer, surface water and unsaturated zone

4. Percolation and capillary rise between unsaturated zone and groundwater

5. Infiltration and seepage between groundwater and deeper groundwater

6. Horizontal flow between groundwater and surface water

Precipitation, evaporation and the infiltration and seepage between groundwater and deeper groundwater are external forces that can be defined by the modeler.

Flows through drainage systems and sewer systems are computed in a separate 1Dmodule, which can fully interact with the overland and groundwater flows (see Figure 6-2). This enables the computation of the overland flow on the course grid, 
which minimizes the computation time and still takes all the geometrical details of canals, weirs, culvers and pumps into account. The module is based on the continuity equations and solved with a converging nested Newton-type algorithm. Further details about this method can be found in Casulli and Stelling (2013).

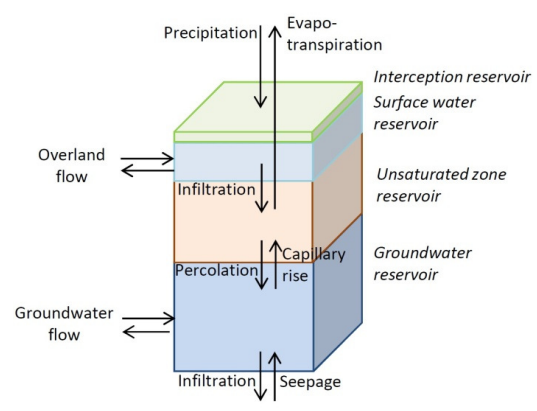

Figure 6-1: Groundwater flows

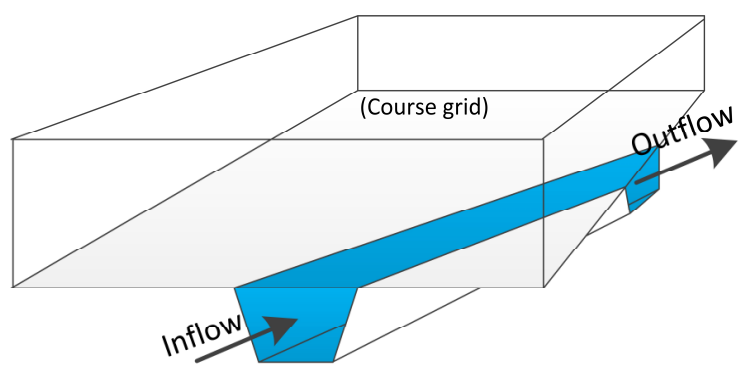

Figure 6-2: 1D-module, coupled with the sub-grids

All spatial characteristics of the study areas were defined on the level of the subgrids of 0,5 by 0,5 by their elevation, surface roughness, interception, infiltration rate, crop type and the porosity and permeability of the soil, location of canals and ditches, accompanying bottom profiles and roughness and object data of weirs, culverts and pumps. The following databases were used to collect this data: Objects Database of the regional water boards Hoogheemraadschap Hollands Noorderkwartier and Waterschap Amstel Gooi en Vecht, Current Heights of the Netherlands (AHN2), New Land Use Map of the Netherlands (STOWA), Soil map of the Netherlands (STIBOKA), a conversion table to convert land uses to roughness values, infiltration rates and interception and a conversion table to convert soil types to permeability values and porosity values (Grotentraast 1988).

The input of the model consisted of initial water levels defined for each canal or ditch. A very extreme rainfall event of 100 millimeters in one hour was chosen, with an estimated return period longer than 100 year (Rioned 2010). The output of the models consisted of water levels over time on each sub-grid, which could be evaluated in animations, cross sections or point graphs. 


\section{Numerical methods}

The water movement in the model is based on the continuity equation, which describes the conservation of mass and momentum. For shallow water this is mathematically described in the Saint Venant equations (Gerbeau and Perthame 2000):

$$
\begin{gathered}
\frac{\partial \eta}{\partial t}+\frac{\partial(\eta u)}{\partial x}+\frac{\partial(\eta v)}{\partial y}=0 \\
\frac{\partial(\eta u)}{\partial t}+\frac{\partial}{\partial x}\left(\eta u^{2}+\frac{1}{2} g \eta^{2}\right)+\frac{\partial(\eta u v)}{\partial y}=0 \\
\frac{\partial(\eta v)}{\partial t}+\frac{\partial(\eta u v)}{\partial x}+\frac{\partial}{\partial y}\left(\eta v^{2}+\frac{1}{2} g \eta^{2}\right)=0
\end{gathered}
$$

Here $\eta$ is the total fluid column height. The $2 \mathrm{D}$ vector $(u, v)$ is the fluid's horizontal velocity, averaged across the vertical column. $g$ is acceleration due to gravity. The first equation is derived from mass conservation, the second and third from momentum conservation in two dimensions.

The numerical method to quickly solve these equations, under the condition that a high resolution of model output be maintained, is based on four novel principles. More details can be found in Stelling (2012) and Casulli and Stelling (2013).

1. The sub-grid method. In this method a distinction is made between a detailed grid and a course grid. In the detailed grid (i.e. the sub-grid) all details can be taken into account at a high resolution (e.g. 1 by 1 meter). This includes elevation, surface roughness and parameters for groundwater flow, such as interception capacity, infiltration rate and seepage rate. In the course grid the pixels are clustered for the computation of water levels and velocities (see Figure 6-3).

2. Quadtrees to detail the course grid, in which the water levels and velocities are calculated on places were the elevation grid has a high variation, such as along high line elements including railways (see Figure 6-4).

3. Bottom friction based on the concept of roughness depth, in which the spatial variation of the roughness in the sub-grid is taken into account in calculating the water levels and velocities in the course grid.

4. The finite-volume staggered grid method for shallow water equations with rapidly varying flows, including semi-implicit time integration. This method ensures that the continuity equations are always solved strictly. 


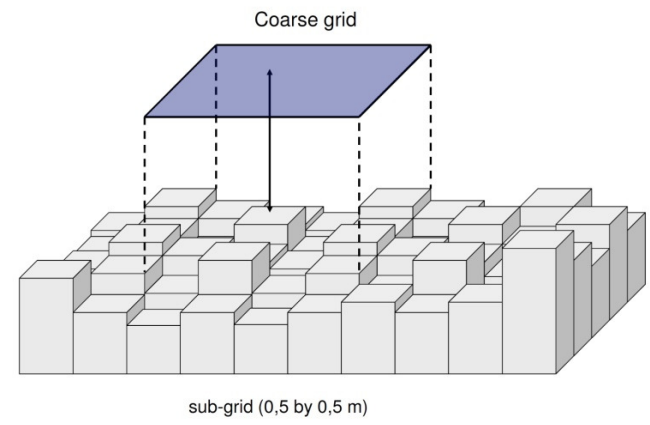

Figure 6-3: Sub-grid method

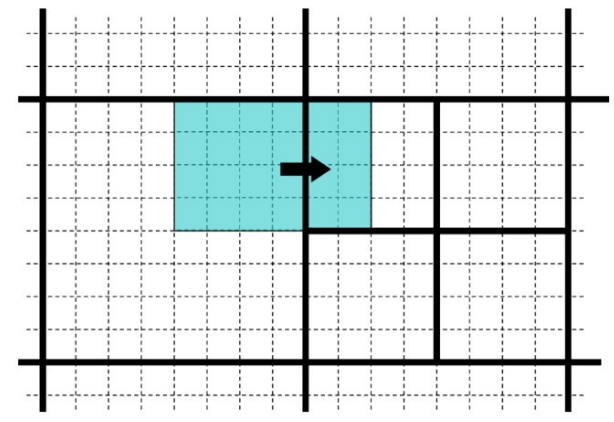

Figure 6-4: Quadtrees method 


\section{References}

AHN. (2015). "Actueel Hoogtebestand Nederland." from www.ahn.nl.

Al-Sabhan, W., M. Mulligan, et al. (2003). "A real-time hydrological model for flood prediction using GIS and the WWW." Computers, Environment and Urban Systems 27(1): 9-32.

Apel, H., A. H. Thieken, et al. (2004). "Flood risk assessment and associated uncertainty." Natural Hazards and Earth System Science 4(2): 295-308.

Argyris, C. and D. A. Schön (1978). Organizational learning: A theory of action perspective, Addison-Wesley Reading, MA.

Armitage, D., F. Berkes, et al. (2011). "Co-management and the co-production of knowledge: Learning to adapt in Canada's Arctic." Global Environmental Change 21(3): 995-1004.

Balica, S. F., I. Popescu, et al. (2013). "Parametric and physically based modelling techniques for flood risk and vulnerability assessment: A comparison." Environmental Modelling \& Software 41(0): 84-92.

Bankes, S. (1993). Exploratory modelling and the use of simulaton for policy analysis. Santa Monica, California, RAND.

Banks, J. A. (1993). "The canon debate, knowledge construction, and multicultural education." Educational Researcher 22(5): 4-14.

Bates, P. D. and A. P. J. De Roo (2000). "A simple raster-based model for flood inundation simulation." Journal of Hydrology 236(1-2): 54-77.

Bouwen, R. (2001). "Developing relational Practices for knowledge intensive organizational context." Career Development International 6/7: 361-369.

Bouwen, R. and T. Taillieu (2004). "Multi-party collaboration as social learning for interdependence: developing relational knowing for sustainable natural resource management." Journal of Community \& Applied Social Psychology 14(3): 137-153.

Brandon, D. P. and A. B. Hollingshead (1999). "Collaborative learning and computer-supported groups." Communication Education 48(2): 109-126.

Brugnach, M., A. Dewulf, et al. (2011). "More is not always better: Coping with ambiguity in natural resources management." Journal of Environmental Management 92(1): 78-84. 
Brugnach, M., A. Dewulf, et al. (2008). "Toward a relational concept of uncertainty: About knowing too little, knowing too differently, and accepting not to know." Ecology and Society 13(2).

Brugnach, M. and C. Pahl-Wostl (2007). A broadened view on the role for models in natural resource management: Implications for model development. Adaptive and Integrated Water Management. Coping with Complexity and Uncertainty. C. Pahl-Wostl, P. Kabat and J. Möltgen, Springer Verlag: 184-203.

Brugnach, M., A. Tagg, et al. (2007). "Uncertainty matters: Computer models at the science-policy interface." Water Resources Management 21(7): 10751090.

Butler, R. J., W. G. Astley., et al. (1979). "Strategic decision-making: concepts of content and process." International Studies of Management and Organization 9(4): 5-36.

Cash, D. W., W. C. Clark, et al. (2003). "Knowledge systems for sustainable development." Proceedings of the National Academy of Sciences 100(14): 8086-8091.

Castelletti, A. and R. Soncini-Sessa (2007). "Bayesian Networks and participatory modelling in water resource management." Environmental Modelling \& Software 22(8): 1075-1088.

Casulli, V. and G. S. Stelling (2013). "A semi-implicit numerical model for urban drainage systems." International Journal for Numerical Methods in Fluids.

Choo, C. W. (2001). "Environmental scanning as information seeking and organizational learning." Information Research 7(1).

Collins, H. and R. Evans (2002). "The third wave of science studies: studies of expertise and experience." Social Studies of Science 32(2): 235-296.

Cornell, S., F. Berkhout, et al. (2013). "Opening up knowledge systems for better responses to global environmental change." Environmental science \& policy 28: 60-70.

Dachsbacher, C., C. Vogelgsang, et al. (2003). Sequential point trees. ACM Transactions on Graphics (TOG), ACM.

Dawson, R. (2007). "Re-engineering cities: A framework for adaptation to global change." Philosophical Transactions of the Royal Society A: Mathematical, Physical and Engineering Sciences 365(1861): 3085-3098.

De Haan, G. (2009). "Scalable visualization of massive point clouds." Nederlandse Commissie voor Geodesie KNAW 49: 59.

De Haan, G. (2010). Interactive visualization of massive aerial LiDAR point clouds. European LiDAR Mapping Forum. 
De Moel, H. and J. Aerts (2011). "Effect of uncertainty in land use, damage models and inundation depth on flood damage estimates." Natural Hazards 58(1): 407-425.

Deltares. (2015). "Sobek suite." from https://www.deltares.nl/en/software/sobek/.

Deltares, Nelen\&Schuurmans, et al. (2015). "3Di Water management." from http://www.3di.nu/en/international/.

Demeritt, D., S. Nobert, et al. (2010). "Challenges in communicating and using ensembles in operational flood forecasting." Meteorological Applications $\mathbf{1 7}(2)$ : 209-222.

Demir, I. and W. F. Krajewski (2013). "Towards an integrated Flood Information System: Centralized data access, analysis, and visualization." Environmental Modelling \& Software 50(0): 77-84.

Derry, S. J., R. D. Pea, et al. (2010). "Conducting video research in the learning sciences: Guidance on selection, analysis, technology, and ethics." The Journal of the Learning Sciences 19(1): 3-53.

DHI. (2015). "Mike 11." from http://www.mikepoweredbydhi.com/products/mike11.

Downton, M. W., R. E. Morss, et al. (2005). "Interactions between scientific uncertainty and flood management decisions: Two case studies in Colorado." Environmental Hazards 6(3): 134-146.

Ebener, S., A. Khan, et al. (2006). "Knowledge mapping as a technique to support knowledge translation." Bulletin of the World Health Organization 84(8): 636-642.

EU (2005). DIRECTIVE 2007/60/EC on the assessment and management of flood risks, The European Parliament Council of the European Union.

Faulkner, H., D. Parker, et al. (2007). "Developing a translational discourse to communicate uncertainty in flood risk between science and the practitioner." Ambio 36(8): 692-703.

Fischer, F., J. Bruhn, et al. (2002). "Fostering collaborative knowledge construction with visualization tools." Learning and Instruction 12(2): 213232.

Frick, J. and C. Hegg (2011). "Can end-users' flood management decision making be improved by information about forecast uncertainty?" Atmospheric Research 100(2-3): 296-303.

Gemert-Pijnen, L. v., J. Karreman, et al. (2010). Participatory development via user-involvement. A Case Study about the development of a Web-based Patient communication system about Methicillin-resistant Staphylococcus aureus Enschede, The Netherlands, University of Twente. 
Gerbeau, J.-F. and B. Perthame (2000). "Derivation of viscous Saint-Venant system for laminar shallow water; numerical validation."

Gergen, K. J. and T. J. Thatchenkery (1996). "Organization science as social construction: Postmodern potentials." The Journal of Applied Behavioral Science 32(4): 356-377.

Gibbons, M. (1999). "Science's new social contract with society." Nature 402: C81C84.

Giebels, D., A. van Buuren, et al. (2015). "Using knowledge in a complex decisionmaking process-Evidence and principles from the Danish Houting project's ecosystem-based management approach." Environmental science \& policy 47: 53-67.

Graaf, H. and R. v. d. Hoppe (1996). Beleid en Politiek. Bussum, Coutinho.

Gray, B. (1989). Collaborating: Finding common ground for multiparty problems, Jossey-Bass San Francisco.

Grotentraast, G. J. (1988). Cultuurtechnisch vademecum. Utrecht, Cultuurtechnische Vereniging.

Gummesson, E. (2000). Qualitative methods in management research. Thousand Ozaks, California, USA, Sage Publications, Inc.

Haasnoot, M., H. Middelkoop, et al. (2009). "A Method to Develop Sustainable Water Management Strategies for an Uncertain Future." Sustainable Development.

Hage, J. (1980). Theories of Organizations: Form, Process and Transformation. New York, Wiley.

Hanel, M. and T. A. Buishand (2010). "On the value of hourly precipitation extremes in regional climate model simulations." Journal of Hydrology 393(3-4): 265-273.

Hegger, D., M. Lamers, et al. (2012). "Conceptualising joint knowledge production in regional climate change adaptation projects: success conditions and levers for action." Environmental science \& policy 18: 52-65.

Herrick, C. and D. Sarewitz (2000). "Ex post evaluation: a more effective role for scientific assessments in environmental policy." Science, Technology \& Human Values 25(3): 309-331.

Hesselink, A. W., G. S. Stelling, et al. (2003). "Inundation of a Dutch river polder, sensitivity analysis of a physically based inundation model using historic data." Water Resources Research 39(9).

Hiltz, S. R. (1993). "Correlates of learning in a virtual classroom." International Journal of Man-Machine Studies 39(1): 71-98.

Hoekstra, H. (2008). Evaluation of the regional flood calamity exercise North Holland Nat. Edam, Regional Waterboard Hollands Noorderkwartier. 
Holleman, I. (2008). Echotops for annotation on radar imagery, Koninklijk Nederlands Meteorologisch Instituut.

Holmes, P. R. (2004). On risky ground: The water professional in politics. 49: 117125.

Houghton, J. T., G. J. Jenkins, et al. (1990). "Climate change: the IPCC scientific assessment." Climate change: the IPCC scientific assessment.

Huang, I. B., J. Keisler, et al. (2011). "Multi-criteria decision analysis in environmental sciences: Ten years of applications and trends." Science of the Total Environment 409(19): 3578-3594.

Hummel, H. G. K., J. van Houcke, et al. (2011). "Scripted collaboration in serious gaming for complex learning: Effects of multiple perspectives when acquiring water management skills." British Journal of Educational Technology 42(6): 1029-1041.

Isenberg, P., T. Isenberg, et al. (2013). "Data visualization on interactive surfaces: A research agenda." IEEE Computer Graphics and Applications 33(2): 16-24 .

Janis, I. L. and L. Mann (1977). Decision making: A psychological analysis of conflict, choice, and commitment, Free Press.

Janssen, J. A. E. B., A. Y. Hoekstra, et al. (2009). "Delineating the modelstakeholder gap: Framing perceptions to analyse the information requirement in river management." Water Resources Management 23(7): 1423-1445.

Jensen, E. (2007). "Sensemaking in military planning: a methodological study of command teams." Cognition, Technology \& Work 11: 103-118.

Kabat, P., L. O. Fresco, et al. (2009). "Dutch coasts in transition." Nature Geoscience 2(7): 450-452.

Kahneman, D. and A. Tversky (1979). "Prospect theory: An analysis of decision under risk." Econometrica: Journal of the Econometric Society: 263-291.

Kehl, C. and G. de Haan (2012). "Interactive Simulation and Visualisation of Realistic Flooding Scenarios." Intelligent Systems for Crisis Management.

Keller, A. C., C. K. Ansell, et al. (2012). "Improving Pandemic Response: A Sensemaking Perspective on the Spring 2009 H1N1 Pandemic." Risk, Hazard \& Crisis in Public Policy 3(2).

Kinzig, A., D. Starrett, et al. (2003). "Coping with uncertainty: A call for a new science-policy forum." Ambio 32(5): 330-335.

Kittleson, J. M. and S. A. Southerland (2004). "The Role of Discourse in Group Knowledge Construction: A Case Study of Engineering Students." Journal of Research in Science Teaching 41(3): 267-293. 
Kolen, B. and I. Helsloot (2012). "Time needed to evacuate the Netherlands in the event of large-scale flooding: strategies and consequences." Disasters 36(4): 700-722.

Krueger, T., T. Page, et al. (2012). "The role of expert opinion in environmental modelling." Environmental Modelling \& Software 36(0): 4-18.

Kryachko, Y. (2005). "Using vertex texture displacement for realistic water rendering." GPU Gems 2: 283-294.

Kuchera-Morin, J., M. Wright, et al. (2014). "Immersive full-surround multi-user system design." Computers \& Graphics 40: 10-21.

Kwakkel, J. H., W. E. Walker, et al. (2010). From Predictive Modeling to Exploratory Modeling: How to use Non- Predictive Models for Decisionmaking under Deep Uncertainty. Uncertainty and Robustness in Planning and Decision Making, Coimbra, Portugal.

Landström, C. and S. J. Whatmore (2014). "Virtually Expert: Modes of Environmental Computer Simulation Modeling." Science in context 27(04): 579-603.

Langley, A., H. Mintzberg, et al. (1995). "Opening up Decision Making: The View from the Black Stool." Organization Science 6(3): 260-279.

Leedal, D., J. Neal, et al. (2010). "Visualization approaches for communicating real-time flood forecasting level and inundation information." Journal of Flood Risk Management 3(2): 140-150.

Leeuwis, C. and A. W. Van den Ban (2004). Communication for Rural Innovation: Rethinking Agricultural Extension. Oxford, Blackwell Science Ltd.

Leskens, A. (2011). Case study Petten jaar 2. Utrecht, 3Di Water management (Delft University of Technology, Deltares, Nelen \& Schuurmans).

Leskens, A. and O. Pleumeekers (2011). Report case study Calamity Exercise Delft. Utrecht, 3Di Water management.

Leskens, J. G., M. Brugnach, et al. (2014). "Application of an interactive Water Simulation Model in urban water management, a case study in Amsterdam." Water Science \& Technology 70(11): 1729-1739.

Leskens, J. G., M. Brugnach, et al. (2014). "Why are decisions in flood disaster management so poorly supported by information from flood models?" Environmental Modelling \& Software 53(0): 53-61.

Leskens, J. G., C. Kehl, et al. (2015). "An interactive simulation and visualization tool for flood analysis usable for practitioners." Mitigation and Adaptation Strategies for Global Change: 1573-1596.

Leskens, J. G. and O. Pleumeekers (2012). Case study Delfland jaar 2, Toepassing 3Di proces Ruimtelijke Ordening en Water (Application 3Di in process of 
Spatial Planning and Water). Utrecht, 3Di Water Management (Delft University of Technology, Deltares, Nelen \& Schuumans).

Levin, D. Z. and R. Cross (2004). "The Strength of Weak Ties You Can Trust:

The Mediating Role of Trust in Effective Knowledge Transfer."

Management Science 50(11): 1477-1490.

Liebowitz, J. (2005). "Linking social network analysis with the analytic hierarchy process for knowledge mapping in organizations." Journal of Knowledge Management 9(1): 76-86.

Lindblom, C. E. (1959). "The Science of "Muddling Through"." $\underline{\text { Public }}$ Administration Review 19(2): 79-88.

Lindley, S. J., J. F. Handley, et al. (2007). "The role of spatial risk assessment in the context of planning for adaptation in UK urban areas." Built Environment 33(1): 46-69.

Linkov, I., M. Wood, et al. (2009). Cognitive barriers in floods risk perception and management: A mental modeling framework and illustrative example, San Antonio, TX.

López-Rodríguez, M., A. Castro, et al. (2015). "Science-policy interface for addressing environmental problems in arid Spain." Environmental science \& policy 50: 1-14.

Losasso, F. and H. Hoppe (2004). "Geometry clipmaps: terrain rendering using nested regular grids." ACM Transactions on Graphics (TOG) 23(3): 769776 .

Lumbroso, D., K. Stone, et al. (2011). "An assessment of flood emergency plans in England and Wales, France and the Netherlands." Natural Hazards 58(1): 341-363.

MacCrimmon, K. R. and J. N. Taylor (1976). Decision Making and Problem Solving. Handbook of Industrial and Organizational Psychology. M. D. Dunnette. Chicago, Rand McNally.

MacKenzie, L. (2010). "Rotterdam: The water city of the future." Water and Wastewater International 25(5).

Maguire, M. (2001). "Methods to support human-centred design." International Journal of Human Computer Studies 55(4): 587-634.

March, J. G. (1978). "Bounded Rationality, Ambiguity, and the Engineering of Choice." The Bell Journal of Economics 9(2): 587-608.

Marton, F., M. Agus, et al. (2012). "Natural exploration of 3D massive models on large-scale light field displays using the FOX proximal navigation technique." Computers \& Graphics 36(8): 893-903. 
Mauser, W., G. Klepper, et al. (2013). "Transdisciplinary global change research: the co-creation of knowledge for sustainability." Current Opinion in Environmental Sustainability 5(3): 420-431.

McCarthy, S., S. Tunstall, et al. (2007). "Risk communication in emergency response to a simulated extreme flood." Environmental Hazards 7(3): 179192.

McGranahan, G., D. Balk, et al. (2007). "The rising tide: assessing the risks of climate change and human settlements in low elevation coastal zones." Environment and Urbanization 19(1): 17-37.

Meadow, C. T. and W. Yuan (1997). "Measuring the impact of information: Defining the concepts." Information Processing and Management 33(6): 697-714.

Mintzberg, H., D. Raisinghani, et al. (1976). "The Structure of "Unstructured" Decision Processes." Administrative Science Quarterly 21(2): 246-275.

Morss, R. E., O. V. Wilhelmi, et al. (2005). "Flood risk, uncertainty, and scientific information for decision making: Lessons from an interdisciplinary project." Bulletin of the American Meteorological Society 86(11): 1593-1601.

Newman, D. R., B. Webb, et al. (1995). "A content analysis method to measure critical thinking in face-to-face and computer supported group learning." Interpersonal Computing and Technology 3(2): 56-77.

Nicholls, R. J. (2004). "Coastal flooding and wetland loss in the 21st century: Changes under the SRES climate and socio-economic scenarios." Global Environmental Change 14(1): 69-86.

Nobert, S., D. Demeritt, et al. (2010). "Informing operational flood management with ensemble predictions: lessons from Sweden." Journal of Flood Risk Management 3: 72-79.

Nóbrega, R., A. Sabino, et al. (2008). Flood emergency interaction and visualization system, Springer.

Nonaka, I. (1994). "A Dynamic Theory of Organizational Knowledge Creation." Organization Science 5(1): 14-37.

Pahl-Wostl, C., M. Craps, et al. (2007). "Social Learning and Water Resources Management." Ecology \& Society 12(2).

Pena-Shaff, J. B. and C. Nicholls (2004). "Analyzing student interactions and meaning construction in computer bulletin board discussions." Comput. Educ. 42(3): 243-265.

Porter, J. and D. Demeritt (2012). "Flood-risk management, mapping, and planning: the institutional politics of decision support in England." Environment and Planning-Part A 44(10): 2359. 
Reda, K., A. Febretti, et al. (2013). "Visualizing large, heterogeneous data in hybrid-reality environments." IEEE Computer Graphics and Applications (4): 38-48.

Ren, X. and X. Zhou (2012). "Gpu-accelerated large-scale water surface simulation." International Proceedings of Computer Science and Information Technology 50: 187-194.

Renner, M., M. Werner, et al. (2009). "Verification of ensemble flow forecasts for the River Rhine." Journal of Hydrology 376(3): 463-475.

Rioned, S. (2010). Leidraad Riolering (Guideline for Design of Sewer Systems), Stichting Rioned.

Roux, D. J., K. H. Rogers, et al. (2006). "Bridging the science-management divide: Moving from unidirectional knowledge transfer to knowledge interfacing and sharing."

Rusinkiewicz, S. and M. Levoy (2000). QSplat: A multiresolution point rendering system for large meshes. Proceedings of the 27th annual conference on Computer graphics and interactive techniques, ACM Press/AddisonWesley Publishing Co.

Schuurmans, W., J. G. Leskens, et al. (2010). Plan van aanpak jaar 1 3Di-Water Management.

Seijger, C., G. Dewulf, et al. (2013). "Understanding interactive knowledge development in coastal projects." Environmental science \& policy 29: 103114.

Simon, H. A. (1987). "Making management decisions: the role of intuition and emotion." The Academy of Management Executive 1: 57-64.

Stelling, G. S. (2012). "Quadtree flood simulations with sub-grid DEMs." Water Management 165: 1-14.

Stive, M. J. F., L. O. Fresco, et al. (2011). "How the dutch plan to stay dry over the next century." Proceedings of the Institution of Civil Engineers: Civil Engineering 164(3): 114-121.

STOWA (2008). Richtlijn - Normering Keringen langs Regionale Rivieren (Guideline Standardization of Safety Levels of Regional Levees) STOWA. Sunstein, C. (2002). Risk and Reason. New York, Cambridge University Press.

Thacher, D. (2009). "The Cognitive Foundations of Humanistic Governance." International Public Management Journal 12(2): 261-286.

Timmerman, J. G., E. Beinat, et al. (2010). "A methodology to bridge the water information gap." Water Science and Technology 62(10): 2419-2426.

Tran, P., R. Shaw, et al. (2009). "GIS and local knowledge in disaster management: a case study of flood risk mapping in Viet Nam." Disasters 33(1): 152-169. 
Van den Hoek, R., M. Brugnach, et al. (2012). "Shifting to ecological engineering in flood management: Introducing new uncertainties in the development of a building with nature pilot project." Environmental science \& policy $\mathbf{2 2}$ : 85-99.

Voinov, A. and F. Bousquet (2010). "Modelling with stakeholders." Environmental Modelling and Software 25(11): 1268-1281.

Wahlström, M. (2012). Annual Report. Geneva, Global Facility For Disaster Reduction And Recovery.

Walker, W. E., P. Harremoës, et al. (2003). "Defining uncertainty: a conceptual basis for uncertainty management in model-based decision support." Integrated assessment 4(1): 5-17.

Walker, W. E., S. A. Rahman, et al. (2001). "Adaptive policies, policy analysis, and policy-making." European Journal of Operational Research 128: 282289.

Walsh, C. L., R. J. Dawson, et al. (2011). "Assessment of climate change mitigation and adaptation in cities." Proceedings of the Institution of Civil Engineers: Urban Design and Planning 164(2): 75-84.

Walsh, C. L., D. Roberts, et al. (2013). "Experiences of integrated assessment of climate impacts, adaptation and mitigation modelling in London and Durban." Environment and Urbanization 25(2): 361-380.

Weick, K. (1995). Sensemaking in organizations. Thousand Oaks, California, USA, Sage Publications.

Weick, K. E. and K. M. Sutcliffe (2005). "Organizing and the Process of Sensemaking." Organization Science 16(4): 409-421.

Weinberger, A. and F. Fischer (2006). "A framework to analyze argumentative knowledge construction in computer-supported collaborative learning." Computers \& education 46(1): 71-95.

Wenger, E. (2000). "Communities of Practice and Social Learning Systems." Organization $7(2)$ : 225-246.

Wesseling, J. G. (1991). CAPSEV - Steady state moisture flow theory, program description; User manual. Wageningen. SC-rapport: 37-51.

Wesselink, A., H. De Vriend, et al. (2009). "Hydrology and hydraulics expertise in participatory processes for climate change adaptation in the Dutch Meuse." Water Science \& Technology 60(3): 583-595.

Whatmore, S. J., S. N. Lane, et al. (2011). "Coproducing flood risk knowledge: redistributing expertise in critical participatory modelling." Environment and Planning A 43(7): 1617-1633. 
White, D. D., A. Wutich, et al. (2010). "Credibility, salience, and legitimacy of boundary objects: Water managers' assessment of a simulation model in an immersive decision theater." Science and Public Policy 37(3): 219-232.

WHO (2013). "Annual report."

Wood, M., D. Kovacs, et al. (2012). "Flood Risk Management: US Army Corps of Engineers and Layperson Perceptions." Risk Analysis 32(8): 1349-1368.

Zagonari, F. and C. Rossi (2013). "A heterogeneous multi-criteria multi-expert decision-support system for scoring combinations of flood mitigation and recovery options." Environmental Modelling \& Software 49(0): 152-165.

Zhu, B. and H. Chen (2005). "Information visualization." Annual review of information science and technology 39(1): 139-177. 



\section{Dankwoord/acknowledgements}

Chronologisch gezien is dit het laatste hoofdstuk van mijn proefschrift. Wat een werk heb ik mogen verzetten en wat heb ik er eigenlijk van genoten! Ik ben hierin afhankelijk geweest van vele anderen, die ik in dit hoofdstuk graag wil bedanken. First of all I want to thank Marcela for the daily supervision of my work. You always put much effort in reading and commenting my drafts and you were always available for a meeting, a skype call or just a chat. All your attention and dedication is very much appreciated and it truly improved my work a lot.

Daarnaast wil ik ook graag Arjen bedanken voor het gestelde vertrouwen en de algehele begeleiding van mijn onderzoek. Ik vond het soms verbazingwekkend hoe snel je tot de kern van mijn redeneringen kon doordringen en daar ook vaak de zwaktes in bloot kon leggen. Ik heb hier heel veel aan gehad.

Zonder Nelen \& Schuurmans was er helemaal geen onderzoek geweest. Fons en Wytze, hartelijk dank voor de mogelijkheid om dit onderzoek te mogen doen. Ook de discussies die we met elkaar hebben gevoerd (en nog vaak voeren) hebben mede de richting van mijn onderzoek bepaald. Wytze, met jou heb ik tijdens LondonEdinburgh-London ontdekt wat doorzetten echt betekent. Dit is bijzonder goed van pas gekomen tijdens mijn onderzoek. Veel collega's van Nelen \& Schuurmans hebben direct of indirect bijgedragen aan mijn onderzoek, bijvoorbeeld in de organisatie van workshops of het opzetten van testmodellen. Hiervoor mijn hartelijke dank.

Ondanks dat ik maar één of twee dagen per week in Enschede kwam werd ik daar altijd met veel warmte ontvangen en voelde ik mij echt deel van vakgroep WEM. Ik heb dit enorm gewaardeerd. Het heeft mij daarnaast ook altijd gestimuleerd om toch weer de (vroege) trein naar Hengelo te pakken. Heel veel dank voor al mijn WEM-collega's. Graag wil ik Joke hiervoor nog in het bijzonder bedanken. Erik, Olav, Ronald en Suleyman, ontzettend leuk dat ik jullie heb mogen leren kennen en bedankt voor de leuke gesprekken, borrels en daghappen (tot nu toe).

Tijdens de afronding van mijn proefschrift heeft een aantal personen mij geholpen met de laatste loodjes. Myrtle, Albert en Kees, bedankt voor de correcties van mijn Engels. Theo Zijderveld, bedankt voor de correcties van het Nederlands. Theo Horstink bedankt voor het mooie ontwerp van de cover. Elgard, dank voor je hulp 
bij de opmaak en het design en daarnaast natuurlijk voor je hemelbestormende ideeën over al het andere.

De belangstelling en steun van familie, vrienden, sportmaatjes, zanggenoten en natuurlijk van de mannenbroeders heb ik zeer gewaardeerd. Een speciaal woord van dank is er natuurlijk voor mijn ouders. Jullie hebben mij alle mogelijkheden gegeven om te studeren en jullie hebben mij altijd gestimuleerd mijn gaven zo goed mogelijk te benutten.

Lieve Iris, wat geweldig dat ik in het laatste jaar ook samen met jou aan mijn onderzoek heb gewerkt; jij aan je studie, ik aan mijn proefschrift. Ik heb het in nog veel meer opzichten enorm getroffen met jou. 


\section{List of publications}

\section{Peer-reviewed journal papers}

Leskens JG, Brugnach M, Hoekstra AY, under review. Assessing the influence of using interactive simulation models on the knowledge construction process in flood policy decision-making, Environmental Modelling \& Software.

Leskens JG, Kehl C, Tutenel T, Kol T, Haan Gd, Stelling G, Eisemann E (2015), An interactive simulation and visualization tool for flood analysis usable for practitioners, Mitigation and Adaptation Strategies for Global Change 1573-1596.

Leskens JG, Brugnach M, Hoekstra AY, Schuurmans W (2014b), Why are decisions in flood disaster management so poorly supported by information from flood models? Environmental Modelling \& Software 53: 53-61.

Leskens JG, Brugnach M, Hoekstra AY (2014a) Application of an interactive Water Simulation Model in urban water management, a case study in Amsterdam, Water Science \& Technology 70 (11): 1729-1739.

\section{Conference papers}

Leskens, J.G., Boomgaard, M., Van Zuijlen, C., Hollanders, P. (2013), A multilevel flood safety approach towards resilient cities, In: Proceedings of the International conference on Flood Resilience: Experiences in Asia and Europe, $5^{\text {th }}$ $7^{\text {th }}$ of September 2013, Exeter, United Kingdom.

Leskens, J.G., (2012) Interactive modelling during work sessions: a test with the new 3Di-model, In: International Water Conference, New Developments in IT and Water, 4th - 7th of November 2012, Amsterdam.

Leskens, J.G., (2012) Real reasons why actual flood models are not being used during flood calamities, In: Proceedings of the 2nd European Conference on Flood Risk Management, science policy and practice: closing the gap, $20^{\text {th }}-22^{\text {nd }}$ of November 2012, Rotterdam.

Leskens JG, Brugnach M (2012), Applying a network approach to identify reasons for the limited use of flood models, In: 19th Annual Conference on Multi- 
organisational Partnerships, Alliances and Networks (MOPAN), $2^{\text {nd }}-4^{\text {th }}$ of July 2012, Wageningen University, The Netherlands.

\section{Extended conference abstracts}

Leskens JG (2015), A method to assess how interactive water simulation tools influence transdisciplinary decision-making processes in water management, In: Geophysical Research Abstracts Vol. 17, EGU 2015-15125, European Geosciences Union General Assembly 2015, 12th $-17^{\text {th }}$ of April 2015, Vienna, Austria.

Leskens JG (2014), Exercising decision-making during flood disasters by the use of 'Flood Simulators', In: Extended Workshop Descriptions, Deltas in Times of Climate Change II, $24^{\text {th }}-26^{\text {th }}$ of September 2014, Rotterdam, The Netherlands.

Leskens, J.G. (2013), Interactive modelling with stakeholders in two cases in flood management, In: Geophysical Research Abstracts, Vol. 15, EGU2013-1420-1, European Geosciences Union General Assembly 2013, 7th - $12^{\text {th }}$ of April 2013, Vienna, Austria. 


\section{About the author}

Johannes G. (Anne) Leskens was born on the $3^{\text {rd }}$ of January 1982 in Hattem, The Netherlands. He received his pre-university education (VWO) at the Greijdanus College in Zwolle (1994-2000). Thereafter, he studied Civil Engineering at the University of Twente in Enschede, The Netherlands (2000-2006). During this study he specialized in 'Water Engineering and Management'. In 2005 he did an internship at Alterra Wageningen in which he contributed to a research about the influence of heavy rainfall on land degradation in the

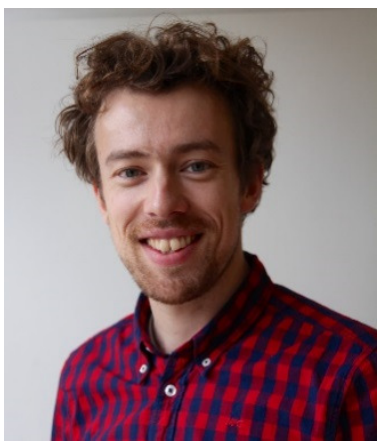
Indian Himalaya. During this internship he stayed in Dehradun in India. Anne obtained his MSc. degree in September 2006. His graduation project was carried out at the Faculty of Geo-Information Science and Earth Observation (ITC) in Enschede and at the Universidade Federal do Ceará (UFC) in Fortaleza, Brazil. He investigated the inter-annual variety of water availability and water use around the Orós reservoir in the northeast of Brazil.

In November 2006 Anne started working as advisor for the consultancy company Nelen \& Schuurmans in Utrecht, The Netherlands. Four years later, Anne had the opportunity to start a $\mathrm{PhD}$ project as part of the research and development program '3Di Water Management'. Nelen \& Schuurmans is one of the participants in 3Di Water Management. In September 2010 Anne started his PhD project named 'Water Management is Information Management', supervised by prof. dr. ir. A.Y. Hoekstra and dr. M. Brugnach at the department of Water Engineering and Management at the University of Twente. This project was carried out in parttime, besides his job at Nelen \& Schuurmans.

Anne published the results of his research in international peer-reviewed journals, such as Environmental Modelling and Software, Water Science and Technology and Mitigation and Adaptation Strategies for Global Change. The paper "Why are decisions in flood disaster management so poorly supported by information from flood models?" in Environmental Modelling \& Software was awarded as the best PhD paper of 2015 of the Twente Water Centre. Anne presented his research at international conferences in The Netherlands (European Conference on Flood Risk 
Management 2012, International Water Conference 2012, MOPAN 2012), United Kingdom (International Conference on Flood Resilience 2013) and Austria (Conferences of the European Geosciences Union 2013 and 2015).

Nowadays, Anne continues to work on water issues and the interactive use of simulation models at Nelen \& Schuurmans. As project leader he carries out various projects in the Netherlands and abroad. 
